\title{
Molecular determinants of surface colonisation in diarrhoeagenic Escherichia coli (DEC): from bacterial adhesion to biofilm formation
}

\author{
Valentin Ageorges ${ }^{1}$, Ricardo Monteiro ${ }^{1,2}$, Sabine Leroy $^{1}$, Catherine \\ M. Burgess ${ }^{3}$, Mariagrazia Pizza ${ }^{2}$, Frédérique Chaucheyras-durand ${ }^{1,4}$ and \\ Mickaël Desvaux ${ }^{1, *}$
}

${ }^{1}$ Université Clermont Auvergne, INRAE, MEDiS, F-63000 Clermont-Ferrand, France, ${ }^{2}$ GSK, Via Fiorentina 1, 53100 Siena, Italy, ${ }^{3}$ Food Safety Department, Teagasc Food Research Centre, Ashtown, Dublin 15, Ireland and ${ }^{4}$ Lallemand Animal Nutrition SAS, F-31702 Blagnac Cedex, France

*Corresponding author: INRAE (Institut National de Recherche pour l'Agriculture, l'Alimentation et l'Environnement) Clermont-Auvergne-Rhône-Alpes, Centre de Recherche de Clermont-Ferrand, UMR454 MEDiS (Microbiologie, Environnement Digestif, Santé), Site de Theix, F-63122 Saint-Genès Champanelle, France. Tel: +33 04736247 23; Fax: +33 04736245 81; E-mail: mickael.desvaux@inrae.fr

One sentence summary: Diarrhoeagenic Escherichia coli (DEC) express numerous surface colonisation factors contributing to their contamination of the food chain, from natural environments, animal reservoirs, food processing environments to food matrices and ultimately, human infection.

Editor: Birgitta Henriques Normark

\begin{abstract}
Escherichia coli is primarily known as a commensal colonising the gastrointestinal tract of infants very early in life but some strains being responsible for diarrhoea, which can be especially severe in young children. Intestinal pathogenic E. coli include six pathotypes of diarrhoeagenic E. coli (DEC), namely, the (i) enterotoxigenic E. coli, (ii) enteroaggregative E. coli, (iii) enteropathogenic E. coli, (iv) enterohemorragic E. coli, (v) enteroinvasive E. coli and (vi) diffusely adherent E. coli. Prior to human infection, DEC can be found in natural environments, animal reservoirs, food processing environments and contaminated food matrices. From an ecophysiological point of view, DEC thus deal with very different biotopes and biocoenoses all along the food chain. In this context, this review focuses on the wide range of surface molecular determinants acting as surface colonisation factors (SCFs) in DEC. In the first instance, SCFs can be broadly discriminated into (i) extracellular polysaccharides, (ii) extracellular DNA and (iii) surface proteins. Surface proteins constitute the most diverse group of SCFs broadly discriminated into (i) monomeric SCFs, such as autotransporter (AT) adhesins, inverted ATs, heat-resistant agglutinins or some moonlighting proteins, (ii) oligomeric SCFs, namely, the trimeric ATs and (iii) supramolecular SCFs, including flagella and numerous pili, e.g. the injectisome, type 4 pili, curli chaperone-usher pili or conjugative pili. This review also details the gene regulatory network of these numerous SCFs at the various stages as it occurs from pre-transcriptional to post-translocational levels, which remains to be fully elucidated in many cases.
\end{abstract}

Keywords: Biofilm formation; Pathogenic Escherichia coli; Surface colonisation; Bacterial adhesion; Surface proteins; Exopolymers

Received: 15 November 2019; Accepted: 31 March 2020

(C) FEMS 2020. All rights reserved. For permissions, please e-mail: journals.permissions@oup.com 


\section{INTRODUCTION}

Most recent phylogenetic analyses have revealed that the Escherichia genus is subdivided into eight groups containing three species, namely, Escherichia coli, Escherichia fergusonii and Escherichia albertii, as well as five clades numbered from I to V (Lawrence and Hartl 1991; Walk et al. 2009). Escherichia coli is undoubtedly the most investigated bacterial species and is used as a model organism in microbiology. This lipopolysaccharidic (LPS) diderm bacterium (archetypical Gram-negative bacterium) is primarily known as a harmless commensal of the gastrointestinal tract (GIT) (Mason and Richardson 1981; Chagnot et al. 2013). While E. coli is prevalently an inhabitant of the gut of warm-blooded animals, especially mammals but also birds, it is worth mentioning this bacterial species can also be isolated from fish, frogs or reptiles, such as crocodiles, turtles or snakes, but also insects, such as flies (Janisiewicz et al. 1999; Souza et al. 1999; Gordon and Cowling 2003; Escobar-Paramo et al. 2006; Blazar, Allard and Lienau 2011); E. coli generally appears more prevalent in herbivores and omnivores than carnivores. In humans, E. coli colonises the GIT of young children early in life and usually represents less than $1 \%$ of the human intestinal microbiota in adults (Eckburg et al. 2005).

Nevertheless, some E. coli species possess some virulence factors that enable them to cause a broad range of human extraintestinal and intestinal infections. On one side extraintestinal pathogenic E. coli (ExPEC) mainly comprises the uropathogenic E. coli (UPEC), neonatal meningitis E. coli (NMEC), necrotoxic E. coli (NTEC) and sepsis-associated E. coli (SEPEC). On the other side, and in addition to the adherent invasive $E$. coli (AIEC) associated with Crohn's disease (Mann and Saeed 2012), the intestinal pathogenic $E$. coli (InPEC) essentially encompasses six pathotypes of diarrhoeagenic E. coli (DEC), namely, the (i) enterotoxigenic E. coli (ETEC), (ii) enteroaggregative E. coli (EAEC), (iii) enteropathogenic E. coli (EPEC), (iv) enterohemorragic E. coli (EHEC), (v) enteroinvasive E. coli (EIEC) and (vi) diffusely adherent E. coli (DAEC) (Kaper et al. 2004; Croxen and Finlay 2010); of note, EHEC belong to the larger group of shigatoxin-encoding E. coli (STEC) or shigatoxin-producing E. coli, which are not all considered as pathogenic as they can exhibit very various virulence levels ranging from avirulence to hyper-virulence (Karmali et al. 2003; Laing et al. 2009; Monteiro et al. 2016). The pathogenicity of DEC strains is well documented and their main virulence factors are also well defined (Croxen and Finlay 2010). Some of these pathotypes are not restricted to human infections, but can be responsible for diarrhoea in animals, for instance (i) ETEC in porcines (piglets), bovines (calves) or ovines (lambs), (ii) EPEC in rabbits, dogs, cats, pigs, calves, lambs and goats and (iii) STEC in calves and piglets (Beutin 1999; DebRoy and Maddox 2001); to date, EAEC, EIEC and DAEC have not been reported as etiological agents of diarrhoea in animals. Despite the high genome plasticity demonstrating intensive gene flow, the population structure of E. coli remains mostly clonal (Touchon et al. 2009), with a clear delineation into seven principal phylogenetic groups (A, B1, B2, C, D, E and F) (Jaureguy et al. 2008; Walk et al. 2009; Tenaillon et al. 2010; Clermont et al. 2013; Beghain et al. 2018). Commensal E. coli strains generally belong to phylogroup A, whereas DEC usually belong to phylogroups A, B1, C, D and E (Jaureguy et al. 2008; Okeke et al. 2010; Croxen et al. 2013; Hazen et al. 2016; Rossi et al. 2018): (i) ETEC can be found in phylogroups A and B1 and to lesser extent in D, (ii) EAEC are found within phylogroup A but also B1, D and to a smaller extend in B2, (iii) EPEC can belong to phylogroups E and B2, (iv) EHEC strains are mostly found in phylogroups B1 and D but also in E (with the with serotype O157:H7 or O104:H4), (v) EIEC are mainly present in phylogroups A, B1 and E, together with Shigella, which are essentially E. coli species from phylogenetic and taxonomic perspectives (Brenner et al. 1972; Lan and Reeves 2002; Chaudhuri and Henderson 2012; Pettengill, Pettengill and Binet 2015) and (vi) DAEC which mostly belong to phylogroups B2 and D (Servin 2014; Mosquito et al. 2015; Walczuk et al. 2019). This distinct grouping suggests a parallel evolution of the different pathotypes on multiple occasions, possibly with the intervention of mobile elements enabling the acquisition of specific combinations of virulence factors (Chaudhuri and Henderson 2012; Croxen et al. 2013).

DEC can be found all along the food chain (Giaouris et al. 2014; Kim, Cho and Rhee 2017). They can have various environmental reservoirs, such as ruminants for EHEC, and are mainly transmitted to humans by the faecal-oral route through the consumption of contaminated food, including water or contact with contaminated surfaces (Croxen et al. 2013). Besides anthropozoonosis, transmission can also occur from host to host between humans. In any case, the colonisation of the food chain by DEC is a major issue for the agri-food and public health sectors alike. The surface colonisation process can occur via bacterial adhesion and/or biofilm formation to various biotic or abiotic surfaces. When the reversible adhesion to the surface by low energy linkages (e.g. electrostatics and Van der Waals interactions) is overcome, some bacteria can grow at the surface. As such, biofilm formation can be broadly defined as the sessile development of microorganisms at a surface or interface (Azeredo et al. 2017). Biofilm can be monospecies but are more generally multispecies in the natural environment, forming a complex multicellular community, which is often embedded in an exopolymeric matrix (EPM) (Costerton 1995; Costerton, Stewart and Greenberg 1999). It confers to bacterial cells an increased resistance against environmental stress, antibiotics and/or immunological defences of the host. Once the reversible adhesion is overcome, the bacterial biofilm formation is per se divided in several steps: (i) initial and irreversible adhesion of bacterial cells to the surface, (ii) bacterial division at the site of adhesion resulting in the formation of microcolonies, (iii) maturation of the biofilm architecture into a three-dimensional structure and (iv) bacterial dispersion enabling the colonisation of other sites (O'Toole, Kaplan and Kolter 2000; Hall-Stoodley and Stoodley 2002). Biofilm formation can thus plays a key role in DEC ecophysiology by enabling colonisation of various environmental niches (soil, water, vegetables, agri-food surfaces, etc...), the asymptomatic and direct colonisation of some hosts, as well as contributing to transmission through the food chain and ultimately human infection (Ahmed et al. 2013).

Most information about the colonisation process in $E$. coli is focused on the domesticated laboratory strain K12, commonly considered as representative of the $E$. coli species (Beloin et al. 2008). However, this notion is biased due to the numerous and very significant genotypic and/or phenotypic differences with commensal and pathogenic E. coli isolates (Hobman, Penn and Pallen 2007). Indeed, E. coli K12 has one of the smallest genomes compared to other genome-sequenced strains of $E$. coli due to the loss of a large variety of genes during its domestication (Lenski 2017). With regards to the selective pressures that shapes the genome evolution, E. coli K12 have been replicated and studied for a long time under laboratory conditions, far from those encountered in natural environments (Hobman, Penn and Pallen 2007); some molecular determinants, including some surface colonisation factors (SCFs), could thus be lacking or misregulated in domesticated laboratory strains of E. coli compared to commensal and pathogenic E. coli isolates. As the interface 


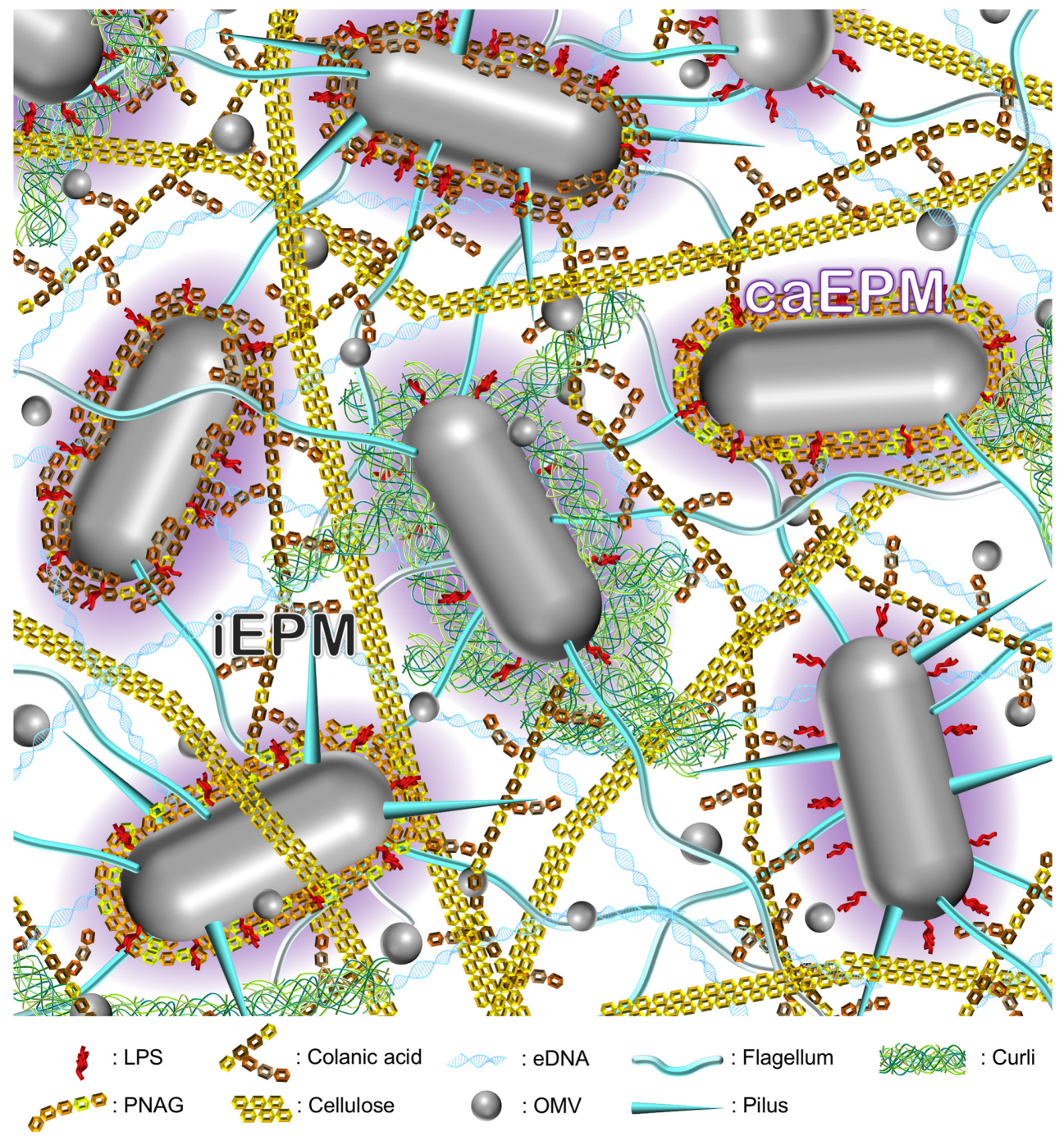

Figure 1. Schematic representation of the exopolymeric matrix (EPM) in E. coli biofilm. By analogy with the extracellular matrix (ECM) in mammalian tissue, the EPM in bacterial biofilm can be further discriminated between (i) the EPM closely associated with the bacterial cells, i.e. the cell-associated EPM (caEPM) (purple shade background), and (ii) the interstitial EPM (iEPM) (white background). Molecular determinants of the caEPM are attached, anchored or linked to the bacterial cell surface. Besides cell-surface proteinaceous determinants including monomeric proteins (not depicted in the picture) and supramolecular protein structures, such the flagella and pili, molecular components of caEPM further comprise extracellular polysaccharides (EPS), namely, some lipopolysaccharides (LPS) as well as poly- $\beta$-1,6-N-acetylD-glucosamine (PNAG) and colanic acid, which both form a capsule. Together with colanic acid that can be released from the bacterial cell surface, cellulose can compose the EPS part of the iEPM. Besides extracellular DNA (eDNA), some exoproteins (not depicted in the picture) and outer membrane vesicles (OMV) may also constitute the iEPM in E. coli biofilm.

between the bacterial cell and its surroundings, the molecular surface determinants are key players in the initial adhesion and sessile development processes and this review aims at summarising exhaustively the SCFs present in DEC. The complexity of the regulation network occurring at various stages, from pre-transcriptional to post-translocational levels, is also highlighted. A greater understanding of the parameters that influence adhesion and biofilm formation may inform the development of interventions to minimise DEC dissemination in the food chain, from the environment, animal, food, to human.

\section{MOLECULAR DETERMINANTS INVOLVED IN SURFACE COLONISATION BY DEC}

The colonisation processes along the food chain, from natural environments, such as soil, plants and animals, to food environments, including the industrial processing food chain and food matrices, and ultimately infection or asymptomatic carriage in human, are very complex and involves many molecular determinants. Sessile development at a surface or interface is generally accompanied by the formation of an EPM embedding the bacterial cells in biofilms (Fig. 1). These exopolymers can act as glue for adherence of the bacterial cell to the support and shape the architecture of the biofilm (Hobley et al. 2015). Furthermore, the EPM provides protection by shielding the bacteria from desiccation and antimicrobial compounds but also participates in the channelling of nutrients and signalling molecules (Sutherland 2001; Starkey et al. 2004; Beloin et al. 2008). As such, the EPM contribute to the survival strategy and persistence of bacteria in various environmental conditions (Branda et al. 2005). Molecular determinants participating in the surface colonisation by DEC can either be closely associated with the bacterial cell surface and form the cell-associated EPM (caEPM) or present in the extracellular milieu, namely the interstitial EPM (iEPM) (Fig. 1) (van Houdt and Michiels 2005). 
At a biochemical level, EPM components can be broadly discriminated between (i) extracellular polysaccharides (EPS), (ii) extracellular DNA (eDNA) and (iii) surface proteins. Depending on the different DEC pathotypes, these various determinants can be either present or absent (Table 1). Outer membrane vesicles (OMVs) have been reported to be components of the EPM in E. coli K12 (Schooling and Beveridge 2006) and their presence in biofilm from DEC is likely, although it remains to be demonstrated. To date, there is no report of their contribution to biofilm formation in DEC, as observed in Pseudomonas aeruginosa or Helicobacter pylori (Yonezawa et al. 2009; Wang, Chanda and Zhong 2015), but it is an aspect that would deserve further investigation in DEC. Of note, poly- $\gamma$-glutamate (PGA) can be found as a component of the EPM of numerous bacteria, especially parietal monoderm bacteria (archetypical Gram-positive bacteria) and only a few LPS-diderm bacteria, where it can either be released or cell-surface attached to form a capsule (Candela and Fouet 2006; Ogunleye et al. 2015; Radchenkova et al. 2018) but, to date, this has never been reported in any E. coli strain.

\section{Exopolysaccharides (EPS)}

EPS are one of the main components of the EPM in E. coli biofilms (Beloin, Roux and Ghigo 2008). DEC can biosynthesise a variety of EPS, namely, (i) lipopolysaccharide (LPS), (ii) poly- $\beta-1,6-\mathrm{N}-$ acetyl-D-glucosamine (PNAG), (iii) colanic acid and (iv) cellulose. Because of their intimate association with the bacterial cell surface, several of these EPS can contribute to the caEPM and the formation of a so-called capsule. Actually, E. coli harbours some serotype-specific polysaccharides, namely lipopolysaccharides (LPS) (O antigen) and capsular polysaccharides (K antigen). E. coli capsules are composed of high-molecular weight polysaccharides embedding the bacterial cells and linked to the cell-surface via covalent attachments (Whitfield 2006). More than 80 capsular antigens have been reported in $E$. coli, which are divided into four groups, from G1 to G4 (Whitfield 2006; Yaron and Romling 2014). DEC (including EPEC, ETEC and EHEC) produce G1 and G4 capsules that share a common assembly system and can be associated with the lipid A of LPS ( $\mathrm{K}_{\mathrm{LPS}}$ ) or be structurally similar to the O-polysaccharides of the LPS (O-antigen capsules). During an infection, these capsules allow bacteria to be protected from opsonophagocytosis and complement-mediated killing (Whitfield 2006). In EHEC 0104:H4, the capsule has been shown to play a role in bacterial survival in the environment and in direct bacterial interaction with plants (Jang and Matthews 2018).

\section{Lipopolysaccharide (LPS)}

LPS is located at the outer leaflet of the outer membrane (OM) and part of the caEPM (Raetz and Whitfield 2002). This glycolipidic polymer is formed around a toxic component, lipid A, and for this reason is also considered an endotoxin; the LPS is further composed of the core region linked to the lipid A (divided into an inner and outer part) and the O-antigen that is linked to the outer part of the core region (Raetz and Whitfield 2002). Biosynthesis and assembly pathways of LPS have been fully described and involve more than 50 genes encoded in operons or monocistrons scattered on the bacterial chromosome (Sandkvist 2001; Szalo, Taminiau and Mainil 2006). The structures of lipid A and its core region are highly conserved in E. coli but the core region has five basic structures, called R1, R2, R3, R4 and K12. Among these, R1 is the most prevalent in non-STEC clinical isolates of E. coli and R3 is more associated with STEC strains (Gibb et al. 1992; Appelmelk et al. 1994; Currie and Poxton 1999; Amor et al. 2000). In E. coli clinical isolates, R1 is most prevalent, whilst the
K12 core is not detected (Gibb et al. 1992; Appelmelk et al. 1994). More than $170 \mathrm{O}$-antigens have been identified and consist of 10-25 repeating units containing one to eight sugar residues (Stenutz, Weintraub and Widmalm 2006). The O-antigen can be present (smooth LPS, also called S-LPS or LPS I, resulting in colonies with a smooth phenotype) or absent (rough LPS, also called R-LPS or LPS II, resulting in colonies with a rough phenotype) depending on the E. coli strain; if the core region is also absent, it is called deep-rough LPS (Hitchcock et al. 1986). Smooth strains are the most commonly found in nature, including in DEC, whereas the rough phenotype is more commonly found in laboratory strains (Whitfield and Keenleyside 1995; Nataro and Kaper 1998). For smooth strains, the LPS length is positively correlated with the force of adhesion (Strauss, Burnham and Camesano 2009). The O-antigen assists adhesion through hydrogen binding (Tomme et al. 1996). For example, it has been demonstrated that the O-antigen enables EHEC 0157:H7 strains to colonise animal hosts (Sheng et al. 2008). Mutations in LPS biosynthesis genes have been shown to affect the adhesion of E. coli to abiotic surfaces and its biofilm formation ability (Bilge et al. 1996; Genevaux et al. 1999; Landini and Zehnder 2002; Beloin et al. 2006). Additionally, LPS can promote or inhibit biofilm formation by two distinct mechanisms, mainly by interacting with cell-surface-exposed adhesion factors. It has been shown that alteration of LPS synthesis can impair type 1 pili and colanic acid expression as well as bacterial motility, whereas the reduction in LPS expression may unmask E. coli adhesins and thus promote adhesion or biofilm formation as observed for EHEC 0157:H7 strain (Bilge et al. 1996; Beloin et al. 2006; Beloin, Roux and Ghigo 2008).

\section{Poly-N-acetyl glucosamine (PNAG)}

PNAG is an EPS attached to the bacterial surface and is involved in biofilm formation on abiotic surfaces (Wang, Preston and Romeo 2004). The biosynthetic pathway for PNAG is encoded by the pgaABCD locus (formerly ycdSRQP). Initiation of PNAG production occurs with the PgaDC, a glycosyl transferase localised on the cytoplasmic side of the inner membrane that uses the UDP-N-acetyl-D-glucosamine as substrate (Wang et al. 2004; Itoh et al. 2005, 2008). The PNAG polymer is exported and anchored to the bacterial surface through the $\beta$-barrel formed by two outer membrane proteins (OMPs), namely PgaB and PgaA. Although PNAG forms a surface capsule and is one of the main components of the caEPM in diverse bacterial biofilm, the pga locus is not present in all E. coli strains (Cerca et al. 2007; Cimdins et al. 2017). In DEC, PNAG plays a role in the stabilisation of biofilm architecture (Wang et al. 2004; Al Safadi et al. 2012). It has been demonstrated to be important for biofilm formation of EHEC on sprouts and tomato roots (Matthysse et al. 2008). In vivo expression of pgaA during infection by EHEC O104:H4 suggests that biofilm formation is a key step in pathogenesis (Al Safadi et al. 2012). PNAG is also expressed by some ETEC strains and often induced by conditions found in the environment (Gonzales-Siles and Sjoling 2016).

\section{Colanic acid}

Colanic acid is a negatively charged polymer of glucose, galactose, fucose, and glucuronic acid produced by most E. coli strains, including DEC (Obadia et al. 2007). The wca operon (or cps) encodes 19 proteins including polymerases involved in colanic acid synthesis from sugar residues (Stevenson et al. 1996). Colanic acid actually forms the G1 capsule but a significant portion of the colanic acid produced can also be released into the extracellular milieu to contribute to the IEPM (Whitfield and 


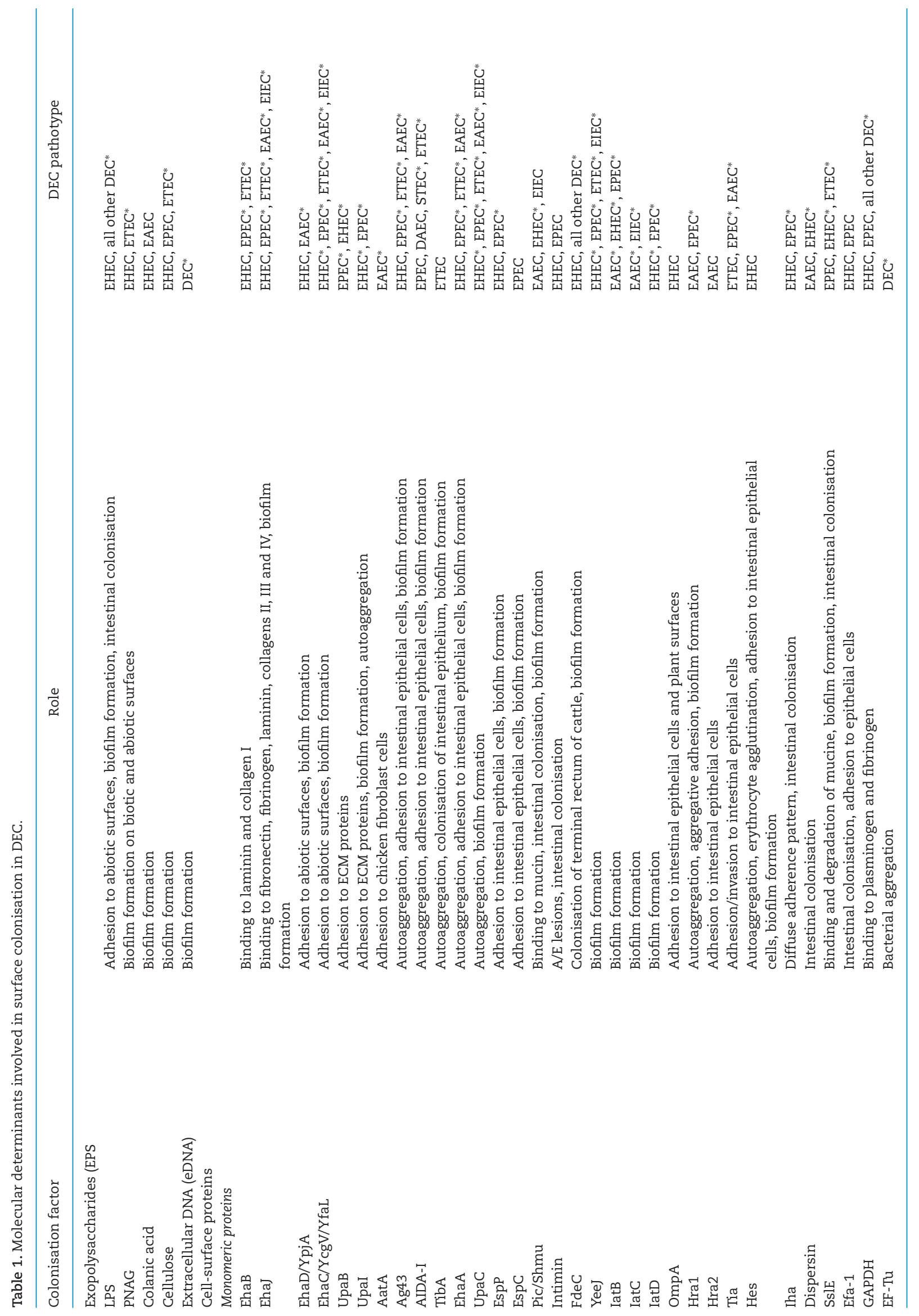




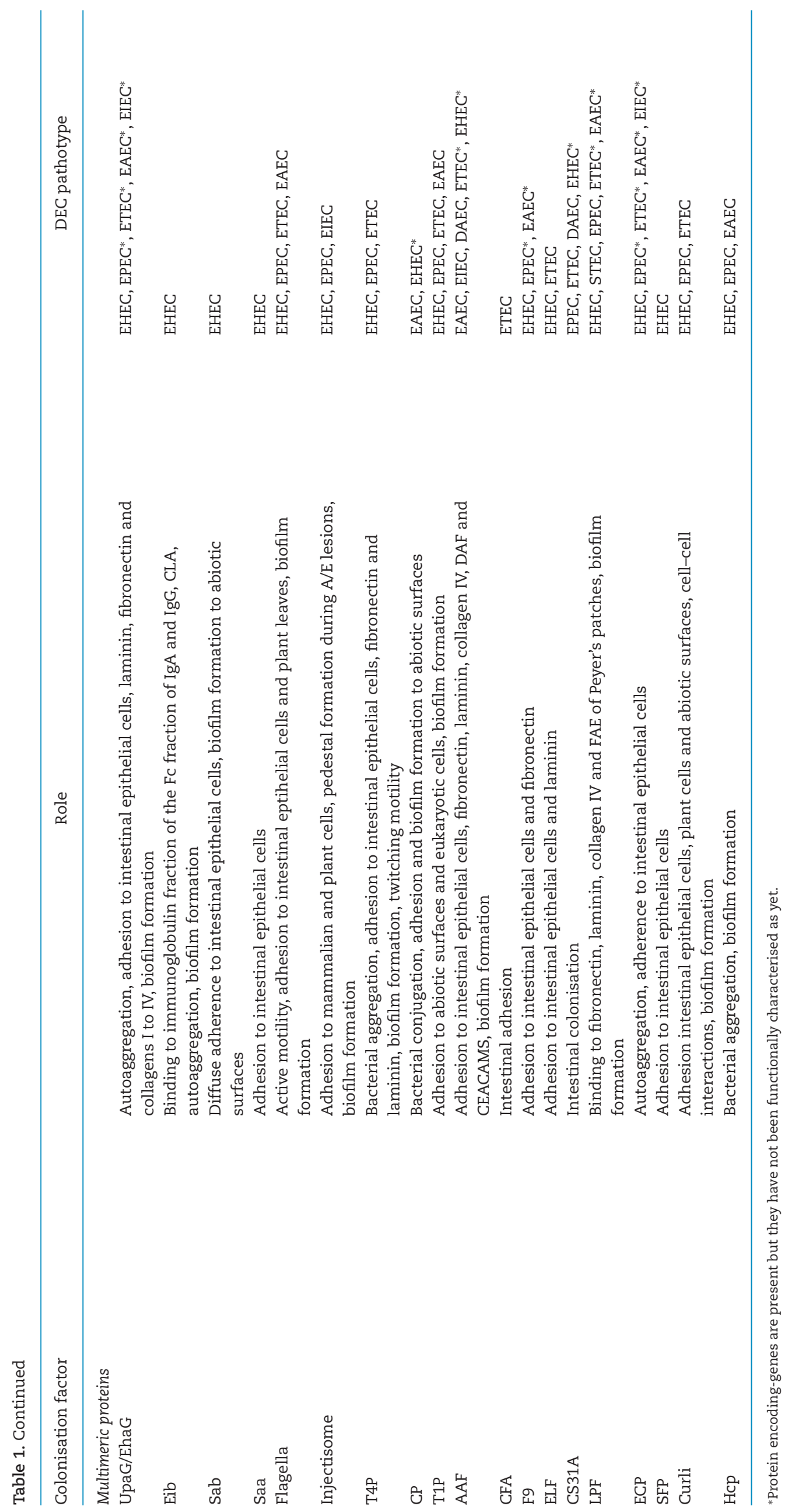


Roberts 1999; Beloin et al. 2008; Beloin, Roux and Ghigo 2008). The exact contribution of colanic acid to biofilm formation is still unclear (Matthysse et al. 2008; May and Okabe 2008). Nonetheless, it forms a physical barrier that helps bacteria to survive outside the host with the formation of a protective capsule around the bacterial cell. This capsule allows E. coli biofilms to resist osmotic and oxidative stresses as well as to temperature variations (Whitfield and Roberts 1999; Chen, Lee and Mao 2004). In EHEC 0157:H7, it has been shown to play a role in the bacterial survival in simulated GIT fluids (Mao, Doyle and Chen 2006). In EAEC, the presence of colanic acid has been linked with the formation of large biofilm structures on the surface of sprouts (Borgersen et al. 2018). In contrast, the production of colanic acid could also mask some cell-surface adhesins and consequently impair initial adhesion to some supports (Hanna et al. 2003; Schembri et al. 2004; Beloin et al. 2008).

\section{Cellulose}

Cellulose is a linear homopolysaccharide composed of Dglucopyranose units linked by $\beta-1 \rightarrow 4$ glycosidic bonds. While this widespread biopolymer is generally related to plant biology, it is also present in the IEPM in some bacterial species where it plays a role in protection, maturation and structure of the biofilm (Solano et al. 2002; Ude et al. 2006). In E. coli, cellulose biosynthesis genes are located in two operons, namely, bcsQABZC and bcsEFG (Zogaj et al. 2001; Solano et al. 2002; Le Quere and Ghigo 2009). The cellulose synthase is formed by $\mathrm{BCSAB}$, which catalyses cellulose biosynthesis from UDP-glucose subunits and forms a transmembrane pore across the inner membrane for cellulose export prior to secretion across the OM via a $\beta$-barrel pore formed by BcsC (Keiski et al. 2010; Omadjela et al. 2013). The role of the bcsEFG operon is still unclear but its presence is necessary for cellulose production (Solano et al. 2002). These genes are found in both commensal and pathogenic E. coli strains (Beloin et al. 2008). Although cellulose production is essential for biofilm maturation, over-production negatively impacts biofilm formation and bacterial aggregation, possibly by coating and thus masking the adhesive properties of surface proteins such as curli (Gualdi et al. 2008). In EHEC 0157:H7 and EPEC 0127:H6 cellulose production has been shown to contribute to biofilm formation, and consequently, host colonisation and survival in different environments (Saldana et al. 2009). The involvement of cellulose in E. coli colonisation of plant materials has also been demonstrated but it depends on the vegetable, as its presence seems dispensable for biofilm formation by $\mathrm{E}$. coli $\mathrm{O} 157: \mathrm{H7}$ to spinach leaves, but it is required for bacterial adhesion to alfalfa sprouts (Matthysse et al. 2008; Macarisin et al. 2012). Expression of these genes in some ETEC strains is often induced at ambient temperatures, low ionic strength and nutrient limitation (Bokranz et al. 2005; Szabo et al. 2005).

\section{Extracellular DNA (eDNA)}

The importance of eDNA in biofilm maturation has been demonstrated in numerous bacterial species (Muto and Goto 1986; Kadurugamuwa and Beveridge 1995; Steinberger et al. 2002), including E. coli (Xi and Wu 2010; Nakao et al. 2012). As a component of the IEPM, eDNA serves as structural component of the biofilm but can also contribute to a cation gradient, as a nutrient source, induce antibiotic resistance and aid horizontal gene transfer (Bockelmann et al. 2006; Palchevskiy and Finkel 2006; Sanchez-Torres, $\mathrm{Hu}$ and Wood 2011). However, the role of eDNA in DEC strains remains to be elucidated. The molecular mechanism explaining the presence of eDNA has been a subject of investigation for some time but essentially results from the release of genomic DNA upon cell lysis, following the bacteriophage lytic cycle or bacterial cell apoptosis (Palmen and Hellingwerf 1995; Steinmoen, Knutsen and Havarstein 2002; Qin et al. 2007). Nonetheless, the lysis of outer membrane vesicles (OMVs) containing DNA (Kadurugamuwa and Beveridge 1996; Whitchurch et al. 2002), as well as DNA secretion through the conjugative Type IV, subtype $b$, secretion system (T4bSS) (Hamilton et al. 2005; Chagnot et al. 2013) could also contribute to the presence of eDNA. The extent and respective contribution of these different mechanisms to the presence of eDNA would undoubtedly require further investigations, especially in DEC, also considering the impact of the apparent presence of pancreatic nuclease in the intestine (Maturin and Curtiss 1977).

\section{Cell-surface proteins}

The cell surface of LPS-diderm bacteria can display a number of proteins associated with the OM. Proteinaceous determinants found at the bacterial cell surface and acting as SCFs can be broadly discriminated into (i) monomeric proteins, (ii) multimeric proteins (Fig. 2).

In the scientific literature, E. coli adhesins have generally been discriminated between fimbrial and afimbrial (or non-fimbrial). However, according to animal classification, a group is much better defined by features that are present rather than by the absence of some features. As such, the term afimbrial adhesins does not tell anything about the nature of these adhesins. In addition, some afimbrial adhesins later appeared to be atypical fimbriae secreted by the same family of protein secretion system, e.g. the CS31A (coli surface associated 31a antigen) pili (Adams et al. 1997). For these reasons, we here propose to regroup those cell-surface proteins under the term of monomeric proteinaceous adhesins, or monomeric proteinaceous colonisation factors. Besides, the term fimbriae is not very well defined across the Bacteria kingdom when considering different bacterial species. On the contrary, the term pili can be used as a generic term encompassing the various type of pili and fimbriae, including curli or injectisome. In addition, some cellsurface appendages contributing to surface colonisation in bacteria cannot be categorised as fimbrial adhesins per se, e.g. the flagella and the trimeric autotransporters. To avoid any ambiguity, these different cell-surface appendages are proposed to be regrouped under the term of multimeric proteinaceous colonisation factors.

\section{Monomeric proteinaceous surface colonisation factors}

In E. coli, monomeric protein acting as SCFs include some autotransporters (ATs), inverted autotransporters (IATs), and some OMPs, but also the surface-exposed lipoprotein SslE, Efa-1 (E. coli factor adherence 1), dispersin, as well as some moonlighting proteins. Of note, the ATs (also sometimes called classical ATs) only belong to the Type V, subtype a, secretion system (T5aSS) and correspond to monomeric polypeptides with modular organisation into at least three main regions, i.e. (i) a $\mathrm{N}$ terminal signal peptide, (ii) a central passenger and (iii) a translocator at the C-terminus (Desvaux, Parham and Henderson 2003; Desvaux et al. 2004; Leo et al. 2012). ATs (T5aSS) should not be mistaken with the trimeric ATs, hybrid ATs and inverted ATs, which belong the T5sSS, T5dSS and T5eSS, respectively.

Autotransporters (ATs) Classical ATs acting as SCFs comprise the autotransporter adhesins (ATAs), the self-associating autotransporters (SAATs) and some serine protease autotransporters from Enterobacteriaceae (SPATES) (Henderson and Desvaux 2004; 


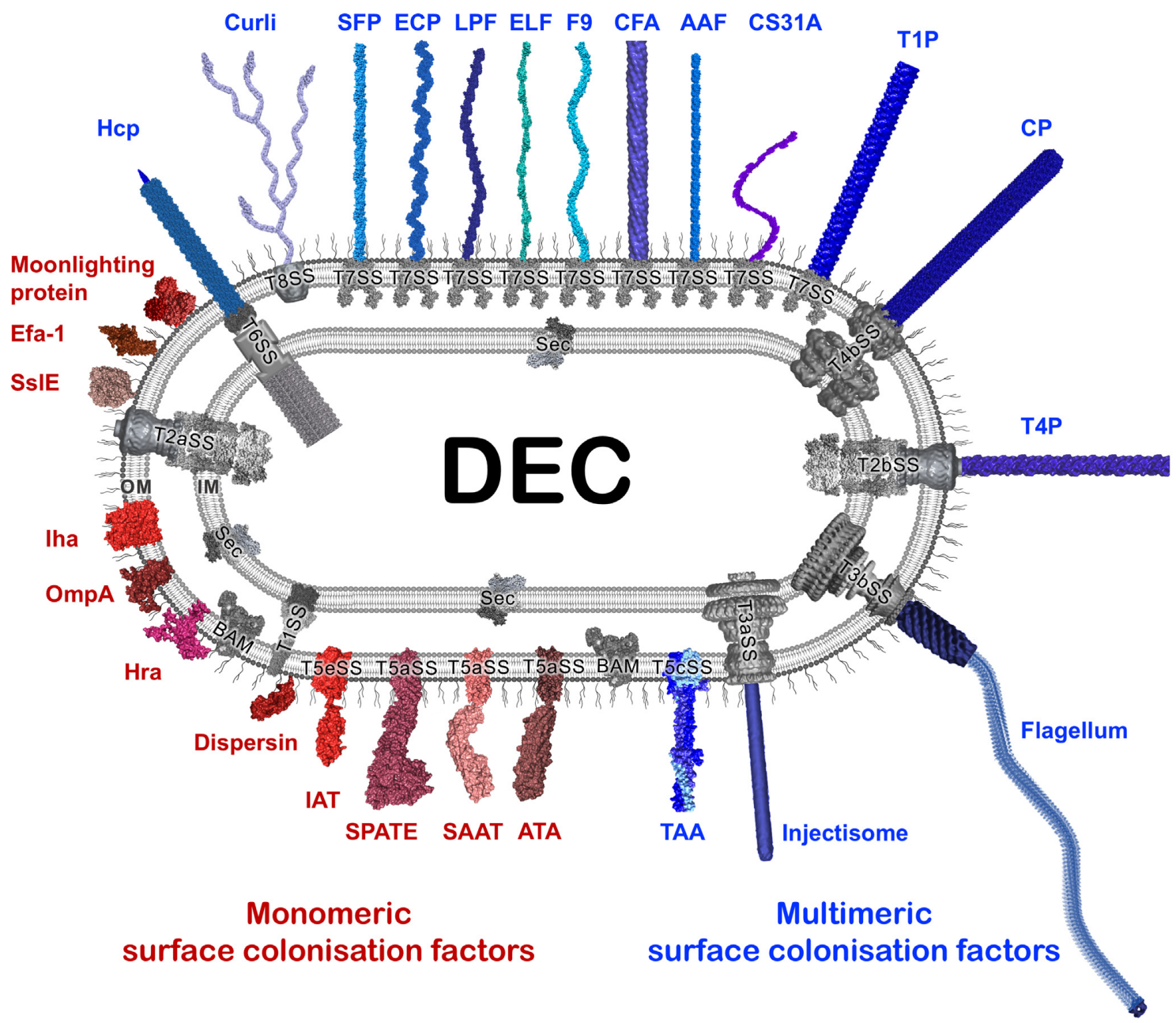

Figure 2. Schematic representation of the cell-surface proteinaceous determinants acting as CFs in DEC. Monomeric proteins are depicted in shades of red, whereas multimeric protein complexes are depicted in shades of blue. Whenever possible, molecular structures were obtained from the protein databank (PDB) (Berman et al. 2002, Rose et al. 2017) or the electron microscopy databank (EMBD) (Lawson 2010). Regarding ATs, no structure for ATAs is currently available but Ag43 (PDB: 4KH3) is provided as a representative of a SAAT and EspP (PDB: 3SLI, 3SZE) as a representative of SPATE. Intimin (PDB: 3NCW, 4E1S) is given as a representative of an IAT. Proteins secreted across the OM by the T5SS are first exported via the Sec translocase (SecYEG-DF/SecA) (PDB: 2AKH, 3AQO, 5XAM) across the inner membrane (IM). Dispersin (PDB 2JVU) is secreted via T1SS (PDB: 5066). Besides ATs, all OMPs including the Hra, OmpA (PDB: 2GE4) and Iha are first exported via Sec before being integrated into the OM via the $\beta$-barrel assembly machinery (Bam) complex (BamABCDE) (PDB: 5LJO). The surface-associated lipoprotein of $E$. coli (SslE) is secreted by a T2aSS (EMDB: 1763, PDB: 3CIO, 3OSS, 4KSR, 2W7V, 2BH1) after Sec export. Like the moonlighting proteins represented here by GAPDH (PDB: 5ZA0), the secretion mechanisms of Efa-1 remain unknown. EibD (PDB: 2XQH) is provided as a representative of TAAs. The injectisome is secreted and assembled by the T3aSS (EMDB: 1875). The flagellum (EMDB: 1132, 1873; PDB: 1IO1) is secreted and assembled by the T3bSS (EMDB: 1887). The T4P (EMDB: 0070) is secreted and assembled by the T2bSS. The conjugative pilus (CP) (PDB: 5LEG) is secreted and assembled by the T4bSS (EMDB: 2567). The T1P (EMDB: 3222), CS31A, AAF (PDB: IUT2, 2XQ), CFA (EMDB: 1952), F9 pilus, ELF, LPF (PDB: 5AFO), ECP (PDB: 3QS3) and SFP are all secreted and assembled by T7SS (PDB: 4J30) after Sec export. The curli are secreted and assembled by the T8SS (EMDB: 2750). Hcp form a tube, which is displayed extracellularly upon triggering of the T6SS (EMDB: 2524; PDB: 4HKH, 3RX9, 4JIV).

Henderson et al. 2004; Desvaux et al. 2006; Rojas-Lopez et al. 2017).

Autotransporter ADHESINS (ATAs) ATAs enable direct adhesion to abiotic supports, e.g. glass, stainless steel or plastic ware and/or biotic surface, e.g. mammalian cells or extracellular matrix (ECM) components such as collagens (Vo et al. 2017). As such, they can also belong to MSCRAMM (microbial surface components recognizing adhesive matrix molecules) proteins (Chagnot et al. 2012).

In EHEC, several enterohaemorrhagic E. coli autotransporters (Eha) have been identified (Wells et al. 2008). Among them, EhaB has been shown to promote bacterial cells binding to laminin and collagen I (Wells et al. 2008; Wells et al. 2009), whereas
EhaJ causes strong adherence to fibronectin, fibrinogen, collagens II, III and V, and laminin (Easton et al. 2011). EhaB has also been identified in EPEC and ETEC (Zude, Leimbach and Dobrindt 2014). Immediately adjacent to the eha gene, egtA encodes a glycosyltransferase. EhaJ requires glycosylation to mediate strong biofilm formation but not for adhesion to ECM components (Easton et al. 2011). Following genomic analysis, ehaJ appears to be also present in EAEC, EIEC and ETEC where its function is still unknown. In EPEC, its exact function in the colonisation process remains unclear, as it does not seem to be required for bacterial adhesion and biofilm formation (Easton et al. 2011). While EhaD has been shown to mediate biofilm formation, its role in bacterial adhesion has not been determined yet and its contribution to sessile development in DEC would require more in-depth 
investigation (Wells et al. 2008). In the laboratory strain E. coli K12, the EhaD homologue YpjA has been shown to promote adhesion to glass and polyvinyl chloride (PVC), as well as biofilm formation together with the EhaC homologue YfaL and YcgV (Roux, Beloin and Ghigo 2005). In EHEC, however, EhaC was not shown to promote biofilm formation (Wells et al. 2008). A homologue of $y c g V$ has been genetically identified in several DEC, namely, EPEC, ETEC, EAEC and EIEC (Wells, Totsika and Schembri 2010; Zude, Leimbach and Dobrindt 2014). Altogether, this information emphasises the need for further experimental characterisation of the adhesive functions of Eha, particularly considering the diversity of DEC.

Some ATs originally identified in UPEC and acting as adhesins have been identified in DEC, namely, UpaB (uropathogenic E. coli autotransporter B) and UpaI (Zude, Leimbach and Dobrindt 2014). From UPEC investigations, these proteins appeared to promote adhesion to a wide range of ECM components (Allsopp et al. 2012; Zude, Leimbach and Dobrindt 2014), whilst UpaI was further demonstrated to mediate biofilm formation (Zude, Leimbach and Dobrindt 2014). Although the genes are found in EPEC and STEC, none of them have been functionally characterised in any DEC to date (Zude, Leimbach and Dobrindt 2014).

Following genomic analysis, AatA (avian pathogenic E. coli autotransporter A) appears to be also present in some DEC strains (Zude, Leimbach and Dobrindt 2014). In APEC (avian pathogenic E. coli), AatA is important for pathogenesis as it enhanced adhesion to chicken fibroblast cells (Dai et al. 2010; Li et al. 2010; Wang et al. 2011). However, its role and contribution in DEC is still unknown.

SELF-ASSOCIATING AUTOTRANSPORTERS (SAATS) SAATS are primarily enable to associate to one another resulting in bacterial cell autoaggregation (Klemm, Vejborg and Sherlock 2006). In E. coli, the SAATs regroup ATs from the Ag43 (antigen 43), AIDAI (adhesin involved in diffuse adherence phenotype) and TibA (toxigenic invasion locus b) families (Trunk, Khalil and Leo 2018). Of note, SAATs differentiate from ATAs as they do not necessarily play a role in direct adhesion to biotic or abiotic surfaces but can nonetheless contribute directly or indirectly to surface colonisation.

Ag43 is probably the SAAT which has triggered the most research to date, with most of the information resulting from investigations in the E. coli K12 laboratory strain (van der Woude and Henderson 2008). Besides autoaggregation, Ag43 has been demonstrated to increase biofilm formation on abiotic surfaces (Kjaergaard et al. 2000) and adhesion to epithelial cells (Sherlock et al. 2006; de Luna et al. 2008) but to decrease bacterial motility (Ulett et al. 2007a,b). The gene encoding Ag43 has been shown to be highly expressed during the early stage of biofilm formation (Schembri, Kjaergaard and Klemm 2003) but not in mature biofilms (Beloin et al. 2004). While biofilm formation is favoured by the autoaggregation phenomenon (van der Woude and Henderson 2008), Ag43 is not involved in gut colonisation (de Luna et al. 2008). It is also known that the expression of pili would shield the interaction between Ag43 and thus prevent the autoaggregation (Korea et al. 2010). Phylogenetic analysis revealed the agn43 gene is distributed into two subfamilies, namely, subfamily I (SF-I) and SF-II, and is only found among, but not all, E. coli (including some Shigella spp.) (van der Woude and Henderson 2008). It has been suggested that agn43 is more prevalent in pathogenic E. coli strains than in commensal E. coli strains (van der Woude and Henderson 2008). It can be detected as a single gene copy, like in $E$. coli $\mathrm{K} 12$, or in multiple alleles, like in EHEC 0157:H7 EDL933 where two identical copies are found in two different pathogenicity islands, namely the O-island 43 (OI43) and OI-48 (Torres et al. 2002). In UPEC CFT073, Ag43 is encoded by two different alleles, namely agn $43 a$ and agn $43 b$ (Ulett et al. 2007b). Compared to the Ag43 encoded by the first allele, Ag43 from allele $b$ had a slower autoaggregation kinetics and lower propension for biofilm formation.

Autoaggregation results from the L-shape structure of Ag43 passenger region, which drives molecular interaction via salt bridges and hydrogen bonds along the $\beta$-helix structure in a molecular Velcro-like handshake mechanism (Heras et al. 2014). In E. coli O157:H7 EDL933, Ag43 was shown to promote autoaggregation, calcium binding and biofilm formation but was unable to mediate adhesion to epithelial cells (Torres et al. 2002). While present in other DEC, such as EPEC, ETEC and EAEC (Zude, Leimbach and Dobrindt 2014; Vo et al. 2017), functional characterisation of Ag43 in these different pathotypes has not be examined in details to date. Most recently, phylogenetic network analysis revealed the Ag43 passengers were distributed into four distinct classes, namely, C1, C2, C3 and C4 (Ageorges et al. 2019). Structural alignment and modelling analyses indicated the $\mathrm{N}$-terminal and $\mathrm{C}$-terminal regions of the passengers belonged to two different subtypes which gave rise to these four distinct Ag43 classes upon domain shuffling. Functional analyses demonstrated that expression of $\mathrm{Ag} 43^{\mathrm{C} 3}$ (which both agn $43 a$ and agn $43 b$ from UPEC CFT073 belong to) induced a slower sedimentation kinetics of bacterial cells and smaller aggregates compared to the three other Ag43 classes (Ageorges et al. 2019). Using prototypical Ag43 ${ }^{\mathrm{C} 1}$ from E. coli K12 MG1655, Ag43 C2 from EHEC EDL933, Ag43 C3 from UPEC CFT073 (allele agn43b) and Ag43 ${ }^{\mathrm{C} 4}$ from ETEC H10407, it appeared that heterotypic interactions occurred in a very limited number of cases compared to homotypic interactions. This ability of Ag43 variants to specifically identify genetic copies of themselves in other bacterial cells through Ag43-Ag43 interactions further suggests a greenbeard effect (Gardner and West 2010; Wall 2016), the ecophysiological relevance of which undoubtedly require further investigation (Ageorges et al. 2019).

AIDA-I is involved in the diffuse adherence of DEC strains (Benz and Schmidt 1989; Benz and Schmidt 1992) and also in bacterial autoaggregation, biofilm formation and adherence to a wide range of human and non-human cells (Benz and Schmidt 1989; Sherlock et al. 2006). While the function of AIDA-I is quite similar to Ag43, they clearly belong to different protein families (Vo et al. 2017). The gene encoding AIDA-I is especially prevalent in ETEC and STEC strains from porcine origin, which suggests pork as a main animal reservoir for this gene (Niewerth et al. 2001; Ha et al. 2003). In EPEC, the AIDA-I gene (aidA) is associated with aah which encodes a 45-KDa heptosyltransferase (Benz and Schmidt 2001). These genes are plasmid located and transcribed as bicistronic mRNA, but their expression seems to be restricted to a small number of DEC strains (Owen et al. 1996; Sherlock et al. 2004). Aah (adhesin associated heptosyltransferase) modifies the AIDA-I by addition of 19 heptose residues on average, which enables EPEC to adhere to human cells (Benz and Schmidt 1992; Benz and Schmidt 2001; Laarmann and Schmidt 2003; Schembri, Dalsgaard and Klemm 2004). In EHEC O157:H7, though, AIDA-I does not play a role in adherence to cultured cells or to pig intestinal epithelial cells (Yin et al. 2009). This suggests different subfamilies or classes of AIDA-I could exist as observed for Ag43, which would require further in-depth investigation.

TibA has been found to self-aggregate, promote biofilm formation and facilitate colonisation of the intestinal epithelia (Sherlock, Vejborg and Klemm 2005; Cote and Mourez 2011). In 
ETEC, TibA is encoded by the tib operon, which also encodes the glycosyltransferase TibC (Lindenthal and Elsinghorst 1999). Glycosylation of TibA is important for its function since its unglycosylated form is less stable and cannot oligomerise properly and in turn cannot promote bacterial adhesion to epithelial cells (Cote, Charbonneau and Mourez 2013); nonetheless, it can autoaggregate, promote biofilm formation and cell invasion. Interestingly, TibA, AIDA-I and Ag43 have been reported to interact with one another resulting in the formation of mixed bacterial aggregates (Klemm, Vejborg and Sherlock 2006). These interesting findings deserve further in-depth characterisation, especially with regards to recent findings where the interactions between Ag43 variants appears quite specific (Ageorges et al. 2019).

In E. coli O157:H7, EhaA has been shown to mediate autoaggregation and adhesion to primary epithelial cells derived from the bovine terminal rectum, as well as biofilm formation (Wells et al. 2008). As such, EhaA can be considered as an additional member of SAAT also found in EAEC, EPEC and ETEC (Vo et al. 2017). Similarly, UpaC was reported to promote autoaggregation, as well as biofilm formation (Zude, Leimbach and Dobrindt 2014). UpaC is found in a wide range of InPEC (Zude, Leimbach and Dobrindt 2014). Of note, some ATAs such as UpaI can further promote autoaggregation to some extent (Zude, Leimbach and Dobrindt 2014).

SERINE PROTEASE AUTOTRANSPORTERS FROM ENTEROBACTERIACEAE (SPATES) SPATEs correspond to a subfamily of protease autotransporters that specifically exhibit a serine protease domain (IPR034061) in the passenger region (Rojas-Lopez et al. 2017). While their primary function is associated with the degradation of various proteins, such as mucin or haemoglobin, they can contribute to bacterial virulence via their cytotoxic effect, and some can even be involved in bacterial colonisation (Dautin 2010).

In EHEC, EspP (extracellular serine protease plasmidencoded), also known as PssA (protein secreted by Stx-producing E. coli), contributes to biofilm formation, bacterial adherence to intestinal epithelial cells, including bovine primary rectal cells and colonisation of the bovine intestine (Dziva et al. 2007; Puttamreddy, Cornick and Minion 2010; Farfan and Torres 2012). EspP is encoded on the p0157 plasmid and can be found in diverse STEC isolates (van Diemen et al. 2005; Dziva et al. 2007; Ruiz-Perez and Nataro 2014). At the bacterial cell surface, EspP passenger domains self-assemble to form supramolecular structures, called ropes (Xicohtencatl-Cortes et al. 2010). Besides cytopathic activities, the EspP ropes have strong adhesive properties to host epithelial cells and can further serve as a substratum for bacterial adherence and biofilm formation. Similar observations have also been made for EspC from EPEC (Xicohtencatl-Cortes et al. 2010).

In EAEC, Pic (protein involved in colonisation) is involved in mucin degradation but also directly in mucin binding (GutierrezJimenez, Arciniega and Navarro-Garcia 2008; Andrade et al. 2017). It thus participates in intestinal colonisation and may also be involved in bacterium-mucus biofilm (Navarro-Garcia and Elias 2011). Pic is also expressed by the hybrid EHEC/EAEC E. coli $0104: \mathrm{H} 4$ but its exact contribution to the colonisation process in this genetic background remains to be ascertained (Henderson et al. 1999; Harrington et al. 2009; Abreu et al. 2015; Abreu et al. 2016). Of note, Shmu is a mucinase identical to Pic found in Shigella (Rajakumar, Sasakawa and Adler 1997).
Inverted autotransporters (IATs) In IATs, which correspond to the Type V, subtype e, secretion system (T5eSS), the translocator is located in the $\mathrm{N}$-terminal region and the passenger at the C-terminal, which is the opposite of the modular organisation found in ATs (Tsai et al. 2010; Oberhettinger et al. 2012). In DEC, there are several IATs acting as SCFs, namely, intimin, FdeC (Factor adherence of E. coli) and YeeJ. More recently, additional IATs have been identified in E. coli, where iatA appeared quite prevalent but the functional characterisation of the gene product is still awaited (Goh et al. 2019). IatB, IatC and IatD from an environmental $E$. coli strain were further shown to be involved in strong biofilm formation when overexpressed in a recombinant $E$. coli K12 background, but not in autoaggregation nor adhesion to ECM proteins (Goh et al. 2019). While identified in several DEC, their role and contribution in their native genetic background is still unknown.

INTIMIN Intimin is the prototypical member of IATs (Leo, Grin and Linke 2015). In EPEC and EHEC, the intimin is encoded by the eae (for E. coli attachment effacement) gene in the locus of enterocyte effacement (LEE) (Nataro and Kaper 1998). This protein interacts specifically with its receptor Tir (translocated intimin receptor) allowing the establishment of the intimate attachment of the bacteria with the host cell, pedestal formation and attaching/effacing lesions (A/E) (Schmidt 2010). In addition, intimin contributes to intestinal colonisation in a Tir-independent manner (Mallick et al. 2012). Intimin may also bind to alternative receptors such as $\beta_{1}$ integrins or nucleolin but this remains to be clarified (Liu, Magoun and Leong 1999; Leo et al. 2015).

FACTOR ADHERENCE OF E. coli (FDEC) FdeC is a widespread IAT in E. coli and present in all DEC pathotypes (Nesta et al. 2012; Easton et al. 2014). In EHEC O26:H11, FdeC was shown to contribute to biofilm formation and potentially in colonisation of the terminal rectum of cattle (Easton et al. 2014).

YEEJ More recently, the gene encoding YeeJ has been reported to be present in some DEC, namely, EHEC, EPEC, ETEC and EIEC (Martinez-Gil et al. 2017). In E. coli K12, this IAT has been shown to participate in biofilm formation. While YeeJ exists into two distinct variants of different lengths, no functional difference could be detected between them. However, the contribution of YeeJ to biofilm formation in DEC remains to be established.

Other outer membrane proteins (OMPs) Besides ATs and IATs, several additional monomeric OMPs can act as SCFs in DEC, namely, OmpA, Hra (Heat-resistant agglutinin), and Iha (Iron-regulated protein A homologue adhesin). OMPs are integrated to the OM via the $\beta$-barrel assembly machinery (Bam) complex (Leyton, Belousoff and Lithgow 2015; Botos, Noinaj and Buchanan 2017; Schiffrin, Brockwell and Radford 2017).

OUTER MEMBRANE PROTEIN A (OMPA) While originally considered as a pore forming protein (Sugawara and Nikaido 1992), whether the OmpA $\beta$-barrel offers a channel for the continuous passage of water or solutes remains controversial (Smith et al. 2007). Nowadays, OmpA is rather viewed as a multifaceted protein with functions of an adhesin as well as an invasin. In EHEC O157:H7, OmpA is involved in adhesion to intestinal epithelial cells (Torres and Kaper 2003; Kudva et al. 2015). OmpA further appears to be the key molecular determinant for bacterial adhesion to plant surfaces, such as alfalfa sprouts (Torres et al. 2005). The role of OmpA as an invasin was demonstrated in NMEC (Prasadarao et al. 1996) but remains to be established in DEC. 
Interestingly, OmpA can be encoded by at least two different alleles, namely ompA1 and ompA2 (Power et al. 2006). Many of the interaction properties of OmpA emanate from protein loops external to the OM, which are displayed on the bacterial cell surface (Smith et al. 2007); in the two alleles, differences in these regions could influence the adhesin and/or invasin properties of the protein. Of note, OmpA further serves as a receptor for bacteriophages and bacteriocins (Smajs, Pilsl and Braun 1997; Power et al. 2006). Regarding biofilm formation, the direct contribution of OmpA remains controversial; while OmpA from E. coli K12 has been shown to bind to abiotic surfaces and to significantly influence biofilm formation (Lower et al. 2005; Barrios et al. 2006), the role of OmpA in EHEC 0157:H7 biofilm formation appears to be minor and it acts rather as a modulator than a contributor to sessile development (Torres et al. 2005; Kudva et al. 2015). Keeping in mind that OmpA is an important contributor to the structural integrity of the bacterial cell envelope by bridging the $\mathrm{OM}$ and cell wall, along with lipoproteins (Wang 2002), the interpretations of phenotypes from OmpA mutants must be considered with caution due to possible pleiotropic effects that can be confounding. Further investigations on these various aspects are clearly needed, and in particular the allelic variation of OmpA should also be more carefully considered to decipher their exact role.

HeAt-REsistant Agglutinin (Hra) The Hra family of OMPs were first described with Hek (haemagglutinin from E. coli K1) in NMEC, where it was reported to promote autoaggregation, interactions with human erythrocytes and epithelial cells, as well as adhesion to, and invasion of epithelial cells (Fagan and Smith 2007). Hek was originally identified because of its homology with Tia (toxigenic invasion protein A) (Bhargava et al. 2009). In ETEC, Tia mediates attachment to intestinal epithelial cells as well as their invasion (Fleckenstein et al. 1996; Sjoling, von Mentzer and Svennerholm 2015). It also appears to bind several mammalian heparan sulphate binding proteins suggesting, that ETEC use these ubiquitous cell surface heparan sulphate proteoglycans as receptors to adhere and invade host epithelial cells (Fleckenstein, Holland and Hasty 2002).

In EAEC O42, Hra1 (heat-resistant agglutinin 1) was demonstrated to be responsible for autoaggregation and aggregative adherence, as well as biofilm formation (Bhargava et al., 2009). While these observations were made upon protein expression in nonadherent and nonpathogenic laboratory E. coli strains, an EAEC 042 hra1 deletion mutant was not deficient in these phenotypes, indicating that Hra1 is an accessory colonisation factor in this genetic background. While hra1/hek was originally considered absent from DEC but restricted to UPEC, NMEC and sepsis E. coli (Dobrindt et al. 2002; Cooke et al. 2010), it later became clear that hra1 and tia are common among DEC, especially EAEC but also EPEC (Fleckenstein et al. 1996; Mancini et al. 2011). In the EAEC strain 60A, Hra2 it is not involved in autoaggregation or invasion, but only in adherence to epithelial cells (Mancini et al. 2011); its involvement in bacterial adhesion to abiotic supports and biofilm formation remains to be elucidated. The prevalence of hra2, however, seems to be very low among DEC.

More recently, a novel member of the Hra family has been identified in STEC, namely, Hes (Hemagglutinin from shigatoxinencoding E. coli) (Montero et al. 2017). Hes was shown to promote autoaggregation and biofilm formation as well as erythrocyte agglutination and adherence to epithelial cells, but not invasion. The gene was observed to be present in LEE-negative STEC but not LEE-positive STEC (Montero et al. 2017).
IRON-REGULATED PROTEIN A HOMOLOGUE ADHESIN (IHA) Iha is an adherent-conferring protein homologous to IrgA (iron-regulated protein A) found in Vibrio cholerae (Tarr et al. 2000). As well as a $\beta$-barrel structure enabling membrane anchoring as in any OMP, Iha has externally exposed domains. Rather than localised adherence, Iha confers a diffuse adherence pattern in E. coli O157:H7. Besides STEC, iha has been identified in EPEC and UPEC (Szalo et al. 2002; Kanamaru et al. 2003; Gomes et al. 2011). In UPEC, Iha was shown to further act as a catecholate siderophore receptor (Herold et al. 2009) and a virulence factor (Johnson et al. 2005) but these roles in DEC remain to be established. In EHEC, Iha has been clearly demonstrated to be involved in intestinal colonisation and contribute to pathogenesis by promoting adherence to the intestinal epithelium (Yin et al. 2009).

Secreted and surface-associated lipoprotein of E. coli (SslE) SslE, formerly known as YghJ (Yang et al. 2007; Iguchi et al. 2009), was recently described as a novel E. coli mucinase thanks to its zinc metallopeptidase motif (Luo et al. 2014; Nesta et al. 2014). This protein is secreted by a Type II, subtype a, secretion system (T2aSS) but the molecular mechanisms of its maturation as a surface lipoprotein remains unclear. The gene encoding SslE is present in different DEC pathotypes such as EPEC, ETEC and EHEC (Decanio, Landick and Haft 2013). In EPEC, SslE was shown to mediate biofilm formation and intestinal colonisation (Baldi et al. 2012; Vermassen et al. 2019). This protein can be divided into two main variants and antibodies raised against variant I (from ExPEC strain IHE3034) are able to inhibit translocation of E. coli strains through a mucin-based matrix. In addition, immunisation of animals with SslE I significantly reduces gut colonisation by strains of different pathotypes expressing SslE II (Nesta et al. 2014). These observations make SslE a key factor in E. coli colonisation of the mucosal surface in humans and could serve as a component for a protective vaccine against DEC (Naili et al. 2016; Naili et al. 2017; Rojas-Lopez et al. 2018; Rojas-Lopez et al. 2019).

E. coli factor adherence 1 (Efa-1) Efa-1, also known as LifA (lymphostatin A), present in EPEC and some non-O157 EHEC strains, is known to inhibit the proliferation of mitogen-activated lymphocytes and the synthesis of proinflammatory cytokines and gamma interferon (Klapproth et al. 2000; Abu-Median et al. 2006). Efa-1 has been shown to mediate colonisation of the calf intestine independently of glycotransferase and cysteine protease motifs (Deacon et al. 2010). In EHEC 0157 strains, ToxB is homologous to Efa-1 and appears to contribute to adherence to cultured epithelial intestinal cells (Tatsuno et al. 2001). However, no lymphostatin-like activity has been associated with this protein and it is not involved in intestinal colonisation in animal models (Stevens et al. 2004; Abu-Median et al. 2006). While Efa-1 has an extracytoplasmic domain and is presumably cell-surface exposed (Nicholls, Grant and Robins-Browne 2002), the molecular mechanisms at play for its secretion and cell-surface display remain unknown.

Dispersin Dispersin is an anti-aggregation protein (Aap) involved in the spreading of bacterial cells along the host intestinal mucosa (Sheikh et al. 2002). This protein contributes to adherence and colonisation of EAEC by preventing hyper-aggregation and collapse of AAF (aggregative adherence fimbriae). Dispersin is present at the bacterial cell-surface via binding to LPS in a non-covalent manner after secretion through a Type I secretion system (T1SS) (Velarde et al. 2007). This secretion system 
and cognate-secreted protein are encoded in the aat (aggregative $A B C$ transporter) locus located in the pAA plasmid of some EAEC (Nishi et al. 2003). Dispersin is also present in some STEC strains (Monteiro et al. 2009; Muniesa et al. 2012).

Moonlighting proteins At the bacterial cell surface of E. coli, some unexpected proteins primarily known to be localised in the cytoplasm have been reported. Among these unexpected cell surface proteins, glycolytic enzymes are frequently uncovered (Henderson and Martin 2011). These so-called moonlighting proteins have been demonstrated to exhibit a secondary function at the bacterial cell-surface, completely unrelated to their primary function in the cytoplasm (Khan et al. 2014). As a common glycolytic enzyme frequently found at the bacterial cell surface, GAPDH (glyceraldehyde 3-phosphate dehydrogenase) has been demonstrated to bind plasminogen and fibrinogen in EHEC and EPEC (Egea et al. 2007); although there is no evidence of GAPDH acting directly as a plasminogen activator (Coleman and Benach 1999; Seidler 2013). In addition, GAPDH is clearly involved in adhesion to intestinal epithelial cells upon infection. A common theme for moonlighting proteins present at the bacterial cell surface is that these proteins lack a $\mathrm{N}$-terminal signal peptide for translocation across the $\mathrm{CM}$ and the protein secretion systems enabling their translocation across the OM are often unknown, which is covered by the generic term of non-classical protein secretion (Bendtsen and Wooldridge 2009; Desvaux et al. 2009b). For GAPDH, though, it has been strongly suggested to occur via piggybacking through the Type III, subtype a, secretion system (T3aSS) (Aguilera et al. 2012). While it is also known that enolase can also be extracellularly located in E. coli (Boel et al. 2004), its contribution to bacterial adhesion remains to be determined. The elongation factor $\mathrm{Tu}$ (EF-Tu) is also found at the bacterial cell surface and has been reported to be involved in bacterial aggregation (Amimanan et al. 2017). In DEC, the contribution of putative moonlighting glycolytic enzymes and other moonlighting proteins to the colonisation process deserves more thorough investigation

\section{Multimeric proteinaceous surface colonisation factors}

Multimeric protein complexes acting as SCFs can be classified as (i) homooligomeric proteins, namely, the trimeric autotransporter adhesins (TAAs) and (ii) cell-surface supramolecular structures, including flagella and numerous pili.

Trimeric autotransporter adhesins (TAAs) TAAs are characterised by the presence of a short translocator domain, which is functional upon homotrimeric assembly and corresponds to the Type V, subtype c, secretion system (T5cSS) (Cotter, Surana and St Geme 2005; Leo, Grin and Linke 2012). In DEC, TAAs include UpaG (UPEC autotransporter G), Eib (E. coli immunoglobulin-binding protein), Sab (STEC-autotransporter mediating biofilm formation) and Saa (STEC autoagglutinating adhesin).

UPEC AUTOTRANSPORTER G (UPAG) While UpaG was originally identified in UPEC, it was also found in the EAEC 042 strain (Zude, Leimbach and Dobrindt 2014). UpaG is involved in autoaggregation, biofilm formation, adhesion to fibronectin and laminin, as well as human epithelial cells (Valle et al. 2008). In EHEC, EhaG (EHEC autotransporter G) is a positional orthologue of UpaG, which is also involved in autoaggregation, biofilm formation, adhesion to laminin, fibronectin and collagens I, II, II and IV as well as some epithelial cells (Valle et al. 2008; Totsika et al. 2012; Zude, Leimbach and Dobrindt 2014). The gene encoding EhaG has been also identified in a wide range of DEC including EPEC, EIEC, ETEC and EAEC (Zude, Leimbach and Dobrindt 2014).

E. coli IMMUNOGLOBULIN-BINDING PROTEIN (EIB) Eibs were originally characterised for their ability to bind immunoglobulin fractions, especially to the Fc (fragment crystallisable) region of IgA and IgG (Sandt and Hill 2000; Sandt and Hill 2001; Leo and Goldman 2009); up to seven different Eibs have been identified to date, namely, EibA, B, C, D, E, F and G. In LEE-negative STEC O91, it further appeared that EibG is involved in adherence to epithelial cells in a chain-like adhesion (CLA) pattern (Lu et al. 2006). CLA corresponds to the formation of a long chain cell aggregate, which EibG induces on both human and bovine intestinal epithelial cells. The gene encoding EibG is distributed into 21 different alleles clustered into three eibG subtypes, namely, eibG- $\alpha,-\beta$ and $-\gamma$ (Merkel et al. 2010). While EibG- $\alpha$ and EibG- $\beta$ are responsible for the typical CLA phenotype, EibG- $\gamma$ induces adherence in much shorter cell chains and smaller cell aggregates, corresponding to an atypical CLA. EibD has been further shown to promote autoaggregation and biofilm formation (Leo et al. 2011). Considering their structural similarity, other Eibs have been suggested to have similar biological functions but experimental confirmation is still required to ascertain this. Eib genes are found in some STEC strains, as well as some E. coli commensal strains (Lu et al. 2006).

STEC-AUTOTRANSPORTER MEDIATING BIOFILM FORMATION (SAB) Sab contributes to the diffusive adherence of STEC to human epithelial cells and biofilm formation to abiotic surfaces (Herold, Paton and Paton 2009; Farfan and Torres 2012). Genes encoding Sab are especially present in LEE-negative STEC.

STEC AUTOAGGLUTINING ADHESIN (SAA) Saa promotes adhesion to HEp-2 cells in a semilocalised adherence pattern (Paton et al. 2001). So far, the saa gene has only been reported in some STEC, including some LEE-negative EHEC strains (Paton and Paton 2002; Jenkins et al. 2003; Monaghan et al. 2011).

Cell-surface supramolecular structures Flagella and pili are organelles resulting from the supramolecular assembly of different protein subunits to form heteromultimeric protein complexes on the bacterial cell-surface.

FLAGELLA Flagellar components are secreted and assembled via the Type III, subtype b, secretion system (T3bSS) and more than 50 genes divided in three hierarchical classes are involved in the flagellar apparatus formation (Young, Schmiel and Miller 1999; Chilcott and Hughes 2000). The main component of the flagellum filament is the flagellin, which has considerable diversity in ultrastructure and is responsible for the $\mathrm{H}$-antigen variability (H1 to H56) (Zhou et al. 2015). In E. coli, the flagellation is peritrichous but the sites of cell surface localisation and the number of flagella (typically around 6-10) are considered random (Macnab 1987a, 1987b). Nonetheless, it must be stressed that when swimming, the flagella in motion coalesce into an undulating bundle, forming one rigid helical ponytail about $14 \mathrm{~nm}$ in diameter and $10 \mu \mathrm{m}$ long that appears as polarly localised in E. coli (Bray 2001). A swimming bacterial cell has a run-andtumble behaviour, where it progresses linearly (run) and then changing abruptly in direction (tumble), but also slow-randomwalk behaviour, where it moves at a relatively low speed (Qu et al. 2018). Upon chemotaxis, the rotational direction of the flagella motor can be switched to control motility, a factor that 
might help approaching the intestinal mucosa in a more coordinated movement (Kitao and Hata 2018; Rossi et al. 2018). The approach to the surface is an important step towards initial bacterial adhesion and subsequent sessile development. Active motility involving the flagella allows the bacterial cells to overcome repulsive electrostatic and hydrodynamic forces at the adhesion site (Donlan 2002).

Besides swimming, flagella can participate in an alternative type of motility called swarming where bacterial cells move and spread on a surface (Kaiser 2007). Swarming directly contributes to the surface colonisation process and is associated with the expression of an alternative system, the lateral flagella (Merino, Shaw and Tomas 2006). In EAEC O42, the Flag-2 locus encodes such a system (Ren et al. 2005), although, a mutation frameshift has likely inactivated this system in this strain. Nonetheless, the Flag-2 cluster appeared to be present in about $20 \%$ of E. coli strains from the ECOR collection. In the environmental strain E. coli SMS-3-5, although the Flag-2 gene cluster is complete and intact, swarming motility could not be observed (Fricke et al. 2008); to date, the functionality of this system in E. coli remains to be elucidated. In the absence of polar flagella, E. coli is not as efficient at surface colonisation but is still considered a temperate swarmer, enabling it to swarm over surfaces with rheology corresponding to $0.5 \%-0.8 \%$ agar (in comparison to $\geq 1.5 \%$ agar for robust swarmers) (Partridge and Harshey 2013).

Besides motility, flagella can directly act as adhesins, as shown in EPEC, where they are involved in adhesion to epithelial cells (Giron et al. 2002; Cleary et al. 2004). In EAEC, flagella contribute to adhesion to plant leaves (Berger et al. 2009). In EHEC, the flagellin FliC favours initial attachment, adhesion to epithelial cells and biofilm formation on abiotic surfaces as well as spinach leaves (McNeilly et al. 2008; Mahajan et al. 2009; Xicohtencatl-Cortes et al. 2009; Vikram et al. 2013; Nagy et al. 2015). In ETEC, flagella contribute to bacterial adhesion to salad leaves and intestinal epithelial cells, as well as biofilm formation (Shaw et al. 2011; Duan et al. 2012; Zhou et al. 2013; Zhou et al. 2014). Interestingly, in this pathotype, flagella can also mediate indirect adhesion through EtpA (ETEC two-partner secretion protein A), a protein secreted by a T5bSS (two-partner secretion system), which bridges the flagella with host cell receptors, thus allowing bacterial cell attachment to some epithelial cells and mucin-expressing regions in mouse small intestinne (Fleckenstein et al. 2006; Roy et al. 2009). In EHEC and EPEC, the adhesion of $\mathrm{H} 6$ and $\mathrm{H7}$ flagella to the intestinal epithelium and epithelial cells has been suggested to occur though mucins (Giron et al. 2002; Mahajan et al. 2009) as reported for H1 flagella from the probiotic E. coli Nissle 1917 (Troge et al. 2012). In some EHEC/STEC strains, namely LEE-negative EHEC 0113:H21 and STEC 0139:H1:F18ab strains, flagella can also contribute to bacterial invasion of intestinal epithelial cells but the molecular mechanisms at work remains to be clarified (Luck et al. 2006; Rogers et al. 2012; Duan et al. 2013). These latter aspects would undoubtedly deserve further in-depth investigation.

While different flagellin variants have been shown to be involved in direct binding to host cells, such as H1 and H19 flagella in ETEC (Duan et al. 2012; Duan et al. 2013), systematic analysis of the colonisation properties of all of the different $\mathrm{H}$ antigens in E. coli has not been investigated as yet. Except for EIEC which are generally considered as nonmotile (Nataro and Kaper 1998), the contribution of flagella as a motility factor over an adhesion factor in the colonisation processes has not been clearly resolved as of yet in DEC, particularly regarding bacterial adhesion and biofilm formation to biotic and abiotic surfaces (Wood et al. 2006; Servin 2014).
PILI Pili, also referred to in the E. coli literature as fimbriae, are key actors during the initial attachment of bacteria to surfaces, which is characterised by a stronger and longer interaction coupled with a decrease of bacterial motility (Pruss et al. 2006). While binding can be considered reversible as evidenced for the chaperon-usher fimbriae to lectin (Hultgren et al. 1989; Lin et al. 2002), bacterial binding can also be very strong due to the numerous pili expressed simultaneously by a single cell creating an avidity effect, as well as the flexibility of the stalk itself (Andersson et al. 2006). These pili can be secreted and assembled by different protein secretion systems, namely, the Type II, subtype c (T2cSS), Type III, subtype a (T3aSS), Type IV, subtype b (T4bSS), Type VII (T7SS) or Type VIII (T8SS) secretion systems (Figure 2). It should be stressed that this numerical protein secretion nomenclature was intended and restricted to the LPS-diderm bacteria in the first place (Desvaux et al. 2009a). In mycolate diderm bacteria (archetypical acid-fast bacteria, namely, mycobacteria) and some parietal monoderm bacteria, the ESX (ESAT-6) system involved in protein export across the IM (or cytoplasmic membrane) was also termed T7SS, which is (i) misleading when considering that no ESX component enabling protein translocation across the mycolic outer membrane has yet been identified (Converse and Cox 2005; Bitter et al. 2009; Groschel et al. 2016; Bosserman and Champion 2017; Unnikrishnan et al. 2017; Vaziri and Brosch 2019) and (ii) a misnomer with respect to both the bacterial export systems (and especially parietal monoderm bacteria), which do not follow the numerical nomenclature (e.g. Sec or Tat), and the numerical nomenclature for protein secretion systems in LPS-diderm, which is primarily based on the presence of a translocon at the OM (Desvaux et al. 2004; Desvaux et al. 2009a,b Sutcliffe 2011). In diderm bacteria, the ESX is truly an export system in the same line than the Sec or Tat systems (van der Woude, Luirink and Bitter 2013) but not a secretion system per se. In the present review, the T7SS refers exclusively to the chaperone-usher pathway in LPS-diderm bacteria (Desvaux et al. 2009a,b; Chagnot et al. 2013; Abby et al. 2016; Gagic et al. 2016; Monteiro et al. 2016), which is the main pathway responsible for the secretion of a wealth of pili in E. coli (Wurpel et al. 2013). Of note, P pili have been well investigated in UPEC infection (Kuehn et al. 1992; Lillington, Geibel and Waksman 2014; Behzadi 2020) but their prevalence in DEC and potential contribution (or not) in diarrhoeic infection is much less documented although they contribute to intestinal colonisation of commensal E. coli (Nowrouzian, Wold and Adlerberth 2001) and have been detected in some strains causing bovine diarrhoea (Dozois et al. 1997).

The INJectisome The injectisome is a bacterial molecular syringe assembled and secreted by the T3aSS (Desvaux et al. 2006; Galan and Waksman 2018). The injectisome forms a needle, which is functionally closer to the Hrp (hypersensitive response and pathogenicity) pilus in Pseudomonas syringae than to a flagellum (He and Jin 2003; Tampakaki et al. 2004; Cornelis 2006). This cell-surface appendage can vary in size depending on the bacterial species and even bacterial strains (Cornelis 2006); in a controlled process, the pilus length can further adapt for cell surface contact. In DEC, this peculiar pilus is encoded by genes located in the LEE pathogenicity island (McDaniel, Donnenberg and Kaper 1995), a landmark for all EPEC but is also present in some EHEC strains (namely, the LEE-positive strains), such as E. coli O157:H7, and EIEC (including Shigella spp.) (Hueck 1998; Galan and Wolf-Watz 2006; Coburn, Sekirov and Finlay 2007). Tir (translocated intimin receptor) is encoded by the tir gene located in the LEE and is injected in the host cell by the 
injectisome (Hueck 1998). This protein is then exposed at the host cell surface and serves as the receptor for the intimin, enabling intimate bacterial interaction with the intestinal epithelia (Donnenberg et al. 1993; Liu et al. 1999). In EPEC, the injectisome is involved in cell adhesion and pedestal formation that occurs during the formation of attaching and effacing lesions upon actin rearrangement in the infected eukaryotic cell (A/E) (Wong et al. 2011). Of note, while A/E lesions are observed in vitro from infected epithelial cell cultures or colonic epithelium with LEE-positive EHEC (Lewis et al. 2015), these kinds of lesions are never observed from clinical samples of EHEC infections (Nataro and Kaper 1998); a clear explanation of why this is the case is unclear but would undoubtedly deserve further investigation to match up lab experiments with clinical observations (Lewis et al. 2015). In addition to the infection of mammalian cells, the injectisome is involved in adhesion to plants with a marked tropism for the stomata (Schroeder and Hilbi 2008; Shaw et al. 2008; Berger et al. 2010; Croxen et al. 2013). EspA, the main component of the filament in the injectisome is directly involved in adhesion, as well as in biofilm formation, in EPEC (Knutton et al. 1998; Moreira et al. 2006). In EIEC, the injectisome contributes to the invasion capabilities (Hueck 1998).

TYPE 4 PILI (T4P) T4P are assembled and secreted by the T2cSS (Ramer et al. 2002; Chagnot et al. 2013). T4P have been demonstrated to play a role in several E. coli pathotypes, including host cell adherence and bacterial aggregation (Craig, Pique and Tainer 2004). Some of these pili can exhibit a unique feature in their ability to extend and retract, which results in twitching motility further contributing to biofilm formation (Mattick 2002; Craig, Forest and Maier 2019). In EPEC, T4P are also known as BFP (bundle-forming pili) and their subunits assemble in a helical manner to form polymeric fibres and can further interact to create higher-order bundles or tangled aggregates (Giltner, Nguyen and Burrows 2012; Melville and Craig 2013). These T4P are involved in the colonisation of the GIT and contribute to bacterial virulence (Bieber et al. 1998; Tacket et al. 1998). BFP are encoded by the $b f p$ operon comprising of 14 genes, including $b f p A$, which encodes the major repeating subunit of the pilus fibre (Ramer, Bieber and Schoolnik 1996; Sohel et al. 1996). In EHEC strains, the T4P are called HCP (haemorrhagic E. coli pili) (Xicohtencatl-Cortes et al. 2009). Inactivation of the hcpA gene in EHEC 0157:H7 reduces adherence to human and bovine epithelial cells. HCP is also able to bind to fibronectin and laminin, to agglutinate rabbit red blood cells, to mediate biofilm formation and to promote twitching motility (Xicohtencatl-Cortes et al. 2009). HCP are also encoded in some STEC strains (Farfan and Torres 2012). Because of their size, peculiar T4P called longus pili have been reported in ETEC (Giron, Levine and Kaper 1994). The N-terminal part of the major subunit LngA is homologous with Bfp of EPEC, CofA subunit of CFA/III (colonisation factor antigen) of ETEC and TCP (the toxin-coregulated pilin) of V. cholerae (Giron et al. 1995; Gomez-Duarte and Kaper 1995). Longus pili are involved in colonisation of the human gut (Clavijo, Bai and Gomez-Duarte 2010; Mazariego-Espinosa et al. 2010), in bacterium-bacterium interaction and resistance to antimicrobial agents as a result of biofilm formation (Clavijo, Bai and Gomez-Duarte 2010).

Conjugative pili (CP) CP are assembled and secreted through T4bSS (Lawley et al. 2003). Classically, the genes encoding for F-plasmid transfer are encoded on the tra operon located in the conjugative F plasmid (Manwaring, Skurray and Firth 1999). $\mathrm{CP}$ are responsible for nucleoprotein transfer between a donor bacterial cell (harbouring the F plasmid) and a recipient bacterial cell via the T4bSS (Lawley et al. 2003). Bacterial conjugation is a well-known process enabling horizontal transfer of genes including virulence or colonisation factors (Manwaring, Skurray and Firth 1999; Mazel and Davies 1999; Llosa et al. 2002; Sorensen and Mortensen 2005). Gene transfer is especially promoted in biofilm where physical contact between sessile donor and recipient cells is favoured (Lebaron et al. 1997; Hausner and Wuertz 1999; Dionisio et al. 2002; Molin and Tolker-Nielsen 2003; Maeda et al. 2006). Besides the transfer of genetic material, CP can be directly involved in bacterial adhesion (Beloin et al. 2008; May and Okabe 2008; May, Tsuruta and Okabe 2011). In biofilm, this can be further amplified as cells carrying a conjugative F plasmid promote the establishment of $\mathrm{F}$ pili mating pairs and consequently induce adhesion and biofilm formation between abiotic surfaces and poor biofilm former cells. EAEC strains expressing F pili have been demonstrated to improve mixed biofilm formation (Pereira et al. 2010). In EAEC C1096, pili encoded on the conjugative plasmid Incl1 further contributed to adherence to abiotic surfaces and epithelial cells (Dudley et al. 2006b). In EHEC O157:H7 Xuzhou, a novel conjugative plasmid called p0157-Sal encoding a complete set of genes for the T4bSS was identified, but its involvement in the colonisation process has not been investigated as yet (Wang et al. 2011; Zhao et al. 2013).

TYPE I PILI (TIP) T1P (also called Type 1 fimbriae) are the most investigated pili secreted and assembled via a T7SS (Capitani et al. 2006). The expression of T1P is induced during the initial bacterial adhesion step (Harris et al. 1990; Pratt and Kolter 1998; Cookson, Cooley and Woodward 2002; Orndorff et al. 2004; Reisner et al. 2014) and they are involved in the early and late stages of biofilm formation (Schembri, Kjaergaard and Klemm 2003; Beloin et al. 2004; Reisner et al. 2014). T1P also have a role in the formation of SIgA (secretory IgA) mediated biofilm of the normal flora within the gut (Bollinger et al. 2003; Orndorff et al. 2004; Bollinger et al. 2006). T1P are composed of FimA (fimbrillin A), which constitutes the pilus rod, and FimH at the apex of the pilus tip. FimH is the key adhesin component in T1P as it can link to mannose residues of some receptors on eukaryotic cells (Kaper, Nataro and Mobley 2004; Duncan et al. 2005) but also has nonspecific binding activity to abiotic surfaces (Pratt and Kolter 1998, Beloin et al. 2008). The absence of the FimH adhesin has been shown to hinder biofilm formation by preventing cell-to-surface and cell-to-cell contacts (Danese et al. 2000). In E. coli, different fimH alleles have been reported as conferring distinct colonisation abilities and thus playing different roles in biofilm formation (Martinez et al. 2000; Weissman et al. 2006). It was shown that contact between T1P and abiotic surfaces alters the composition of the OM and changes some physicochemical properties of the bacterial surface, which in turn influences adhesion (Otto et al. 2001; Orndorff et al. 2004). While the laboratory E. coli K12 strain and UPEC NU14 strain are the focus of the majority of the investigations about T1P, their involvement in bacterial adhesion and/or biofilm formation has been further demonstrated in EPEC, EAEC, ETEC and STEC strains (Elliott and Kaper 1997; Cookson, Cooley and Woodward 2002; Moreira et al. 2003; Sheikh et al. 2017). T1P are encoded in the fimBEAICDGHF gene cluster, which is quite widespread in E. coli in both commensal and pathogenic isolates (Sauer et al. 2000; Kaper, Nataro and Mobley 2004; Wurpel et al. 2013). While present in EHEC 0157:H7 (Abraham et al. 1988; Li et al. 1997; Roe et al. 2001; McWilliams and Torres 2014), their contribution to the colonisation process has yet to be demonstrated. 
Genes encoding the F1C pili are present in approximately 7\% of E. coli faecal isolates (Werneburg and Thanassi 2018). F1C pili have been characterised in UPEC strains where they are encoded in the foc (fimbriae of serotype 1C) operon homologous to the fim locus (Klemm et al. 1994). In UPEC, F1C pili are involved in adherence to the bladder and kidney cells, as well as in biofilm formation (Werneburg and Thanassi 2018). Their prevalence and contribution to the colonisation process in DEC remains to be investigated.

CS3I A PILI The CS31A (coli surface associated 31a antigen) plays a key role in the virulence of septicemic E. coli and ETEC, as well as some EPEC and DAEC (Girardeau et al. 1988; Contrepois et al. 1989; Jallat et al. 1994; Adams et al. 1997). Because of their thin structure, as well as their close and packed association to the bacterial cell surface, CS31A was initially described as capsule-like or even nonfimbrial antigens (Bertin et al. 1993; Mechin, Rousset and Girardeau 1996) before being clearly identified as thin capsular pili secreted and assembled by a chaperoneusher pathway (T7SS) (Thanassi, Saulino and Hultgren 1998). These pili are synthesised from the clp operon located on a high-molecular-weight self-transmissible $\mathrm{R}$ plasmid, called p31A (Martin, Boeuf and Bousquet 1991; Jallat et al. 1994; Martin 1996). CS31A are considered homologous to the K88/F4 (fae operon) and F41 pili but with some functional dissimilarities, such as that CS31A does not exhibit haemagglutinin activity (Girardeau et al. 1991). In ETEC, F4 pili allow bacterial adherence to F4-specific receptors present on the brush borders of villous enterocytes thus promoting the colonisation of the small intestine (Snoeck et al. 2008). The locus for diffuse adherence (ldaCDEFGHI) (Scaletsky et al. 2005) from EPEC is homologous to the K88 fae and ETEC CS31A clp operons. LdaH mediates diffuse adherence to Hep-2 cells. The LdaH encoding gene has also been found in STEC strains but no functional characterisation has been reported as yet (Scaletsky et al. 2005).

Aggregative AdHerence fimbriae (AAF) AAF belongs to the Afa/Dr (afimbrial adhesin/decay-accelerating factor receptor) haemagglutinin family together with F1845 pili (Nowicki et al. 1990; Le Bouguenec and Servin 2006). In DAEC and EIEC, Afa and Dr hemagglutinins recognise the Dr blood group antigen (Nowicki et al. 1990). Among the five genes encoded in the afa cluster, $a f a B, a f a C$ and $a f a E$ are required for mannose-resistant hemagglutination (MRHA) (Servin 2005). The Dr hemagglutinin is encoded by the draABCDE operon, where draA, draB, draC, and draD encode accessory proteins and draE encodes the adhesin part (Nowicki et al. 1987; Servin 2005). In addition, it specifically binds collagen IV (Nowicki et al. 1988). Afa and Dr haemagglutinins can link to decay-accelerating factor (DAF) and to carcinoembryonic antigen-related cellular adhesion molecules (CEACAMs) (Nowicki et al. 1988; Westerlund et al. 1989; Berger et al. 2004). While some members of the Afa/Dr family were believed not to form pili as they could not be observed by electron microscopy examination, it is now clear they are secreted as AAF and F1845 by T7SS, to form pili of various architecture depending on the pilin subunits (Anderson et al. 2004; Pettigrew et al. 2004).

In EAEC, the colonisation of the gut occurs through aggregative adherence (AA) due to AAF, which binds to ECM proteins such as fibronectin, laminin and collagen IV (Farfan, Inman and Nataro 2008; Berry et al. 2014) and then promotes biofilm formation (Hicks, Candy and Phillips 1996; Wakimoto et al. 2004). To date, five AAFs (AAF/I to AAF/V) have been identified, all encoded by virulence plasmids of EAEC (PAA) and the main subunits of which are AggA, AafA, Agg3A, Agg4a and Agg5a respectively (Nataro et al. 1992; Czeczulin et al. 1997; Boisen et al. 2008; Jonsson et al. 2015). Another hypothetical Dr-related pilin called HdaA (HUS-associated diffuse adherence) also appears to confer the capacity to cause the AA phenotype in EAEC (Boisen et al. 2008). In DAEC and EIEC, F1845 pili are involved in gut colonisation (Servin 2005). F1845 pili are responsible for diffuse adherence to epithelial cells of the gut and are encoded by the daaABCDE operon (Bilge et al. 1989; Bilge et al. 1993).

COLONISATION FACTOR ANTIGENS (CFA) In ETEC, colonisation factor antigens (CFA), also called coli surface antigens (CS), form pili that take part in adhesion to the small intestine and are critical for virulence (Gaastra and Svennerholm 1996). CFA/I, CFA/II (CS1, 2 and 3) and CFA/IV (CS4, 5 and 6) are the most virulent (Sjoberg et al. 1988; Knutton et al. 1989; Taniguchi et al. 1995; Gaastra and Svennerholm 1996; Svennerholm and Lundgren 2012) but CS12, 14, 17, 18, 19, 20 and 31 can also adhere to intestinal cells (Werneburg and Thanassi 2018). CFA/CS are encoded in operons; taking CFA/I as an example, it is encoded by the cfaABCE operon, where $c f a B$ encodes the main subunit, $c f a E$ the distal subunit, $c f a A$ a chaperone and $c f a C$ the usher involved in pilin transport across the OM (Jordi et al. 1992). Cell adhesion is enabled by $\mathrm{CfaB}$ through its ability to bind glycosphingolipid (Jansson et al. 2006).

F9 PILI In EHEC O157:H7, F9 pili are involved in the colonisation of epithelial bovine cells, bovine gastrointestinal tissue explants and can also bind to fibronectin (Low et al. 2006). Mutants of the main subunit of F9 pili are still able to colonise the terminal rectum, indicating that the adhesin is not solely responsible for the rectal tropism observed but may contribute to colonisation at other sites, especially in young animals (Low et al. 2006). These pili are short but are able to form longer bundles (Low et al. 2006). They are encoded in the F9 gene cluster, a six genes operon located on the pathogenicity island 0161 (Low et al. 2006; Wurpel et al. 2013). This operon has also been identified in EPEC, as well as EAEC (Wurpel et al. 2013). F9 pili are secreted and assembled by a T7SS (Wurpel et al. 2013).

E. coli YCBQ LAMININ-BINDING FIMBRIAE (ELF) In EHEC O157:H7, it has been shown that E. coli YcbQ laminin-binding fimbriae (ELF) bind laminin and are involved in adherence to epithelial cells in humans, cows and pigs (Samadder et al. 2009). ELF form peritrichous flexible fine fibres and are encoded by the elfADCG operon, originally called the $y c b Q R S T$ operon, which was previously identified in UPEC and some commensal E. coli strains (Spurbeck et al. 2011). This operon is homologous to the F17 pili biogenesis genes found in ETEC, which are assembled and secreted by a T7SS (Lintermans et al. 1988; Lintermans et al. 1991; Bertin et al. 1996; Bertin et al. 2000). More generally, ELF are also homologous to $20 \mathrm{~K}, \mathrm{~K} 99$ and $\mathrm{G}$ pili found in various pathogenic E. coli (Guinee, Jansen and Agterberg 1976; Contrepois et al. 1983). These pili have been shown to mediate binding to intestinal mucosal cells, especially to N-acetyl-D-glucosamine-containing receptors (Bertin et al. 1996). The composition of the pili and the sequence of the tip-adhesin differ between the strains and could explain the phenotypic divergence associated with the expression of this family of pili in different E. coli strains (Korea et al. 2010).

LONG POLAR FIMBRIAE (LPF) LPF are encoded by two operons lpf1 and lpf2 located on the pathogenicity islands 0141 and 0154 in EHEC 0157:H7, respectively (Perna et al. 2001). LPF are also present in other DEC, e.g. LEE-negative EHEC, 
EPEC, rabbit-specific EPEC, EAEC and ETEC, as well as in several commensal strains (Doughty et al. 2002; Wurpel et al. 2013). They share homology with the LPF of Salmonella enterica serovar Typhimurium which are involved in adherence to Peyer's patches and $\mathrm{M}$ cells in the human gut (Baumler and Heffron 1995; Baumler Tsolis and Heffron 1996). The lpf1 operon is composed of five genes, with lpfA encoding the main pilus subunit, lpfD and lpfE encoding minor subunits, and lpfB and lpfC encoding the chaperone and usher, respectively (Doughty et al. 2002; Torres et al. 2004). The lpf2 operon also contains five genes with a duplication of lpfD called lpfD' but with no lpfE paralogue (Torres et al. 2004). In E. coli O157:H7, it has been proposed that LPF2 is expressed in early stages whereas LPF1 is expressed in late stages of growth (Torres et al. 2004). LPF are secreted and assembled by a T7SS and can bind fibronectin, laminin and collagen IV, as well as the follicule-associated epithelium (FAE) of Peyer's patches in humans (Fitzhenry et al. 2006; Farfan and Torres 2012; McWilliams and Torres 2014). Expression of lpf2 is increased under conditions similar to those for biofilm formation (Torres et al. 2007). Recently, it has been demonstrated that STEC isolates positive for lpf2 formed significantly more biofilm than lpf2negatives isolates (Vogeleer et al. 2015). In EPEC, LPF have been shown to contribute to the early stages of colonisation of rabbits and the severity of diarrhoea (Newton et al. 2004).

E. coli common PILUs (ECP) In EHEC, ECP (previously called Mat for meningitis-associated temperature dependent pilus) provides adherence to HEp-2, HeLa and HT-29 cells and allows interaction between bacterial cells (Rendon et al. 2007). Secreted and assembled by a T7SS, ECP expression is increased under environmental conditions that are experienced in the GIT, e.g. low oxygen and high $\mathrm{CO}_{2}$ concentrations (Rendon et al. 2007). However, its role seems to be secondary in the colonisation of the human or bovine gut (Tatsuno et al. 2000; Dziva et al. 2004). The ecp operon has been identified in numerous commensal and pathogenic E. coli, including DEC (Rendon et al. 2007).

SORBITOL-FERMENTING FRIMBRIAE PROTEIN (SFP) In EHEC, the expression of sorbitol-fermenting frimbriae protein (SFP) pili is induced in anaerobic conditions and leads to an increased adherence to Caco- 2 and HCT-8 cells, with a mannose-resistance hemagglutination phenotype (Brunder et al. 2001; Musken et al. 2008; Bielaszewska et al. 2009). These pili are encoded on the sfpABDCDJG operon harboured in the virulence plasmid pSFO157 (Brunder, Karch and Schmidt 2006). SFP pili are secreted and assembled by a T7SS (Brunder et al. 2001). Besides E. coli O157, sfp has been identified in other EHEC serotypes, such as 0165 (Bielaszewska et al. 2009), but its prevalence among STEC in general is thought to be quite low (Toma et al. 2004). Distribution of the $s f p$ operon in other DEC has not been investigated in detail as of yet.

CuRLI Curli are thin aggregative pili generally considered as one of the major proteinaceous components of the E. coli biofilm matrix (Smyth et al. 1996; Stathopoulos et al. 2000; Kostakioti et al. 2005; Evans and Chapman 2014). These peculiar pili are secreted and assembled by the T8SS through the extracellularnucleation-pathway (ENP). Curli are helical filamentous amyloid fibres that facilitate cell-surface and cell-cell interactions and promote biofilm formation (Olsen et al. 1993; Cookson, Cooley and Woodward 2002; Szabo et al. 2005; Beloin et al. 2008; McCrate et al. 2013). In EHEC 0157:H7, curli are associated with cellulose production, adherence to spinach leaves and Hep-2 cells as well as abiotic surfaces (Kim and Kim 2004; Pawar, Rossman and Chen 2005; Macarisin et al. 2012). In ETEC, curli facilitate adherence to plastic surfaces (Szabo et al. 2005). Although curli were originally thought not be expressed by EPEC (Ben Nasr et al. 1996), some strains were later reported to synthetise curli, playing a role in bacterial adhesion and biofilm formation in condition mimicking human or bovine hosts (Saldana et al. 2009). However, curli do not seem to be required for biofilm formation and/or adhesion of EAEC strains (Sheikh et al. 2001; Berger et al. 2009; Pereira et al. 2010). In Shigella spp. and EIEC, CsgD and curli expression is often inactivated (Sakellaris et al. 2000). Two operons are involved in curli production, (i) the csgBAC operon, encoding the structural components of curli (CsgA and CsgB) and an accessory protein (CsgC) and (ii) the csgDEFG operon, encoding a transcriptional regulator (CsgD) and the secretion machinery for transport across the OM (CsgE-G) (Arnqvist, Olsen and Normark 1994; Hammar et al. 1995; Beloin et al. 2008). In the current model, CsgB is proposed as embedded in the OM where it acts as a nucleator for the polymerisation of the major CsgA curlin (Van Gerven et al. 2015; Jain and Chapman 2019). While the exact structure of curli fibres has not yet been elucidated with molecular resolution (Van Gerven et al. 2015; Jain and Chapman 2019), the fibres have been reported to display irregular thin branches, which would result from minor incorporation of CsgB along the curli and promoting the formation of branched fibres (Bian and Normark 1997; Soto and Hultgren 1999; Shu et al. 2012; DeBenedictis, Ma and Keten 2017). Recently, CsgC and CsgE were demonstrated to highly inhibit CsgA aggregation and CsgE was shown to prevent pellicle biofilm formation when added exogenously (Andersson et al. 2013; Evans et al. 2015).

HAEMOLYSIN-COREgUlated PROTEIN (HCP) In EAEC, the haemolysin-coregulated protein (Hcp) tube formed by the Type VI secretion system (T6SS) was suggested to be of importance for biofilm formation (Aschtgen et al. 2008). More than ten orthologues of the T6SS components have been identified in EHEC and EPEC strains. This system can also contribute to bacterial aggregation at the host cell surface (Dudley et al. 2006a; Shrivastava and Mande 2008; Lloyd et al. 2009; Aschtgen et al. 2010; Moriel et al. 2010). Further investigations are required in DEC to determine the exact role and molecular mechanisms involved in the colonisation processes by the Hcp and T6SS.

\section{THE DIFFERENT REGULATION LEVELS INVOLVED IN THE EXPRESSION OF COLONISATION FACTORS}

In general, the expression of genes encoded on genomes into proteins can be regulated at pre-transcriptional, transcriptional, post-transcriptional, translational and/or post-translational levels, as well as at translocational and post-translocational levels, the latter of which are especially relevant and important for molecular determinants expressed at the bacterial cell surface (Fig. 3). With the rise of omic approaches, however, some basic bacterial physiology concepts may sometimes be overlooked and gene/protein expression is very often considered as being limited to regulatory networks involving transcriptional repressors or activators. However, when it comes to functions and activities, it is primarily proteins that can help to comprehend bacterial physiology. It must also be kept in mind that the relationship between mRNA and protein abundances only very partially correlates; mRNA levels are just a proxy for the presence of a protein but is not directly proportionate with the increase or decrease folds of protein expression and even less with its 
Regulation levels

Pre-transcriptional

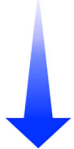

Transcriptional

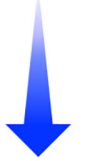

Post-transcriptiona

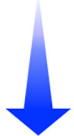

Translational

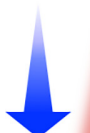

Post-translational

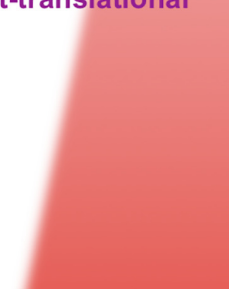

Control mechanisms

DNA replication (phase variation):

-DNA inversion

-Slipped-strand mispairing

-DNA methylation

-DNA deletion

Rate of mRNA synthesis (regulators / effectors):

-Positive control of an inducible gene

-Positive control of a repressible gene

-Negative control of an inducible gene

-Negative control of a repressible gene

Modulate transcripts for translation initiation:

-Stability of the mRNA (half-life)

-Riboswitch

-Attenuation

Rate of protein synthesis:

-Anti-sense RNA (including small RNA)

-Riboregulation

-Codon usage (translation rate)

Modulate protein activity:

-Physical parameters ( $\mathrm{pH}$, etc...)

-Inducers and inhibitors (allostery)

-Proteolytic cleavage

-Chemical modifications (glycosylation, etc..)

-Protein folding (chaperones)

-Association/dissociation multimers

-Stability of the protein (half-life)

-Translocation and final subcellular localisation
Examples

fim operon (T1P)

agn43 (Ag43), clp operon (CS31A)

flic (flagellin)

pga operon (PNAG), wca operon (colanic acid) cfa operon (CFA), LEE (injectisome)

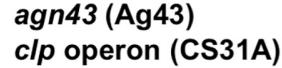

CsrB and CsrC (PNAG), DsrA (colonic acid) OmpA

\author{
Ag43 \\ BcsA (cellulose) \\ TibA, Ag43 \\ Ag43 \\ RcsA (colanic acid) \\ $\mathrm{Ag} 43$
}

Figure 3. Regulation levels and control mechanisms for the expression of genes encoding colonisation factors in DEC. Respective to biochemical process, the sequential steps and events for gene/protein expression flow from pre-transcriptional, transcriptional, post-transcriptional, translational to post-translational regulation levels (as depicted by blue arrows). Thus, at least five regulation levels can be considered in bacteria and at each level, different control mechanisms can be at play. Besides, for a same protein encoded gene different regulation levels and regulatory mechanisms can intervene, e.g. the expression of Ag43 is regulated at pre-transcriptional level by DNA methylation, at transcriptional level by OxyR, at post-transcriptional level by antitermination of transcription and translation initiation in the leader mRNA, and also at post-translational levels with its autoaggregative activity modulated by $\mathrm{pH}$, its native folding requiring chaperones and final subcellular localisation by translocation across the OM. Besides rRNA, tRNA and sRNA, biological functions and activities are essentially represented by proteins and the hierarchy of regulations levels and control mechanisms (as depicted by shades of red) is opposite to the gene/protein expression flow; e.g. whatever the pre-transcriptional (with DNA replication), transcriptional (with mRNA synthesis), post-transcriptional (with the modulation of transcripts) or translational (with the protein synthesis) levels, they are all strictly depend on enzyme activites which can be regulated at post-translational levels in the first place with direct and immediate effect due to modulation of their catalytic activity by temperature or $\mathrm{pH}$ for instance.

activity when we consider an enzyme for instance (Vogel and Marcotte 2012). Here, the different regulatory levels involved in bacterial adhesion and biofilm formation are highlighted using key examples of different SCFs.

\section{Regulation at the pre-transcriptional level: phase} variation

Prior to transcription, some regulatory mechanisms can already be at work at the DNA level, through phase variation. There are four main mechanisms of phase variation (i) DNA inversion, (ii) slipped-strand mispairing, (iii) DNA methylation and (iv) DNA deletion (Henderson et al. 1999). As a commonality, all these regulatory mechanisms primarily occur at the stage of DNA replication and a large majority of genes regulated by phase variation are bacterial cell surface molecular determinants (Owen et al. 1996; Holden and Gally 2004).
In E. coli $\mathrm{K} 12, \mathrm{~T} 1 \mathrm{P}$ are well-known to be subjected to phase variation following DNA inversion (Blomfield 2001). The expression of the fim operon is under the control of the fim promoter, which is located within the fimS-invertible element (Abraham et al. 1985; Wright, Seed and Hultgren 2007). The orientation of the promoter determines the ON or OFF phase and then induces the expression of upstream genes or not. Two tyrosine recombinases, FimB and FimE, are known to control the orientation of the fimS-invertible region. FimB predominantly switches the fim operon transcription from OFF to ON, while FimE mediates ON to OFF phase switching (Klemm 1986; Gally, Leathart and Blomfield 1996; Hannan et al. 2008). Of note, two DNA topological effectors participate in this regulation, namely H-NS (histone-like nucleoid-structuring protein) and IHF (integration host factor); these histones play complementary role, as the DNA inversion is absolutely dependent upon IHF, whereas the inversion rate is slowed down with high levels of H-NS and vice versa (Dorman 
and Ni Bhriain 1993). The existence of this regulation in DEC has not been examined as of yet.

Slipped-strand mispairing occurs in the course of DNA replication in repetitive DNA regions, which can be positioned either upstream of a coding DNA sequence (CDS) and then influences the transcription, such as the promoter efficiency, or within a CDS and can affect the translational reading frame resulting in a mutation frameshift (Henderson et al. 1999). In E. coli, phase variation resulting from strand-lippage has not been reported as yet, nonetheless, there is no molecular mechanistic constraint for it not to occur (Torres-Cruz and van der Woude 2003).

Phase variation resulting from DNA methylation corresponds to a bacterial epigenetic mechanism (Henderson et al. 1999). Ag43 is probably one of most investigated surface proteins subjected to such a regulatory mechanisms (van der Woude and Henderson 2008). This epigenetic regulation involves two proteins, the DNA adenine methylase (Dam) and the OxyR transcriptional regulator (van der Woude and Henderson 2008). When Dam has methylated the GATC sites present in the operator region in the course of DNA replication, the repressor OxyR cannot bind and transcription by the RNA polymerase occurs and Ag43 is expressed (ON phase); however, if OxyR binds the GATC sites before they are methylated by Dam, there is no transcription and no Ag43 expression (OFF phase). Besides Ag43, several pili secreted and assembled by the T7SS have been reported to be subjected to such an epigenetic regulation in E. coli (Henderson et al. 1999; Blomfield 2001). The pap (pyelonephritisassociated pilus) operon in UPEC is considered as a paradigm where the Dam methylation of a GATC-II site in the operator region prevents binding of the repressor Lrp (leucine-responsive regulatory protein), and consequently the papBA operon is transcribed and the pili are expressed (ON phase). In the absence of methylation at GATC-II, Lrp can bind to the operator, repress the transcription and ultimately prevent pili formation (OFF phase). Additionally, this repression can be lifted when Lrp binds to another site called GATC-I. Among DEC, CS31A pili are subjected to this same regulatory mechanism (Crost et al. 2003; Graveline et al. 2014).

As a general trend, phase variation due to DNA deletion is irreversible due to the loss of the genetic element bearing the gene of interest. In E. coli, DNA deletion is responsible for unilateral flagellar phase variation as reported in the H3, H47 and H17 strains (Zhou et al. 2015). While most flagellins are encoded by fliC in E. coli, H3 and H47 are encoded by flkA and H17 is encoded by flnA. For $\mathrm{H} 3$ and $\mathrm{H} 47$, their production results from the expression of flkAB operon, where the transcriptional regulator FlkB represses fliC (Feng et al. 2008). Upon excision of the flk region from the chromosome, flkAB is irreversibly deleted, the repression of fliC is released and the FliC flagellin is produced. Similarly, the H17 strain can irreversibly switch flagellar antigens to H4 (Ratiner 1967). It appears this flagellar phase variation can be caused by excision of $f \ln A$ (Liu et al. 2012). When $f \ln A$ is present in the chromosome, the translation of FliC $\mathrm{H} 4$ is inhibited and only FlnA H17 is produced; once flnA is excised, the repression of the fliC is released and only the FliC H4 is produced. The $\sim 35 \mathrm{~kb}$ DNA deletion region containing the flnA gene is excised as a covalently closed extrachromosomal circular form. While some DNA deletion can occur through homologous recombination (Henderson et al. 1999), flagellar phase variation is mediated by non-homologous recombination via an integrase of the tyrosine recombinase family (Feng et al. 2008). The flagellar phase variation mechanisms in some other $E$. coli $H$ variants and especially in DEC remain to be defined.
Regulation at the transcriptional level: regulators and effectors

Regulation at the transcriptional level is the most well-known level of gene regulation and quite often the only one really considered as a proxy for protein expression levels. Transcriptional regulators can either be repressors or activators but it is wrong to assume a repressor will systematically repress transcription or an activator will activate transcription. A second crucial partner to the process must also be considered, that is the effector, which can be of two types, either an inducer or a corepressor. Four possibilities for regulation at the transcriptional level can be discriminated: (i) positive control of an inducible gene, where an activator is activated by an inducer, (ii) positive control of a repressible gene, where an activator is inactivated by an inhibitor, (iii) negative control of an inducible gene, where a repressor is inactivated by an inducer or (iv) negative control of a repressible gene, where a repressor is activated by a co-repressor. Additionally, a so-called repressor can act as an activator for some genes and vice versa. In other words, the upexpression or down-expression of a regulator is not sufficient to know what kind of transcriptional regulation is taking place without knowing the nature and level of the inducer.

Bacteria can sense and respond to environmental cues thanks to a large range of two-component signal transduction systems where a sensor activates a transcriptional regulator, which further represses or activates gene expression (Hoch 2000; Zschiedrich, Keidel and Szurmant 2016). Some of these systems participate in cell-to-cell communication (CTCC) via a signal molecule called auto-inducer (AI) (Bassler 2002). Quorum sensing (QS) is only one of the different functions of CTCC, which specifically refers to the sensing of the cell density (quorum); QS should not be considered synonymous with CTCC because some sensing can be unrelated to QS sensu stricto but to diffusion sensing, confinement or efficiency sensing for instance (Redfield 2002; Platt and Fuqua 2010; West et al. 2012). This semantic issue is of particular importance in biofilm formation, since by definition, bacteria cells are at a high density following sessile development and therefore the notion of QS makes little sense. Transcriptional regulators of virulence and SCFs have been the subject of intense and extensive research and scientific literature in DEC (Beloin et al. 2008; Tobe 2008; Pruss 2017; Rossi et al. 2018). For these reasons only some key examples will be provided to illustrate the relevance of differentiating the regulation at different levels.

At the transcriptional level, PNAG production is regulated by NhaR, a transcriptional regulator of the LysR family, which activates the transcription of the pgaABCD operon by binding to two sites near the -35 region of the promoter (Goller et al. 2006). In EPS, the production of colanic acid is consistently upregulated within biofilms by the RcsA transcriptional activator (Matthysse et al. 2008; May and Okabe 2008). The transcription of the wca operon is regulated by the $\operatorname{rCSABCF}$ locus that encodes a twocomponent system (Gervais and Drapeau 1992; Ebel and Trempy 1999; Beloin et al. 2008). However, the signal sensed by the RcsC sensor kinase remains unknown (Whitfield and Roberts 1999; Oropeza, Salgado-Bravo and Calva 2015). H-NS is known to act as a transcriptional repressor in bacteria, a so-called bacterial transcriptional silencing, analogous to eukaryotic silencing by histones (Landick, Wade and Grainger 2015; Grainger 2016). While RcsA is present at a low amount in the cell, this was found to be partially due to transcriptional silencing by H-NS (Sledjeski and Gottesman 1995). Cellulose synthesis is under the control 
of the CsgD transcriptional regulator (Romling et al. 2000; Zorraquino et al. 2013). Interestingly in EIEC, csgD expression is often inactivated (Sakellaris et al. 2000), suggesting that biofilm formation can interfere with pathogenesis, making these strains poor biofilm formers.

While no specific transcriptional regulator has been identified for the expression of AIDA-I, it was shown that transcription was enhanced in the absence of H-NS and RfaH transcriptional regulators (Benz et al. 2010). Similarly, the transcription of ehaG and fdeC is regulated by H-NS (Totsika et al. 2012; Easton et al. 2014).

CS31A synthesis is dramatically reduced in media containing alanine or leucine, suggesting that these amino acids can play a role as effectors (Crost et al. 2003). The ON/OFF switch is locked in the OFF phase by alanine, whilst leucine repressed transcription but without affecting the switch frequency. Analysis of clp expression indicated that alanine and leucine could repress clp transcription by a methylation-independent mechanism but also by either promoting methylation or methylation protection of GATC-II and GATC-I respectively, which increased the methylation pattern characteristic of repressed cells. Furthermore, alanine prevented the AfaF-dependent methylation protection and thus the appearance of cells in the ON phase. Additional regulatory proteins, including $\mathrm{ClpB}$, cAMP, receptor protein (CRP) and H-NS, also play important roles in the transcriptional expression of the operons of the pap family combined with regulation at a pre-transcriptional level by phase variation (Blomfield and van der Woude 2007).

For the T4P in EPEC, the expression of the bfp operon is controlled by the BfpT (also called PerA) transcriptional regulator, a member of the AraC family, encoded on the enteroadherence factor plasmid (Tobe et al. 1992; Gomez-Duarte and Kaper 1995). The expression of CFA/I is positively regulated by CfaR, whereas for the expression of CFA/II, CS1 and CS2 is positively regulated by the rns gene product (a homologue to cfaR with 96\% identity) (Caron and Meyer 1989; Caron and Scott 1990; Savelkoul et al. 1990). The expression of AAF is induced by the transcriptional activator AggR (an homologue of AraC) also located on pAA (Nataro et al. 1994); YafK and Fis (factor for inversion stimulation) have also been reported to regulate AAF/II transcription (Sheikh et al. 2001). From a transcriptional regulation point of view, lpf1 is repressed by H-NS and activated by Ler in response to different environmental conditions (Torres et al. 2007; RojasLopez et al. 2011), whereas lpf2 transcription appears to be activated by Fur (Torres et al. 2007). Regulation of curli biogenesis is complex and involves several two-component systems, such as EnvZ/OmpR, CpxA/CpxR or CpxR/H-NS/RstA/IHF/OmpR (Vidal et al. 1998; Prigent-Combaret et al. 2000; Prigent-Combaret et al. 2001; Beloin et al. 2008; Ogasawara et al. 2010; Laverty, Gorman and Gilmore 2014). In EPEC, Fis has been identified as a negative transcriptional regulator of $\operatorname{csg} A$ expression (Saldana et al. 2009). Curli expression can be triggered by a large range of environmental signals such as the temperature, osmolarity or redox potential (Olsen et al. 1993; Prigent-Combaret et al. 1999; Gerstel and Romling 2001; Evans and Chapman 2014).

The transcriptional regulatory control of the locus of enterocyte effacement (LEE) encoding the injectisome is undoubtedly one of the most extensively investigated in DEC, and in particular in EPEC and EHEC (Schmidt 2010; Stevens and Frankel 2014; Franzin and Sircili 2015). For additional information about the complex regulation networks of specific, global and phage encoded regulators, as well as environmental signals such as nutrient sources or metabolic products from the host or microbiota that can affect the transcription of the LEE-encoded genes, readers are referred to recent, specific reviews on the topic (Connolly, Finlay and Roe 2015; Furniss and Clements 2018; Platenkamp and Mellies 2018; Turner, Connolly and Roe 2018).

\section{Regulation at a post-transcriptional level}

At least three main regulation mechanisms can occur posttranscriptionally, (i) the stability of mRNA, which can be quantified by determining its half-life, (ii) a riboswitch, where a molecule such as a metabolite can change the folding of an mRNA with the formation of a termination hairpin that stops the on-going transcription by the RNA polymerase or (iii) attenuation based on the formation of terminator/anti-termnator loops, which couple or uncouple the transcription by the RNA polymerase with the translation of the mRNA. Such posttranscriptional regulations are important regulatory mechanisms that are generally overlooked and underestimated, most likely because they cannot be easily investigated and estimated by transcriptomic analysis on its own (Vogel and Marcotte 2012).

Recently, it was shown that the expression level of agn43 can be controlled by antitermination of transcription and translation initiation in the leader mRNA (Wallecha et al. 2014). Among EPS determinants, PNAG production is regulated by the RNAbinding protein CsrA (carbon storage regulatory protein A) posttranscriptionally (Boles and Horswill 2011; Wang, Yang and Yang 2017), where CsrA binds cooperatively to the pgaA mRNA and competes for recognition with the $30 \mathrm{~S}$ ribosomal subunit. By binding to sites located in the mRNA leader, CsrA can further destabilise the pgaA transcript. The transcription of yeeJ is increased in absence of the mRNA regulator PNPase, an exoribonuclease polynucleotide phosphorylase component of the degradosome (Martinez-Gil et al. 2017).

Pili produced by the pap operon appears to be regulated posttranscriptionally as a result of differential mRNA stability (Baga et al. 1988). The study demonstrated that the papBA transcript is processed and the resulting mRNA encoding the major pilin subunit accumulated. The difference in abundance of the two mRNA species could be readily explained by differences in their half-life. In E. coli, RNA degradation occurs via the degradosome thanks to the combination of endoribonuclease and exoribonuclease activities (Burger, Whiteley and Boshoff 2011; Bandyra et al. 2013).

\section{Regulation at the translational level}

While attenuation collaterally affects the translation, three main mechanisms are directly involved in the regulation of translation, (i) anti-sense RNAs (including the small RNAs), which hybridise with mRNA and thus block the binding of the ribosome, (ii) riboregulation, where a ligand changes the mRNA folding, which consequently prevents the binding of the ribosome and (iii) translational efficiency depending on the codon usage.

In addition to CsrA, PNAG synthesis is regulated by two small RNAs, CsrB and CsrC, which actually sequester CsrA and thus activate the translation of the pgaABCD transcript (Liu et al. 1997; Weilbacher et al. 2003). For colanic acid production, the low level of expression from the rcsA promoter by H-NS transcriptional silencing is alleviated by the DsrA small RNA (Sledjeski and Gottesman 1995).

In E. coli, the OmpA protein is expressed to very high levels, is growth rate dependent and is a paradigm for riboregulation (Lugtenberg et al. 1976; Koebnik, Locher and Van Gelder 
2000). Actually, the ompA mRNA half-life increases proportionally with the bacterial growth rate (Nilsson et al. 1984). While a specific region of the transcript is targeted by the RNaseE (endoribonuclease E), binding of the ribosome induces conformational changes that mitigate the mRNA degradation (Emory and Belasco 1990; Emory, Bouvet and Belasco 1992; Hansen et al. 1994). As an antagonist, Hfq can bind the transcript to decrease its stability, thus inducing RNA decay (Nilsson et al. 1984; Vytvytska et al. 2000). Hfq facilitates the binding of a small RNA called MicA in the vicinity of the ribosome-binding site, thus preventing ribosomal recruitment (Udekwu et al. 2005).

\section{Regulation at the post-translational level}

Regulations at the post-translational level comprises the most diverse range of molecular mechanisms and is hierarchically the most important (Fig. 3). In metabolic pathways, regulation at the post-translational levels is a key mechanism, particularly in relation to the modulation of the enzymatic activity, which can be influenced by physical parameters ( $\mathrm{pH}$, temperature, ionic force, redox, etc...), inducers and inhibitors (irreversible or reversible: competitive, non-competitive, uncompetitive or mixed inhibition) (Guedon et al. 2000; Desvaux and Petitdemange 2002; Desvaux 2004); retro-inhibition and pro-activation can also occur and may also involve allosteric enzymes. Protein activity can be further altered by numerous post-translational modifications, namely, (i) proteolytic cleavage and (ii) chemical modifications such as disulphide bonds, phosphorylation, acetylation, methylation, adenylation or uridylation. Posttranslational regulation also includes the protein folding, association/dissociation of homo- and heteromers, the degradation of proteins following the N-terminal rule by the ClpAP proteolytic complex, which can all influence the protein half-life, as well as the protein translocation to a final subcellular location. Indeed, the maturation of a protein can also occur at translocational and post-translocational levels.

As an example of post-translational regulation, the decreased production of colanic acid at $37^{\circ} \mathrm{C}$ results from the degradation of the RcsA transcriptional activator by the Lon protease (Ebel and Trempy 1999). This post-translational regulation alleviates the wca transcription and explain the low amount of RcsA in cell (Sailer, Meberg and Young 2003). As a two-component system, the RcsA regulator is activated by the transfer of a phosphate group from the RcsC sensor, which is per se another post-translational regulation level (Desai and Kenney 2017). For cellulose biosynthesis, the catalytic activity of the BcsA-B complex using UDP-glucose as a substrate is allosterically controlled by cyclic-di-GMP (c-di-GMP) on the Pilz domain of the cellulose synthetase BcsA (Omadjela et al. 2013). Actually, the Pilz domain was the first effector identified that is activated upon binding of c-di-GMP (Ryan, Tolker-Nielsen and Dow 2012). Furthermore, the diguanylate cyclase AdrA exhibiting a GGDEF domain regulates c-di-GMP production (Romling et al. 2000; Zorraquino et al. 2013). C-di-GMP is a ubiquitous second messenger produced by the diguanylate cyclase exhibiting GGDEF domain, which is antagonistically degraded by the phosphodiesterases exhibiting EAL domain (Romling and Amikam 2006). This molecule controls the motility and virulence of planktonic cells, as well as cell adhesion and persistence of multicellular communities (Jenal and Malone 2006; Romling and Amikam 2006; Beloin et al. 2008).

As an autotransporter, Ag43 exhibits a signal peptide, which drives the preprotein to the Sec export system for translocation across the $\mathrm{CM}$ before being cleaved off after translocation into the periplasm. In the periplasm, several chaperones participate in the folding prior to the translocation across the OM through a cooperative mechanism involving the translocation assembly (TAM) and $\beta$-barrel assemby (BAM) machineries (Selkrig et al. 2014). Additionally, the passenger of Ag43 is glycosylated, which stabilises its conformation (Sherlock et al. 2006). These different post-translational, translocational and post-translocational levels all contribute to the regulation of the expression of this surface protein. While glycosylation is not that important for the functions of Ag43 (Reidl et al. 2009), in TibA it is necessary for autoaggregation, adhesion to epithelial cells and biofilm formation (Cote, Charbonneau and Mourez 2013).

\section{CONCLUSION AND PERSPECTIVES}

Reviewing the different cell-surface molecular determinants that can participate in the surface colonisation process in DEC, from bacterial adhesion to biofilm formation, the wealth of SCFs at play is clearly highlighted. While some of these molecular determinants still remain to be fully characterised, their interplay in surface colonisation must also be carefully considered and kept in mind. The flagella, as force-generating cell-surface organelles, have been demonstrated to be important for biofilm formation (Hobley et al. 2015), but expression of strong adherence factors could replace motility in the early stages of biofilm formation (Pratt and Kolter 1998; Donlan 2002). Although flagella expression is repressed during the switch from the planktonic to sessile lifestyle to reduce the motility capacity of the bacteria, these surface organelles have a structural and architectural role in the EPM (Hung et al. 2013; Serra, Richter and Hengge 2013). While the expression of flagellar genes are repressed, genes involved in the biosynthesis of the EPM components are generally activated during the biofilm maturation step (Guttenplan and Kearns 2013). In E. coli K12, capsule polysaccharide and T1P appear to block the autoaggregation mediated by Ag43 by physically shielding intercellular Ag43-Ag43 interaction (Hasman, Chakraborty and Klemm 1999; Schembri, Dalsgaard and Klemm 2004), whilst, in turn, the autoaggregation overrides bacterial motility (Ulett, Webb and Schembri 2006). In some ExPEC, T1P expression appears to be further modulated and influenced by OmpA or OmpX, together with an increase of exopolysaccharide production, as well as a decrease in bacterial motility (Otto and Hermansson 2004; Teng et al. 2006). In NMEC, OmpA would act together with Hek in the invasion of epithelial cells (Smith et al. 2007; Fagan, Lambert and Smith 2008). All-in-all, this suggests the OMPs' composition of the OM may act as a signal in physiological adaptation of bacteria for surface adhesion and colonisation; this research direction is one of the next frontiers to be explored in DEC.

As a general trend, the average number of pili types appears lower in commensal compared to pathogenic E. coli (Spurbeck et al. 2011). For instance, curli or conjugative pili can compensate for motility during initial adhesion and biofilm development (Prigent-Combaret et al. 2000; Ghigo 2001; Reisner et al. 2003; Beloin et al. 2008). Plasmids in general can encode numerous SCFs as shown in ETEC and EAEC (Amabile-Cuevas and Chicurel 1996; Mainil et al. 1998; Ghigo 2001; Molin and Tolker-Nielsen 2003; Kaper, Nataro and Mobley 2004; Wuertz, Okabe and Hausner 2004; Beloin et al. 2008; Ong et al. 2009). While conjugative plasmids can confer initial adhesion capacity and modulate the biofilm architecture (Ghigo 2001; Wuertz, Okabe and Hausner 2004), the genetic mobility of this extrachromosomal gene pool and its contribution to biofilm formation remain poorly investigated in DEC (Dudley et al. 2006b). In Pseudomonas aeruginosa, 
T4P have been primarily regarded as involved in the attachment of epithelial cells in the course of an infection but later were demonstrated to also bind to abiotic surfaces such as polyvinyl chloride, polystyrene and stainless steel (Giltner et al. 2006) and it even appeared to exhibit a much higher affinity towards steel than the mucosal epithelial surface, which emphasises the relevance of examining T4P in both environmental and clinical conditions (Yu et al. 2007; Burgess, Desvaux and Olmez 2014). In the human and animal cutaneous pathogens Erysipelothrix rhusiopathiae, the RspA (rhusiopathiae surface protein A) and RspB surface proteins have been shown to specifically bind several ECM components, namely, fibronectin, collagens I and IV, but also polystyrene shedding light on the ecophysiology of this microorganism through its binding ability to adhere to both biotic and abiotic surfaces (Shimoji et al. 2003). These aspects have not been reported or examined as yet in DEC but are particularly relevant considering the presence of T4P and ECM-binding proteins, especially some ATs, in the various E. coli enteropathotypes.

The regulatory network for the production of colonisation factors is often depicted as being restricted to the transcriptional level. However, this review clearly demonstrates that the range of regulation levels is much broader and even more complex (Fig. 3). As a general trend, it is important to stress and keep in mind that the primary functional and regulation level is posttranslational and not transcriptional, as is sometimes assumed. Whenever DNA replication, RNA polymerisation or protein synthesis occur, enzymes are essential and required for these physiological processes at pre-transcriptional, transcriptional and translational regulation levels, respectively; any abrupt changes in the environmental conditions, such as some physicochemical parameters (e.g. pH, temperature, redox potential), will have a first and direct effect on the enzyme activity before the cell can even change its transcription profile. For the SCFs, the interplay taking place at the other regulation levels is extremely complex and their hierarchy is extremely difficult to establish at a global scale. As well as this, some regulatory mechanisms in the expression of SCFs in DEC have not been fully investigated, such as attenuation, riboswitches or translational efficiency, but their involvement cannot be excluded. As molecular cellsurface determinants, the SCFs in DEC need to be translocated across a LPS-diderm bacterial cell envelope to be functional and active, which involves further translocational and posttranslocational regulation levels that should not be overlooked in a regulatory network. To this end, our view of the regulatory network for the production of SCFs in E. coli remains incomplete and there is far from an integrated view of all regulation mechanisms. In addition, findings from investigations using domesticated laboratory strains of $E$. coli must be interpreted with caution and reinvestigation in DEC genetic backgrounds would be wise (Hobman, Penn and Pallen 2007). This will undoubtedly lead to new discoveries in the field in the years to come and contribute to our understanding of DEC colonisation mechanisms.

In DEC, SCFs have often been examined for their contribution to bacterial virulence and thus investigated in conditions related to human infection (Nataro and Kaper 1998; Kaper et al. 2004; Rossi et al. 2018). In addition to humans, the GIT of a wide range of animals also harbours E. coli strains, both commensal and pathogenic (Escobar-Paramo et al. 2006; Croxen et al. 2013; Smati et al. 2015; Torres 2017). Following shedding from these animal reservoirs, E. coli is also found in the environment. Out- side the host, the range of extraintestinal environmental conditions that can be encountered by this species is wide, ranging from soil, water to plants, as well as food matrices and food processing facilities (van Elsas et al. 2011; Giaouris et al. 2014; Jang et al. 2017). As foodborne zoonotic pathogens, understanding the ecophysiology of DEC necessitates considering its lifestyle outside the human host. In fact, the role of SCFs should be placed in a context much broader than the colonisation of the GIT, as they can also play an important role in the colonisation of other environmental niches. A focus solely on the physiopathology and GIT environment may bias and limit a full understanding of the wide diversity of SCFs in E. coli. While the notion of virulence factors is a major contribution to the field of microbial pathogenesis (Falkow 1988; Finlay and Falkow 1989), a change of paradigm with the concept of coincidental by-products of commensalism (Le Gall et al. 2007; Diard et al. 2010; Leimbach, Hacker and Dobrindt 2013) or niche factors (Hill 2012) is necessary to more accurately apprehend and understand the ecophysiology of pathogenic species in the food chain and in one-health approach.

Taking a one-health approach considering the whole food chain, the physiology of DEC should not only be considered with respect to human infection only, but also in conditions representative of upstream, i.e. from the natural environments, animal/human reservoirs, agri-food environments and foodstuffs (Burgess, Desvaux and Olmez 2014). Investigating the ecophysiology of the DEC with respect to the various biotopes and biocoenoses encountered in different ecosystems from natural environments, animal reservoirs, food matrices, foodprocessing environments, to human ingestion should shed new light on the relevance and contribution of the SCFs for this species and inform the design of strategic, targeted interventions to improve public health.

\section{ACKNOWLEDGEMENTS}

This work was supported in part by INRAE ("Institut National de Recherche pour l'Agriculture, l'Alimentation et l'Environnement", previously called INRA ("Institut National de la Recherche Agronomique"), by EU FP7 (European Union 7th Framework Programme) Marie Curie Actions ITN (Initiale Training Network) EID (European Industrial Doctorate) DISCo (A multidisciplinary doctoral industrial school on novel preventive strategies against E. coli infections) project ( $n^{\circ}$ FP7-PEOPLE607611), by the RA-FEDER-Bpifrance ("Région Auvergne-Fonds Européen de Développement Régional-Banque Publique d'Investissement des entrepreneurs français") FRI ("Fonds Régional Innovation") Cluster IRP ("Institut de Recherche Pharmabiotique") CoMBa ("Colonisation de la matrice par les bactéries") project ( ${ }^{\circ}$ AV0003483 and $n^{\circ}$ DOS0019690/00), by ANR (Agence National de la Recherche Agronomique) PathoFood (Deciphering the cell heterogeneity and the spatial distribution of foodborne bacterial pathogens in food matrices in interaction with the microbial communities) project ( $\mathrm{n}^{\circ}$ ANR-17-CE21-0002) and by France-Ireland PHC ("Programme Hubert Curien") ULYSSES 2016 Campus France-Irish Research Council ARBiC project ( $\left.{ }^{\circ} 36044 \mathrm{YD}\right)$. RM was a Marie Curie $\mathrm{PhD}$ research fellow granted by the ITN EID DISCo. VA was a $\mathrm{PhD}$ research fellow granted by the RA-FEDER-Bpifrance FRI IRP CoMBa. All authors declare that the work was conducted in the absence of any commercial or financial relationships that could be construed as a potential conflict of interest. 


\section{AUTHORS CONTRIBUTION STATEMENT}

VA and MD wrote the first overall draft of the manuscript and draw the original pictures; RM, SL, MP, CMB and FCD wrote sections of the manuscript. MD contributed to conceptualise the overarching aims and had management as well as coordination responsibility for the execution of the work. MD, MP, CMB and FCD contributed to the acquisition of the financial supports and resources leading to this publication. All authors contributed to the critical revision of the manuscript, read and approved the submitted version.

Conflict of interest. MP is permanent employee of GSK. FCD is permanent employee of Lallemand. These authors declare that their respective company provided support in the form of salaries. All other authors declare no competing interests.

\section{REFERENCES}

Abby SS, Cury J, Guglielmini J et al. Identification of protein secretion systems in bacterial genomes. Scientifc Reports 2016;6:23080.

Abraham SN, Babu JP, Giampapa CS et al. Protection against Escherichia coli-induced urinary tract infections with hybridoma antibodies directed against type 1 fimbriae or complementary $\mathrm{D}$-mannose receptors. Infect Immun 1985;48:625-8

Abraham SN, Sun D, Dale JB et al. Conservation of the Dmannose-adhesion protein among type 1 fimbriated members of the family Enterobacteriaceae. Nature 1988;336:682-4.

Abreu AG, Abe CM, Nunes KO et al. The serine protease Pic as a virulence factor of atypical enteropathogenic Escherichia coli. Gut Microbes 2016;7:115-25.

Abreu AG, Fraga TR, Granados Martinez AP et al. The serine protease Pic from enteroaggregative Escherichia coli mediates immune evasion by the direct cleavage of complement proteins. J Infect Dis 2015;212:106-15.

Abu-Median AB, van Diemen PM, Dziva F et al. Functional analysis of lymphostatin homologues in enterohaemorrhagic Escherichia coli. FEMS Microbiol Lett 2006;258:43-9.

Adams LM, Simmons CP, Rezmann L et al. Identification and characterization of a K88- and CS31A-like operon of a rabbit enteropathogenic Escherichia coli strain which encodes fimbriae involved in the colonization of rabbit intestine. Infect Immun 1997;65:5222-30.

Ageorges V, Schiavone M, Jubelin G et al. Differential homotypic and heterotypic interactions of antigen 43 (Ag43) variants in autotransporter-mediated bacterial autoaggregation. Scientific reports 2019;9:11100.

Aguilera L, Ferreira E, Gimenez $\mathrm{R}$ et al. Secretion of the housekeeping protein glyceraldehyde-3-phosphate dehydrogenase by the LEE-encoded Type III secretion system in enteropathogenic Escherichia coli. Internat J Biochem Cell Biol 2012;44:955-62.

Ahmed D, Islam MS, Begum YA et al. Presence of enterotoxigenic Escherichia coli in biofilms formed in water containers in poor households coincides with epidemic seasons in Dhaka. J Appl Microbiol 2013;114:1223-9.

Allsopp LP, Beloin C, Ulett GC et al. Molecular characterization of $\mathrm{UpaB}$ and $\mathrm{UpaC}$, two new autotransporter proteins of uropathogenic Escherichia coli CFT073. Infect Immun 2012;80:321-32.
Al Safadi R, Abu-Ali GS, Sloup RE et al. Correlation between in vivo biofilm formation and virulence gene expression in Escherichia coli O104:H4. PloS one 2012;7:e41628.

Amabile-Cuevas CF, Chicurel ME. A possible role for plasmids in mediating the cell-cell proximity required for gene flux. $J$ Theor Biol 1996;181:237-43.

Amimanan P, Tavichakorntrakool R, Fong-Ngern $\mathrm{K}$ et al. Elongation factor $\mathrm{Tu}$ on Escherichia coli isolated from urine of kidney stone patients promotes calcium oxalate crystal growth and aggregation. Scientific reports 2017;7: 2953.

Amor K, Heinrichs DE, Frirdich E et al. Distribution of core oligosaccharide types in lipopolysaccharides from Escherichia coli. Infect Immun 2000;68:1116-24.

Anderson KL, Billington J, Pettigrew D et al. An atomic resolution model for assembly, architecture, and function of the $\mathrm{Dr}$ adhesins. Mol Cell 2004;15:647-57.

Andersson EK, Bengtsson C, Evans ML et al. Modulation of curli assembly and pellicle biofilm formation by chemical and protein chaperones. Chem Biology 2013;20:1245-54.

Andersson M, Fallman E, Uhlin BE et al. A sticky chain model of the elongation and unfolding of Escherichia coli P pili under stress. Biophys J 2006;90:1521-34.

Andrade FB, Abreu AG, Nunes KO et al. Distribution of serine protease autotransporters of Enterobacteriaceae in typical and atypical enteroaggregative Escherichia coli. Infect Genet Evolution 2017;50:83-6.

Appelmelk BJ, An YQ Hekker TA et al. Frequencies of lipopolysaccharide core types in Escherichia coli strains from bacteraemic patients. Microbiology 1994;140:1119-24.

Arnqvist A, Olsen A, Normark S. Sigma S-dependent growthphase induction of the csgBA promoter in Escherichia coli can be achieved in vivo by sigma 70 in the absence of the nucleoid-associated protein H-NS. Mol Microbiol 1994;13:1021-32.

Aschtgen MS, Bernard CS, De Bentzmann S et al. SciN is an outer membrane lipoprotein required for Type VI secretion in enteroaggregative Escherichia coli. J Bacteriol 2008;190: 7523-31.

Aschtgen MS, Gavioli M, Dessen A et al. The SciZ protein anchors the enteroaggregative Escherichia coli Type VI secretion system to the cell wall. Mol Microbiol 2010;75:886-99.

Azeredo J, Azevedo NF, Briandet R et al. Critical review on biofilm methods. Criti Rev Microbiol 2017;43:313-51.

Baga M, Goransson M, Normark S et al. Processed mRNA with differential stability in the regulation of Escherichia coli pilin gene expression. Cell 1988;52:197-206.

Baldi DL, Higginson EE, Hocking DM et al. The Type II secretion system and its ubiquitous lipoprotein substrate, SslE, are required for biofilm formation and virulence of enteropathogenic Escherichia coli. Infect Immun 2012;80:2042-52.

Bandyra KJ, Bouvier M, Carpousis AJ et al. The social fabric of the RNA degradosome. Biochimica et biophysica acta: Gene Regulat Mechan 2013;1829:514-22.

Barrios AF, Zuo R, Ren D et al. Hha, YbaJ, and OmpA regulate Escherichia coli $\mathrm{K} 12$ biofilm formation and conjugation plasmids abolish motility. Biotechnol Bioengin 2006;93: 188-200.

Bassler BL. Small talk. Cell-to-cell communication in bacteria. Cell 2002;109:421-4.

Baumler AJ, Heffron F. Identification and sequence analysis of lpfABCDE, a putative fimbrial operon of Salmonella typhimurium. J Bacteriol 1995;177:2087-97. 
Baumler AJ, Tsolis RM, Heffron F. Contribution of fimbrial operons to attachment to and invasion of epithelial cell lines by Salmonella typhimurium. Infect Immun 1996;64:1862-5.

Beghain J, Bridier-Nahmias A, Le Nagard $\mathrm{H}$ et al. ClermonTyping: an easy-to-use and accurate in silico method for Escherichia genus strain phylotyping. Microbial Genom 2018;4:e000192.

Behzadi P. Classical chaperone-usher (CU) adhesive fimbriome: uropathogenic Escherichia coli (UPEC) and urinary tract infections (UTIs). Folia microbiologica 2020;65:45-65.

Beloin C, Houry A, Froment M et al. A short-time scale colloidal system reveals early bacterial adhesion dynamics. PLoS Biol 2008;6:e167.

Beloin C, Michaelis K, Lindner K et al. The transcriptional antiterminator RfaH represses biofilm formation in Escherichia coli. J Bacteriol 2006;188:1316-31.

Beloin C, Roux A, Ghigo JM. Escherichia coli biofilms. Curr Topic Microbiol Immunol 2008;322:249-89.

Beloin C, Valle J, Latour-Lambert P et al. Global impact of mature biofilm lifestyle on Escherichia coli $\mathrm{K}-12$ gene expression. Mol Microbiol 2004;51:659-74.

Bendtsen JD, Wooldridge KG. Chapter 10: Non-classical secretion. In: Wooldridge K (ed). Bacterial secreted proteins: secretory mechanisms and role in pathogenesis. Caister Academic Press, Norwich, United Kingdom. pp. 226-35, 2009.

Ben Nasr A, Olsen A, Sjobring U et al. Assembly of human contact phase proteins and release of bradykinin at the surface of curli-expressing Escherichia coli. Mol Microbiol 1996;20: 927-35.

Benz I, Schmidt MA. AIDA-I, the adhesin involved in diffuse adherence of the diarrhoeagenic Escherichia coli strain 2787 (O126:H27), is synthesized via a precursor molecule. Mol Microbiol 1992;6:1539-46.

Benz I, Schmidt MA. Cloning and expression of an adhesin (AIDA-I) involved in diffuse adherence of enteropathogenic Escherichia coli. Infect Immun 1989;57:1506-11.

Benz I, Schmidt MA. Glycosylation with heptose residues mediated by the aah gene product is essential for adherence of the AIDA-I adhesin. Mol Microbiol 2001;40:1403-13.

Benz I, van Alen T, Bolte J et al. Modulation of transcription and characterization of the promoter organization of the autotransporter adhesin heptosyltransferase and the autotransporter adhesin AIDA-I. Microbiology 2010;156:1155-66.

Berger CN, Billker O, Meyer TF et al. Differential recognition of members of the carcinoembryonic antigen family by $\mathrm{Afa} / \mathrm{Dr}$ adhesins of diffusely adhering Escherichia coli (Afa/Dr DAEC). Mol Microbiol 2004;52:963-83.

Berger CN, Shaw RK, Ruiz-Perez F et al. Interaction of enteroaggregative Escherichia coli with salad leaves. Environ Microbiol Rep 2009;1:234-9.

Berger CN, Sodha SV, Shaw RK et al. Fresh fruit and vegetables as vehicles for the transmission of human pathogens. Environ Microbiol 2010;12:2385-97.

Berman HM, Battistuz T, Bhat TN et al. The protein data bank. Acta crystallographica, section D, biological crystallography 2002;58:899-907.

Berry AA, Yang Y, Pakharukova $\mathrm{N}$ et al. Structural insight into host recognition by aggregative adherence fimbriae of enteroaggregative Escherichia coli. PLoS Pathog 2014;10:e1004404.

Bertin Y, Girardeau JP, Darfeuille-Michaud A et al. Characterization of $20 \mathrm{~K}$ fimbria, a new adhesin of septicemic and diarrhea-associated Escherichia coli strains, that belongs to a family of adhesins with N-acetyl-D-glucosamine recognition. Infect Immun 1996;64:332-42.
Bertin Y, Girardeau JP, Darfeuille-Michaud A et al. Epidemiological study of pap genes among diarrheagenic or septicemic Escherichia coli strains producing CS31A and F17 adhesins and characterization of Pap(31A) fimbriae. J Clinic Microbiol 2000;38:1502-9.

Bertin Y, Girardeau JP, Der Vartanian M et al. The ClpE protein involved in biogenesis of the CS31A capsule-like antigen is a member of a periplasmic chaperone family in Gram-negative bacteria. FEMS microbiology letters 1993;108: 59-67.

Beutin L. Escherichia coli as a pathogen in dogs and cats. Vet Res 1999;30:285-98.

Bhargava S, Johnson BB, Hwang J et al. Heat-resistant agglutinin 1 is an accessory enteroaggregative Escherichia coli colonization factor. J Bacteriol 2009;191:4934-42.

Bian Z, Normark S. Nucleator function of CsgB for the assembly of adhesive surface organelles in Escherichia coli. EMBO ) 1997; 16:5827-36.

Bieber D, Ramer SW, Wu CY et al. Type 4 pili, transient bacterial aggregates, and virulence of enteropathogenic Escherichia coli. Science 1998;280:2114-8.

Bielaszewska M, Prager R, Vandivinit L et al. Detection and characterization of the fimbrial sfp cluster in enterohemorrhagic Escherichia coli O165:H25/NM isolates from humans and cattle. Appl Environm microbiol 2009;75:64-71.

Bilge SS, Apostol JM, Jr., Aldape MA et al. mRNA processing independent of RNase III and RNase $E$ in the expression of the F1845 fimbrial adhesin of Escherichia coli. Proceed Nat Acad Sci USA 1993;90:1455-9.

Bilge SS, Clausen CR, Lau W et al. Molecular characterization of a fimbrial adhesin, F1845, mediating diffuse adherence of diarrhea-associated Escherichia coli to HEp-2 cells. J Bacteriol 1989;171:4281-9.

Bilge SS, Vary JC, Jr., Dowell SF et al. Role of the Escherichia coli O157:H7 O side chain in adherence and analysis of an $\mathrm{rfb}$ locus. Infect Immun 1996;64:4795-801.

Bitter W, Houben EN, Bottai D et al. Systematic genetic nomenclature for Type VII secretion systems. PLoS pathogens 2009;5:e1000507.

Blazar J, Allard M, Lienau EK. Insects as vectors of foodborne pathogenic bacteria. Terrestrial Arthropod Rev 2011;4:5-16.

Blomfield I, van der Woude M. Regulation of fimbrial expression. EcoSal Plus 2: ecosal.2.4.2.2. 2007;2:ecosal.2.4.2.

Blomfield IC. The regulation of Pap and type 1 fimbriation in Escherichia coli. Advanc Microb Physiol 2001;45:1-49.

Bockelmann U, Janke A, Kuhn R et al. Bacterial extracellular DNA forming a defined network-like structure. FEMS Microbiol Lett 2006;262:31-8.

Boel G, Pichereau V, Mijakovic I et al. Is 2-phosphoglyceratedependent automodification of bacterial enolases implicated in their export? J Mol Biol 2004;337:485-96.

Boisen N, Struve C, Scheutz F et al. New adhesin of enteroaggregative Escherichia coli related to the Afa/Dr/AAF family. Infect Immun 2008;76:3281-92.

Bokranz W, Wang X, Tschape $\mathrm{H}$ et al. Expression of cellulose and curli fimbriae by Escherichia coli isolated from the gastrointestinal tract. J Med Microbiol 2005;54:1171-82.

Boles BR, Horswill AR. Staphylococcal biofilm disassembly. Trends Microbiol 2011;19:449-55.

Bollinger RR, Everett ML, Palestrant D et al. Human secretory immunoglobulin A may contribute to biofilm formation in the gut. Immunol 2003;109:580-7.

Bollinger RR, Everett ML, Wahl SD et al. Secretory IgA and mucin-mediated biofilm formation by environmental strains 
of Escherichia coli: role of type 1 pili. Mol Immunol 2006;43: 378-87.

Borgersen Q Bolick DT, Kolling GL et al. Abundant production of exopolysaccharide by EAEC strains enhances the formation of bacterial biofilms in contaminated sprouts. Gut microbes 2018;9:264-78.

Bosserman RE, Champion PA. Esx systems and the mycobacterial cell envelope: What's the connection? J Bacteriol 2017;199:e00131-17.

Botos I, Noinaj N, Buchanan SK. Insertion of proteins and lipopolysaccharide into the bacterial outer membrane. Philosophical transactions of the royal society of London, series B, biological sciences 2017;372:20160224.

Branda SS, Vik S, Friedman L et al. Biofilms: the matrix revisited. Trends Microbiol 2005;13:20-6.

Bray D. Cell movements: from molecules to motility. Second Edn. Taylor, Francis Group, Garland Publishing: New York, USA, 2001.

Brenner DJ, Fanning GR, Skerman FJ et al. Polynucleotide sequence divergence among strains of Escherichia coli and closely related organisms. J bacteriol 1972;109:953-65.

Brunder W, Karch H, Schmidt H. Complete sequence of the large virulence plasmid pSFO157 of the sorbitol-fermenting enterohemorrhagic Escherichia coli O157:H- strain 3072/96. Inter J Med Microbiol 2006;296:467-74.

Brunder W, Khan AS, Hacker J et al. Novel type of fimbriae encoded by the large plasmid of sorbitol-fermenting enterohemorrhagic Escherichia coli 0157:H(-). Infect Immun 2001;69:4447-57.

Burger A, Whiteley C, Boshoff A. Current perspectives of the Escherichia coli RNA degradosome. Biotechnol Lett 2011;33:2337-50.

Burgess C, Desvaux M, Olmez H. Mitigating bacterial colonisation in the food chain: bacterial adhesion, biocide resistance and microbial safety of fresh produce. Res Microbiol 2014;165:305-10.

Candela T, Fouet A. Poly- $\gamma$-glutamate in bacteria. Mol Microbiol 2006;60:1091-8.

Capitani G, Eidam O, Glockshuber $\mathrm{R}$ et al. Structural and functional insights into the assembly of type 1 pili from Escherichia coli. Microb Infect 2006;8:2284-90.

Caron F, Meyer E. Molecular basis of surface antigen variation in paramecia. Ann Rev Microbiol 1989;43:23-42.

Caron J, Scott JR. A rns-like regulatory gene for colonization factor antigen I (CFA/I) that controls expression of CFA/I pilin. Infect Immun 1990;58:874-78.

Cerca N, Maira-Litran T, Jefferson KK et al. Protection against Escherichia coli infection by antibody to the Staphylococcus aureus poly-N-acetylglucosamine surface polysaccharide. Proc Nat Acad Sci USA 2007;104:7528-33.

Chagnot C, Listrat A, Astruc T et al. Bacterial adhesion to animal tissues: protein determinants for recognition of extracellular matrix components. Cell Microbiol 2012;14:1687-96.

Chagnot C, Zorgani MA, Astruc T et al. Proteinaceous determinants of surface colonization in bacteria: bacterial adhesion and biofilm formation fom a protein secretion perspective. Front Microbiol 2013;4:303.

Chaudhuri RR, Henderson IR. The evolution of the Escherichia coli phylogeny. Infect Gene Evolut 2012;12:214-26.

Chen J, Lee SM, Mao Y. Protective effect of exopolysaccharide colanic acid of Escherichia coli O157:H7 to osmotic and oxidative stress. Internat J food Microbiol 2004;93:281-6.

Chilcott GS, Hughes KT. Coupling of flagellar gene expression to flagellar assembly in Salmonella enterica serovar typhimurium and Escherichia coli. Microbiol Mol Biol Rev 2000;64:694-708.

Cimdins A, Luthje P, Li F et al. Draft genome sequences of semiconstitutive red, dry, and rough biofilm-forming commensal and uropathogenic Escherichia coli isolates. Gen Announce 2017;5:e01249-16.

Clavijo AP, Bai J, Gomez-Duarte OG. The longus type 4 pilus of enterotoxigenic Escherichia coli (ETEC) mediates bacterial self-aggregation and protection from antimicrobial agents. Microb Pathogen 2010;48:230-8.

Cleary J, Lai LC, Shaw RK et al. Enteropathogenic Escherichia coli (EPEC) adhesion to intestinal epithelial cells: role of bundleforming pili (BFP), EspA filaments and intimin. Microbiology 2004;150:527-38.

Clermont O, Christenson JK, Denamur E et al. The Clermont Escherichia coli phylo-typing method revisited: improvement of specificity and detection of new phylo-groups. Environ Microbiol Rep 2013;5:58-65.

Coburn B, Sekirov I, Finlay BB. Type III secretion systems and disease. Clinic Microbiol Rev 2007;20:535-49.

Coleman JL, Benach JL. Use of the plasminogen activation system by microorganisms. J Laborat Clinic Med 1999;134:567-76.

Connolly JP, Finlay BB, Roe AJ. From ingestion to colonization: the influence of the host environment on regulation of the LEE encoded Type III secretion system in enterohaemorrhagic Escherichia coli. Front Microbiol 2015;6:568.

Contrepois M, Fairbrother JM, Kaura YK et al. Prevalence of CS31A and F165 surface antigens in Escherichia coli isolates from animals in France, Canada and India. FEMS Microbiol Lett 1989;50:319-23.

Contrepois M, Girardeau JP, Gouet P et al. Expression of K99 pilus of Escherichia coli. Annales de recherches vétérinaires 1983;14:400-7.

Converse SE, Cox JS. A protein secretion pathway critical for Mycobacterium tuberculosis virulence is conserved and functional in Mycobacterium smegmatis. $J$ Bacteriol 2005;187:1238-45.

Cooke NM, Smith SG, Kelleher M et al. Major differences exist in frequencies of virulence factors and multidrug resistance between community and nosocomial Escherichia coli bloodstream isolates. J Clinic Microbiol 2010;48:1099-104.

Cookson AL, Cooley WA, Woodward MJ. The role of type 1 and curli fimbriae of shigatoxin-producing Escherichia coli in adherence to abiotic surfaces. Intern J Med Microbiol 2002;292:195-205.

Cornelis GR. The Type III secretion injectisome. Nature Rev Microbiol 2006;4:811-25.

Costerton JW, Stewart PS, Greenberg EP. Bacterial biofilms: a common cause of persistent infections. Science 1999;284:1318-22.

Costerton JW. Overview of microbial biofilms. J Indust Microbiol 1995;15:137-40.

Cote JP, Charbonneau ME, Mourez M. Glycosylation of the Escherichia coli TibA self-associating autotransporter influences the conformation and the functionality of the protein. PloS one 2013;8:e80739.

Cote JP, Mourez M. Structure-function analysis of the TibA selfassociating autotransporter reveals a modular organization. Infect Immun 2011;79:1826-32.

Cotter SE, Surana NK, St Geme JW, 3rd. Trimeric autotransporters: a distinct subfamily of autotransporter proteins. Trend Microbiol 2005;13:199-205.

Craig L, Forest KT, Maier B. Type 4 pili: dynamics, biophysics and functional consequences. Nat Rev Microbiol 2019;17:429-40. 
Craig L, Pique ME, Tainer JA. Type 4 pilus structure and bacterial pathogenicity. Nat Reu Microbiol 2004;2:363-78.

Crost C, Garrivier A, Harel J et al. Leucine-responsive regulatory protein-mediated repression of clp (encoding CS31A) expression by L-leucine and L-alanine in Escherichia coli. J Bacteriol 2003;185:1886-94.

Croxen MA, Finlay BB. Molecular mechanisms of Escherichia coli pathogenicity. Nat Reu Microbiol 2010;8:26-38.

Croxen MA, Law RJ, Scholz $\mathrm{R}$ et al. Recent advances in understanding enteric pathogenic Escherichia coli. Clinic Microbiol Rev 2013;26:822-80.

Currie CG, Poxton IR. The lipopolysaccharide core type of Escherichia coli 0157:H7 and other non-0157 verotoxinproducing E. coli. FEMS Immunol Med Microbiol 1999;24:57-62.

Czeczulin JR, Balepur S, Hicks S et al. Aggregative adherence fimbria II, a second fimbrial antigen mediating aggregative adherence in enteroaggregative Escherichia coli. Infect Immun 1997;65:4135-45.

Dai J, Wang S, Guerlebeck D et al. Suppression subtractive hybridization identifies an autotransporter adhesin gene of E. coli IMT5155 specifically associated with avian pathogenic Escherichia coli (APEC). BMC Microbiol 2010;10:236.

Danese PN, Pratt LA, Dove SL et al. The outer membrane protein, antigen 43, mediates cell-to-cell interactions within Escherichia coli biofilms. Mol Microbiol 2000;37:424-32.

Dautin N. Serine protease autotransporters of Enterobacteriaceae (SPATEs): biogenesis and function. Toxins 2010;2: 1179-206.

Deacon V, Dziva F, van Diemen PM et al. Efa-1/LifA mediates intestinal colonization of calves by enterohaemorrhagic Escherichia coli O26:H- in a manner independent of glycosyltransferase and cysteine protease motifs or effects on Type III secretion. Microbiology 2010;156:2527-36.

DeBenedictis EP, Ma D, Keten S. Structural predictions for curli amyloid fibril subunits CsgA and CsgB. RSC Adv 2017;7: 48102-12.

DebRoy C, Maddox CW. Identification of virulence attributes of gastrointestinal Escherichia coli isolates of veterinary significance. Anim Health Res Rev 2001;2:129-40.

Decanio MS, Landick R, Haft RJ. The non-pathogenic Escherichia coli strain W secretes SslE via the virulence-associated Type II secretion system $\beta$. BMC Microbiol 2013;13:130.

de Luna M, Scott-Tucker A, Desvaux M et al. The Escherichia coli biofilm-promoting protein Antigen 43 does not contribute to intestinal colonization. FEMS Microbiol lett 2008;284:237-46.

Desai SK, Kenney LJ. To approximately P or Not to approximately P? Non-canonical activation by two-component response regulators. Mol Microbiol 2017;103:203-13.

Desvaux M, Cooper LM, Filenko NA et al. The unusual extended signal peptide region of the Type $\mathrm{V}$ secretion system is phylogenetically restricted. FEMS Microbiol Letters 2006;264: 22-30.

Desvaux M, Hébraud M, Talon R et al. Outer membrane translocation: numerical protein secretion nomenclature in question in mycobacteria. Trends Microbiol 2009a;17:338-40.

Desvaux M, Hébraud M, Henderson IR et al. Type III secretion: what's in a name? Trends Microbiol 2006;14:157-60.

Desvaux M, Hébraud M, Talon R et al. Secretion and subcellular localizations of bacterial proteins: a semantic awareness issue. Trends Microbiol 2009b;17:139-45.

Desvaux M, Parham NJ, Henderson IR. Le système de sécrétion de Type V chez les bactéries Gram-négatives [Type V secretion system in Gram-negative bacteria]. Biofutur 2003;237: 34-7.
Desvaux M, Parham NJ, Henderson IR. The autotransporter secretion system. Res microbiol 2004;155:53-60.

Desvaux M, Parham NJ, Scott-Tucker A et al. The general secretory pathway: a general misnomer? Trends Microbiol 2004;12:306-9.

Desvaux M, Petitdemange H. Sporulation of Clostridium cellulolyticum while grown in cellulose-batch and cellulose-fed continuous cultures on a mineral-salt based medium. Microbial Ecol 2002;43:271-9.

Desvaux M. Mapping of carbon flow distribution in the central metabolic pathways of Clostridium cellulolyticum: Direct comparison of bacterial metabolism with a soluble versus an insoluble carbon source. J Microbiol Biotechnol 2004;14: 1200-10.

Diard M, Garry L, Selva $M$ et al. Pathogenicity-associated islands in extraintestinal pathogenic Escherichia coli are fitness elements involved in intestinal colonization. J bacteriol 2010;192:4885-93.

Dionisio F, Matic I, Radman M et al. Plasmids spread very fast in heterogeneous bacterial communities. Genetics 2002;162:1525-32.

Dobrindt U, Blum-Oehler G, Nagy G et al. Genetic structure and distribution of four pathogenicity islands (PAI I(536) to PAI IV(536)) of uropathogenic Escherichia coli strain 536. Infect Immun 2002;70:6365-72.

Donlan RM. Biofilms: microbial life on surfaces. Emerg Infect Dis 2002;8:881-90.

Donnenberg MS, Tzipori S, McKee ML et al. The role of the eae gene of enterohemorrhagic Escherichia coli in intimate attachment in vitro and in a porcine model. J Clinic Investig 1993;92:1418-24.

Dorman CJ, Ni Bhriain N. DNA topology and bacterial virulence gene regulation. Trends Microbiol 1993;1:92-9.

Doughty S, Sloan J, Bennett-Wood V et al. Identification of a novel fimbrial gene cluster related to long polar fimbriae in locus of enterocyte effacement-negative strains of enterohemorrhagic Escherichia coli. Infection and Immunity 2002;70:6761-9.

Dozois CM, Clement S, Desautels C et al. Expression of P, S, and F1C adhesins by cytotoxic necrotizing factor 1-producing Escherichia coli from septicemic and diarrheic pigs. FEMS Microbiol Lett 1997;152:307-12.

Duan Q, Zhou M, Liang H et al. Contribution of flagellin subunit FliC to piglet epithelial cells invasion by F18ab Escherichia coli. Vet Microbiol 2013;166:220-4.

Duan Q, Zhou M, Zhu X et al. Flagella from F18+ Escherichia coli play a role in adhesion to pig epithelial cell lines. Microbial Pathog 2013;55:32-8.

Duan Q, Zhou M, Zhu X et al. The flagella of F18ab Escherichia coli is a virulence factor that contributes to infection in a IPEC-J2 cell model in vitro. Vet Microbiol 2012;160:132-40.

Dudley EG, Thomson NR, Parkhill J et al. Proteomic and microarray characterization of the AggR regulon identifies a pheU pathogenicity island in enteroaggregative Escherichia coli. Mol Microbiol 2006a;61:1267-82.

Dudley EG, Abe C, Ghigo JM et al. An IncI1 plasmid contributes to the adherence of the atypical enteroaggregative Escherichia coli strain C1096 to cultured cells and abiotic surfaces. Infect Immun 2006b;74:2102-14.

Duncan MJ, Mann EL, Cohen MS et al. The distinct binding specificities exhibited by enterobacterial type 1 fimbriae are determined by their fimbrial shafts. J Biolog Chem 2005;280: 37707-16.

Dziva F, Mahajan A, Cameron P et al. EspP, a Type V-secreted serine protease of enterohaemorrhagic Escherichia coli 
0157:H7, influences intestinal colonization of calves and adherence to bovine primary intestinal epithelial cells. FEMS Microbiol Lett 2007;271:258-64.

Dziva F, van Diemen PM, Stevens MP et al. Identification of Escherichia coli 0157:H7 genes influencing colonization of the bovine gastrointestinal tract using signature-tagged mutagenesis. Microbiology 2004;150:3631-45.

Easton DM, Allsopp LP, Phan MD et al. The intimin-like protein FdeC is regulated by $\mathrm{H}-\mathrm{NS}$ and temperature in enterohemorrhagic Escherichia coli. Appl Environ Microbiol 2014;80: 7337-47.

Easton DM, Totsika M, Allsopp LP et al. Characterization of EhaJ, a new autotransporter protein from enterohemorrhagic and enteropathogenic Escherichia coli. Front Microbiol 2011;2:120.

Ebel W, Trempy JE. Escherichia coli RcsA, a positive activator of colanic acid capsular polysaccharide synthesis, functions to activate its own expression. J Bacteriol 1999;181:577-84.

Eckburg PB, Bik EM, Bernstein CN et al. Diversity of the human intestinal microbial flora. Science 2005;308:1635-8.

Egea L, Aguilera L, Gimenez $\mathrm{R}$ et al. Role of secreted glyceraldehyde-3-phosphate dehydrogenase in the infection mechanism of enterohemorrhagic and enteropathogenic Escherichia coli: interaction of the extracellular enzyme with human plasminogen and fibrinogen. Intern J Biochem Cell Biol 2007;39:1190-203.

Elliott SJ, Kaper JB. Role of type 1 fimbriae in EPEC infections. Microb Pathog 1997;23:113-8.

Emory SA, Belasco JG. The ompA 5' untranslated RNA segment functions in Escherichia coli as a growth-rate-regulated mRNA stabilizer whose activity is unrelated to translational efficiency. J Bacteriol 1990;172:4472-81.

Emory SA, Bouvet P, Belasco JG. A 5'-terminal stem-loop structure can stabilize mRNA in Escherichia coli. Genes Dev 1992;6:135-48.

Escobar-Paramo P, Le Menac'h A, Le Gall T et al. Identification of forces shaping the commensal Escherichia coli genetic structure by comparing animal and human isolates. Environ Microbiol 2006;8:1975-84.

Evans ML, Chapman MR. Curli biogenesis: order out of disorder. Biochimica et biophysica acta: Mol Cell Res 2014;1843:1551-8.

Evans ML, Chorell E, Taylor JD et al. The bacterial curli system possesses a potent and selective inhibitor of amyloid formation. Mol Cell 2015;57:445-55.

Fagan RP, Lambert MA, Smith SG. The Hek outer membrane protein of Escherichia coli strain RS218 binds to proteoglycan and utilizes a single extracellular loop for adherence, invasion, and autoaggregation. Infect Immun 2008;76:1135-42.

Fagan RP, Smith SG. The Hek outer membrane protein of Escherichia coli is an auto-aggregating adhesin and invasin. FEMS Microbiol Lett 2007;269:248-55.

Falkow S. Molecular Koch's postulates applied to microbial pathogenicity. Reu Infect Dis 1988;10:S274-6.

Farfan MJ, Inman KG, Nataro JP. The major pilin subunit of the AAF/II fimbriae from enteroaggregative Escherichia coli mediates binding to extracellular matrix proteins. Infect Immun 2008;76:4378-84.

Farfan MJ, Torres AG. Molecular mechanisms that mediate colonization of shigatoxin-producing Escherichia coli strains. Infect Immun 2012;80:903-13.

Feng L, Liu B, Liu Y et al. A genomic islet mediates flagellar phase variation in Escherichia coli strains carrying the flagellinspecifying locus flk. J Bacteriol 2008;190:4470-7.

Finlay BB, Falkow S. Common themes in microbial pathogenicity. Microbiol Rev 1989;53:210-30.
Fitzhenry R, Dahan S, Torres AG et al. Long polar fimbriae and tissue tropism in Escherichia coli O157:H7. Microb Infect 2006;8:1741-9.

Fleckenstein JM, Holland JT, Hasty DL. Interaction of an outer membrane protein of enterotoxigenic Escherichia coli with cell surface heparan sulfate proteoglycans. Infect Immun 2002;70:1530-7.

Fleckenstein JM, Kopecko DJ, Warren RL et al. Molecular characterization of the tia invasion locus from enterotoxigenic Escherichia coli. Infect Immun 1996;64:2256-65.

Fleckenstein JM, Roy K, Fischer JF et al. Identification of a twopartner secretion locus of enterotoxigenic Escherichia coli. Infect Immun 2006;74:2245-58.

Franzin FM, Sircili MP. Locus of enterocyte effacement: a pathogenicity island involved in the virulence of enteropathogenic and enterohemorragic Escherichia coli subjected to a complex network of gene regulation. BioMed Res Intern 2015;2015:534738.

Fricke WF, Wright MS, Lindell AH et al. Insights into the environmental resistance gene pool from the genome sequence of the multidrug-resistant environmental isolate Escherichia coli SMS-3-5. J Bacteriol 2008;190:6779-94.

Furniss RCD, Clements A. Regulation of the locus of enterocyte effacement in attaching and effacing pathogens. J Bacteriol 2018;200:e00336-17.

Gaastra W, Svennerholm AM. Colonization factors of human enterotoxigenic Escherichia coli (ETEC). Trend Microbiol 1996;4:444-52.

Gagic D, Ciric M, Wen WX et al. Exploring the secretomes of microbes and microbial communities using filamentous phage Display. Front Microbiol 2016;7:429.

Galan JE, Waksman G. Protein-injection machines in bacteria. Cell 2018;172:1306-18.

Galan JE, Wolf-Watz H. Protein delivery into eukaryotic cells by Type III secretion machines. Nature 2006;444:567-73.

Gally DL, Leathart J, Blomfield IC. Interaction of FimB and FimE with the fim switch that controls the phase variation of type 1 fimbriae in Escherichia coli K-12. Mol Microbiol 1996; 21:725-38.

Gardner A, West SA. Greenbeards. Evolution 2010;64:25-38.

Genevaux P, Bauda P, DuBow MS et al. Identification of Tn10 insertions in the $\mathrm{rfaG}, \mathrm{rfaP}$, and galU genes involved in lipopolysaccharide core biosynthesis that affect Escherichia coli adhesion. Arch Microbiol 1999;172:1-8.

Gerstel U, Romling U. Oxygen tension and nutrient starvation are major signals that regulate agfD promoter activity and expression of the multicellular morphotype in Salmonella typhimurium. Environ Microbiol 2001;3:638-48.

Gervais FG, Drapeau GR. Identification, cloning, and characterization of rcsF, a new regulator gene for exopolysaccharide synthesis that suppresses the division mutation ftsZ84 in Escherichia coli K-12. J Bacteriol 1992;174: 8016-22.

Ghigo JM. Natural conjugative plasmids induce bacterial biofilm development. Nature 2001;412:442-5.

Giaouris E, Heir E, Hébraud $M$ et al. Attachment and biofilm formation by foodborne bacteria in meat processing environments: causes, implications, role of bacterial interactions and control by alternative novel methods. Meat science 2014;97:298-309.

Gibb AP, Barclay GR, Poxton IR et al. Frequencies of lipopolysaccharide core types among clinical isolates of Escherichia coli defined with monoclonal antibodies. $J$ Infect Dis 1992;166:1051-7. 
Giltner CL, Nguyen Y, Burrows LL. Type 4 pilin proteins: versatile molecular modules. Microbiol Mol Biol Rev 2012;76:740-72.

Giltner CL, van Schaik EJ, Audette GF et al. The Pseudomonas aeruginosa type 4 pilin receptor binding domain functions as an adhesin for both biotic and abiotic surfaces. Mol Microbiol 2006;59:1083-96.

Girardeau JP, Bertin Y, Martin C et al. Sequence analysis of the clpG gene, which codes for surface antigen CS31A subunit: evidence of an evolutionary relationship between CS31A, K88, and F41 subunit genes. J Bacteriol 1991;173:7673-83.

Girardeau JP, Der Vartanian M, Ollier JL et al. CS31A, a new K88related fimbrial antigen on bovine enterotoxigenic and septicemic Escherichia coli strains. Infect Immun 1988;56:2180-8.

Giron JA, Levine MM, Kaper JB. Longus: a long pilus ultrastructure produced by human enterotoxigenic Escherichia coli. Mol Microbiol 1994;12:71-82.

Giron JA, Torres AG, Freer E et al. The flagella of enteropathogenic Escherichia coli mediate adherence to epithelial cells. Mol Microbiol 2002;44:361-79.

Giron JA, Viboud GI, Sperandio V et al. Prevalence and association of the longus pilus structural gene (lngA) with colonization factor antigens, enterotoxin types, and serotypes of enterotoxigenic Escherichia coli. Infect Immun 1995;63:4195-8.

Goh KGK, Moriel DG, Hancock SJ et al. Bioinformatic and molecular analysis of inverse autotransporters from Escherichia coli. mSphere 2019;4:e00572-19.

Goller C, Wang X, Itoh Y et al. The cation-responsive protein NhaR of Escherichia coli activates pgaABCD transcription, required for production of the biofilm adhesin poly- $\beta-1,6-\mathrm{N}$ acetyl-D-glucosamine. J Bacteriol 2006;188:8022-32.

Gomes TA, Hernandes RT, Torres AG et al. Adhesin-encoding genes from shigatoxin-producing Escherichia coli are more prevalent in atypical than in typical enteropathogenic E. coli. J Clin Microbiol 2011;49:3334-7.

Gomez-Duarte OG, Kaper JB. A plasmid-encoded regulatory region activates chromosomal eaeA expression in enteropathogenic Escherichia coli. Infect Immun 1995;63:1767-76.

Gonzales-Siles L, Sjoling A. The different ecological niches of enterotoxigenic Escherichia coli. Environ Microbiol 2016;18:741-51.

Gordon DM, Cowling A. The distribution and genetic structure of Escherichia coli in Australian vertebrates: host and geographic effects. Microbiology 2003;149:3575-86.

Grainger DC. Structure and function of bacterial H-NS protein. Biochem Soc Transact 2016;44:1561-9.

Graveline R, Garneau P, Martin C et al. Leucine-responsive regulatory protein Lrp and PapI homologues influence phase variation of CS31A fimbriae. J Bacteriol 2014;196:2944-53.

Groschel MI, Sayes F, Simeone R et al. ESX secretion systems: mycobacterial evolution to counter host immunity. Nature Reu Microbiol 2016;14:677-91.

Gualdi L, Tagliabue L, Bertagnoli S et al. Cellulose modulates biofilm formation by counteracting curli-mediated colonization of solid surfaces in Escherichia coli. Microbiology 2008;154:2017-24.

Guedon E, Payot S, Desvaux M et al. Relationships between cellobiose catabolism, enzyme levels, and metabolic intermediates in Clostridium cellulolyticum grown in a synthetic medium. Biotechnol Bioengin 2000;67:327-35.

Guinee PA, Jansen WH, Agterberg CM. Detection of the K99 antigen by means of agglutination and immunoelectrophoresis in Escherichia coli isolates from calves and its correlation with entertoxigenicity. Infect Immun 1976;13:1369-77.
Gutierrez-Jimenez J, Arciniega I, Navarro-Garcia F. The serine protease motif of Pic mediates a dose-dependent mucolytic activity after binding to sugar constituents of the mucin substrate. Microbial Pathog 2008;45:115-23.

Guttenplan SB, Kearns DB. Regulation of flagellar motility during biofilm formation. FEMS Microbiol Rev 2013;37:849-71.

Hall-Stoodley L, Stoodley P. Developmental regulation of microbial biofilms. Curr Opin Biotechnol 2002;13:228-33.

Hamilton HL, Dominguez NM, Schwartz KJ et al. Neisseria gonorrhoeae secretes chromosomal DNA via a novel Type IV secretion system. Mol Microbiol 2005;55:1704-21.

Hammar M, Arnqvist A, Bian Z et al. Expression of two csg operons is required for production of fibronectin- and congo redbinding curli polymers in Escherichia coli K-12. Mol Microbiol 1995;18:661-70.

Hanna A, Berg M, Stout V et al. Role of capsular colanic acid in adhesion of uropathogenic Escherichia coli. Appl Environ Microbiol 2003;69:4474-81.

Hannan A, Saleem S, Chaudhary S et al. Anti bacterial activity of Nigella sativa against clinical isolates of methicillin resistant Staphylococcus aureus. J Ayub Med Coll 2008;20:72-4.

Hansen MJ, Chen LH, Fejzo ML et al. The ompA 5' untranslated region impedes a major pathway for $\mathrm{mRNA}$ degradation in Escherichia coli. Mol Microbiol 1994;12:707-16.

Harrington SM, Sheikh J, Henderson IR et al. The Pic protease of enteroaggregative Escherichia coli promotes intestinal colonization and growth in the presence of mucin. Infect Immun 2009;77:2465-73.

Harris SL, Elliott DA, Blake MC et al. Isolation and characterization of mutants with lesions affecting pellicle formation and erythrocyte agglutination by type 1 piliated Escherichia coli. J Bacteriol 1990;172:6411-8.

Ha SK, Choi C, Chae C. Prevalence of a gene encoding adhesin involved in diffuse adherence among Escherichia coli isolates in pigs with postweaning diarrhea or edema disease. J Veterin Diag Invest 2003;15:378-81.

Hasman H, Chakraborty T, Klemm P. Antigen-43-mediated autoaggregation of Escherichia coli is blocked by fimbriation. J Bacteriol 1999;181:4834-41.

Hausner M, Wuertz S. High rates of conjugation in bacterial biofilms as determined by quantitative in situ analysis. Appl Environ Microbiol 1999;65:3710-3.

Hazen TH, Leonard SR, Lampel KA et al. Investigating the relatedness of enteroinvasive Escherichia coli to other E. coli and Shigella isolates by using comparative genomics. Infect Immun 2016;84:2362-71.

Henderson B, Martin A. Bacterial virulence in the moonlight: multitasking bacterial moonlighting proteins are virulence determinants in infectious disease. Infect Immun 2011;79:3476-91.

Henderson IR, Czeczulin J, Eslava C et al. Characterization of Pic, a secreted protease of Shigella flexneri and enteroaggregative Escherichia coli. Infect Immun 1999;67:5587-96.

Henderson IR, Desvaux M. The Type V secretion pathway: a premium source of virulence factors? Drug Discovery Today 2004;9:241.

Henderson IR, Navarro-Garcia F, Desvaux M et al. Type V protein secretion pathway: the autotransporter story. Microbiol Mol Biol Rev 2004;68:692-744.

Henderson IR, Owen P, Nataro JP. Molecular switches-the ON and OFF of bacterial phase variation. Mol Microbiol 1999;33:919-32.

Heras B, Totsika M, Peters KM et al. The antigen 43 structure reveals a molecular Velcro-like mechanism of 
autotransporter-mediated bacterial clumping. Proc Nation Acad Sci USA 2014;111:457-62.

Herold S, Paton JC, Paton AW. Sab, a novel autotransporter of locus of enterocyte effacement-negative shigatoxigenic Escherichia coli O113:H21, contributes to adherence and biofilm formation. Infect Immun 2009;77: 3234-43.

Herold S, Paton JC, Srimanote P et al. Differential effects of shortchain fatty acids and iron on expression of iha in shigatoxigenic Escherichia coli. Microbiology 2009;155:3554-63.

He SY, Jin Q. The Hrp pilus: learning from flagella. Curr Opin Microbiol 2003;6:15-9.

Hicks S, Candy DC, Phillips AD. Adhesion of enteroaggregative Escherichia coli to formalin-fixed intestinal and ureteric epithelia from children. J Med Microbiol 1996;44:362-71.

Hill C. Virulence or niche factors: what's in a name? J Bacteriol 2012;194:5725-7.

Hitchcock PJ, Leive L, Makela PH et al. Lipopolysaccharide nomenclature-past, present, and future. $J$ Bacteriol 1986;166:699-705.

Hobley L, Harkins C, MacPhee CE et al. Giving structure to the biofilm matrix: an overview of individual strategies and emerging common themes. FEMS Microbiol Rev 2015;39: 649-69.

Hobman JL, Penn CW, Pallen MJ. Laboratory strains of Escherichia coli: model citizens or deceitful delinquents growing old disgracefully? Mol Microbiol 2007;64:881-5.

Hoch JA. Two-component and phosphorelay signal transduction. Curr Opi Microbiol 2000;3:165-70.

Holden NJ, Gally DL. Switches, cross-talk and memory in Escherichia coli adherence. J Med Microbiol 2004;53:585-93.

Hueck CJ. Type III protein secretion systems in bacterial pathogens of animals and plants. Microbiol Mol Biol Rev 1998;62:379-433.

Hultgren SJ, Lindberg F, Magnusson G et al. The PapG adhesin of uropathogenic Escherichia coli contains separate regions for receptor binding and for the incorporation into the pilus. Proc Nat Acad Sci USA 1989;86:4357-61.

Hung C, Zhou Y, Pinkner JS et al. Escherichia coli biofilms have an organized and complex extracellular matrix structure. mBio 2013;4:e00645-13.

Iguchi A, Thomson NR, Ogura $\mathrm{Y}$ et al. Complete genome sequence and comparative genome analysis of enteropathogenic Escherichia coli O127:H6 strain E2348/69. J Bacteriol 2009;191:347-54.

Itoh Y, Rice JD, Goller C et al. Roles of pgaABCD genes in synthesis, modification, and export of the Escherichia coli biofilm adhesin poly- $\beta$-1,6-N-acetyl-D-glucosamine. J Bacteriol 2008;190:3670-80.

Itoh Y, Wang X, Hinnebusch BJ et al. Depolymerization of $\beta$ 1,6-N-acetyl-D-glucosamine disrupts the integrity of diverse bacterial biofilms. J Bacteriol 2005;187:382-7.

Jain N, Chapman MR. Bacterial functional amyloids: Order from disorder. Biochimica et biophysica acta: Proteins and Proteomics 2019;1867:954-60.

Jallat C, Darfeuille-Michaud A, Girardeau JP et al. Selftransmissible $\mathrm{R}$ plasmids encoding CS31A among human Escherichia coli strains isolated from diarrheal stools. Infect Immun 1994;62:2865-73.

Jang $\mathrm{H}$, Matthews KR. Influence of surface polysaccharides of Escherichia coli 0157:H7 on plant defense response and survival of the human enteric pathogen on Arabidopsis thaliana and lettuce (Lactuca sativa). Food Microbiol 2018;70: 254-61.
Jang J, Hur HG, Sadowsky MJ et al. Environmental Escherichia coli: ecology and public health implications-a review. J Appl Microbiol 2017;123:570-81.

Janisiewicz WJ, Conway WS, Brown MW et al. Fate of Escherichia coli 0157:H7 on fresh-cut apple tissue and its potential for transmission by fruit flies. Appl Environ Microbiol 1999;65:1-5.

Jansson L, Tobias J, Lebens $\mathrm{M}$ et al. The major subunit, $\mathrm{CfaB}$, of colonization factor antigen i from enterotoxigenic Escherichia coli is a glycosphingolipid binding protein. Infect Immun 2006;74:3488-97.

Jaureguy F, Landraud L, Passet V et al. Phylogenetic and genomic diversity of human bacteremic Escherichia coli strains. BMC Genom 2008;9:560.

Jenal U, Malone J. Mechanisms of cyclic-di-GMP signaling in bacteria. Annual review of genetics 2006;40:385-407.

Jenkins C, Perry NT, Cheasty T et al. Distribution of the saa gene in strains of shigatoxin-producing Escherichia coli of human and bovine origins. J Clin Microbiol 2003;41:1775-8.

Johnson JR, Jelacic S, Schoening LM et al. The IrgA homologue adhesin tha is an Escherichia coli virulence factor in murine urinary tract infection. Infect Immun 2005;73:965-71.

Jonsson R, Struve C, Boisen $\mathrm{N}$ et al. Novel aggregative adherence fimbria variant of enteroaggregative Escherichia coli. Infect Immun 2015;83:1396-405.

Jordi BJ, Willshaw GA, van der Zeijst BA et al. The complete nucleotide sequence of region 1 of the CFA/I fimbrial operon of human enterotoxigenic Escherichia coli. DNA Seq 1992;2:257-63.

Kadurugamuwa JL, Beveridge TJ. Bacteriolytic effect of membrane vesicles from Pseudomonas aeruginosa on other bacteria including pathogens: conceptually new antibiotics. $J$ Bacteriol 1996;178:2767-74.

Kadurugamuwa JL, Beveridge TJ. Virulence factors are released from Pseudomonas aeruginosa in association with membrane vesicles during normal growth and exposure to gentamicin: a novel mechanism of enzyme secretion. J Bacteriol 1995;177:3998-4008.

Kaiser D. Bacterial swarming: a re-examination of cellmovement patterns. Curr Biol 2007;17:R561-70.

Kanamaru S, Kurazono H, Ishitoya $\mathrm{S}$ et al. Distribution and genetic association of putative uropathogenic virulence factors iroN, iha, kpsMT, ompT and usp in Escherichia coli isolated from urinary tract infections in Japan. J Urol 2003;170:2490-3.

Kaper JB, Nataro JP, Mobley HL. Pathogenic Escherichia coli. Nat Rev Microbiol 2004;2:123-40.

Karmali MA, Mascarenhas M, Shen S et al. Association of genomic O-island 122 of Escherichia coli EDL933 with verocytotoxin-producing Escherichia coli seropathotypes that are linked to epidemic and/or serious disease. J Clin Microbiol 2003;41:4930-40.

Keiski CL, Harwich M, Jain S et al. AlgK is a TPR-containing protein and the periplasmic component of a novel exopolysaccharide secretin. Structure 2010;18:265-73.

Khan I, Chen Y, Dong $\mathrm{T}$ et al. Genome-scale identification and characterization of moonlighting proteins. Biology Direct 2014;9:30.

Kim NH, Cho TJ, Rhee MS. Current interventions for controlling pathogenic Escherichia coli. Adv Appl Microbiol 2017;100:1-47.

Kim SH, Kim YH. Escherichia coli O157:H7 adherence to HEp2 cells is implicated with curli expression and outer membrane integrity. J Vet Sci 2004;5:119-24.

Kitao A, Hata H. Molecular dynamics simulation of bacterial flagella. Biophys Rev 2018;10:617-29. 
Kjaergaard K, Schembri MA, Ramos C et al. Antigen 43 facilitates formation of multispecies biofilms. Environ Microbiol 2000;2:695-702.

Klapproth JM, Scaletsky IC, McNamara BP et al. A large toxin from pathogenic Escherichia coli strains that inhibits lymphocyte activation. Infect Immun 2000;68:2148-55.

Klemm P, Christiansen G, Kreft B et al. Reciprocal exchange of minor components of type 1 and F1C fimbriae results in hybrid organelles with changed receptor specificities. J Bacteriol 1994;176:2227-34.

Klemm P, Vejborg R, Sherlock O. Self-associating autotransporters, SAATs: Functional and structural similarities. Inter J Med Microbiol 2006;296:187-95.

Klemm P. Two regulatory fim genes, fimB and fimE, control the phase variation of type 1 fimbriae in Escherichia coli. EMBO J 1986;5:1389-93.

Knutton S, McConnell MM, Rowe B et al. Adhesion and ultrastructural properties of human enterotoxigenic Escherichia coli producing colonization factor antigens III and IV. Infect Immun 1989;57:3364-71.

Knutton S, Rosenshine I, Pallen MJ et al. A novel EspA-associated surface organelle of enteropathogenic Escherichia coli involved in protein translocation into epithelial cells. EMBO J 1998;17:2166-76.

Koebnik R, Locher KP, Van Gelder P. Structure and function of bacterial outer membrane proteins: barrels in a nutshell. Mol Microbiol 2000;37:239-53.

Korea CG, Badouraly R, Prevost MC et al. Escherichia coli K-12 possesses multiple cryptic but functional chaperone-usher fimbriae with distinct surface specificities. Environ Microbiol 2010;12:1957-77.

Kostakioti M, Newman CL, Thanassi DG et al. Mechanisms of protein export across the bacterial outer membrane. J Bacteriol 2005;187:4306-14.

Kudva IT, Krastins B, Torres AG et al. The Escherichia coli O157:H7 cattle immunoproteome includes outer membrane protein A (OmpA), a modulator of adherence to bovine rectoanal junction squamous epithelial (RSE) cells. Proteomics 2015;15: 1829-42.

Kuehn MJ, Heuser J, Normark S et al. P pili in uropathogenic Escherichia coli are composite fibres with distinct fibrillar adhesive tips. Nature 1992;356:252-5.

Laarmann S, Schmidt MA. The Escherichia coli AIDA autotransporter adhesin recognizes an integral membrane glycoprotein as receptor. Microbiology 2003;149:1871-82.

Laing CR, Buchanan C, Taboada EN et al. In silico genomic analyses reveal three distinct lineages of Escherichia coli O157:H7, one of which is associated with hyper-virulence. BMC Genom 2009;10:287.

Landick R, Wade JT, Grainger DC. H-NS and RNA polymerase: a love-hate relationship? Curr opin Microbiol 2015;24:53-9.

Landini P, Zehnder AJ. The global regulatory hns gene negatively affects adhesion to solid surfaces by anaerobically grown Escherichia coli by modulating expression of flagellar genes and lipopolysaccharide production. J Bacteriol 2002;184: 1522-9.

Lan R, Reeves PR. Escherichia coli in disguise: molecular origins of Shigella. Microb Infect 2002;4:1125-32.

Laverty G, Gorman SP, Gilmore BF. Biomolecular mechanisms of Pseudomonas aeruginosa and Escherichia coli biofilm formation. Pathogens 2014;3:596-32.

Lawley TD, Klimke WA, Gubbins MJ et al. F factor conjugation is a true Type IV secretion system. FEMS Microbiol Lett 2003;224: $1-15$.
Lawrence JG, Hartl DL. Unusual codon bias occurring within insertion sequences in Escherichia coli. Genetica 1991;84: 23-9.

Lawson CL. Unified data resource for cryo-EM. Method Enzymol 2010;483:73-90.

Lebaron P, Bauda P, Lett MC et al. Recombinant plasmid mobilization between Escherichia coli strains in seven sterile microcosms. Canad J Microbiol 1997;43:534-40.

Le Bouguenec C, Servin AL. Diffusely adherent Escherichia coli strains expressing Afa/Dr adhesins (Afa/Dr DAEC): hitherto unrecognized pathogens. FEMS Microbiol Lett 2006;256: 185-94.

Le Gall T, Clermont O, Gouriou S et al. Extraintestinal virulence is a coincidental by-product of commensalism in B2 phylogenetic group Escherichia coli strains. Mol Biol Evolut 2007;24:2373-84.

Leimbach A, Hacker J, Dobrindt U. Escherichia coli as an all-rounder: the thin line between commensalism and pathogenicity. Curr Top Microbiol Immunol 2013;358:3-32.

Lenski RE. Experimental evolution and the dynamics of adaptation and genome evolution in microbial populations. ISME J 2017;11:2181-94.

Leo JC, Goldman A. The immunoglobulin-binding Eib proteins from Escherichia coli are receptors for IgG Fc. Mol Immun 2009;46:1860-6.

Leo JC, Grin I, Linke D. Type V secretion: mechanism(s) of autotransport through the bacterial outer membrane. Philosophical Transactions of the Royal Society of London, Series B, Biological Sciences 2012;367:1088-101.

Leo JC, Lyskowski A, Hattula K et al. The structure of Escherichia coli IgG-binding protein D suggests a general model for bending and binding in trimeric autotransporter adhesins. Structure 2011;19:1021-30.

Leo JC, Oberhettinger P, Schutz $\mathrm{M}$ et al. The inverse autotransporter family: intimin, invasin and related proteins. Int J Med Microbiol 2015;305:276-82.

Le Quere B, Ghigo JM. BcsQ is an essential component of the Escherichia coli cellulose biosynthesis apparatus that localizes at the bacterial cell pole. Mol Microbiol 2009;72: 724-40.

Lewis SB, Cook V, Tighe R et al. Enterohemorrhagic Escherichia coli colonization of human colonic epithelium in vitro and ex vivo. Infect Immun 2015;83:942-9.

Leyton DL, Belousoff MJ, Lithgow T. The $\beta$-barrel assembly machinery complex. Meth Mol Biol 2015;1329:1-16.

Li B, Koch WH, Cebula TA. Detection and characterization of the fimA gene of Escherichia coli O157:H7. Mol Cell Probes 1997;11:397-406.

Li G, Feng Y, Kariyawasam S et al. AatA is a novel autotransporter and virulence factor of avian pathogenic Escherichia coli. Infect Immun 2010;78:898-906.

Lillington J, Geibel S, Waksman G. Biogenesis and adhesion of type 1 and P pili. Biochimica et biophysica acta: General Sub 2014;1840:2783-93.

Lin CC, Yeh YC, Yang CY et al. Selective binding of mannoseencapsulated gold nanoparticles to type 1 pili in Escherichia coli. J Am Chem Soc 2002;124:3508-9.

Lindenthal C, Elsinghorst EA. Identification of a glycoprotein produced by enterotoxigenic Escherichia coli. Infect Immun 1999;67:4084-91.

Lintermans P, Pohl P, Deboeck F et al. Isolation and nucleotide sequence of the F17-A gene encoding the structural protein of the F17 fimbriae in bovine enterotoxigenic Escherichia coli. Infect Immun 1988;56:1475-84. 
Lintermans PF, Bertels A, Schlicker C et al. Identification, characterization, and nucleotide sequence of the F17-G gene, which determines receptor binding of Escherichia coli F17 fimbriae. J Bacteriol 1991;173:3366-73.

Liu B, Hu B, Zhou $\mathrm{Z}$ et al. A novel non-homologous recombination-mediated mechanism for Escherichia coli unilateral flagellar phase variation. Nucleic Acids Res 2012;40:4530-38.

Liu H, Magoun L, Leong JM. $\beta 1$-chain integrins are not essential for intimin-mediated host cell attachment and enteropathogenic Escherichia coli-induced actin condensation. Infect Immun 1999;67:2045-49.

Liu H, Magoun L, Luperchio S et al. The Tir-binding region of enterohaemorrhagic Escherichia coli intimin is sufficient to trigger actin condensation after bacterial-induced host cell signalling. Mol Microbiol 1999;34:67-81.

Liu MY, Gui G, Wei B et al. The RNA molecule CsrB binds to the global regulatory protein CsrA and antagonizes its activity in Escherichia coli. J Biolog Chem 1997;272:17502-10.

Llosa M, Gomis-Ruth FX, Coll M et al. Bacterial conjugation: a two-step mechanism for DNA transport. Mol Microbiol 2002;45:1-8.

Lloyd AL, Henderson TA, Vigil PD et al. Genomic islands of uropathogenic Escherichia coli contribute to virulence. J Bacteriol 2009;191:3469-81.

Low AS, Dziva F, Torres AG et al. Cloning, expression, and characterization of fimbrial operon F9 from enterohemorrhagic Escherichia coli O157:H7. Infect Immun 2006;74:2233-44.

Lower BH, Yongsunthon R, Vellano FP, 3rd et al. Simultaneous force and fluorescence measurements of a protein that forms a bond between a living bacterium and a solid surface. J Bacteriol 2005;187:2127-37.

Luck SN, Badea L, Bennett-Wood V et al. Contribution of FliC to epithelial cell invasion by enterohemorrhagic Escherichia coli O113:H21. Infect Immun 2006;74:6999-7004.

Lugtenberg B, Peters R, Bernheimer $\mathrm{H}$ et al. Influence of cultural conditions and mutations on the composition of the outer membrane proteins of Escherichia coli. Mol Gen Gene 1976;147:251-62.

Luo Q, Kumar P, Vickers TJ et al. Enterotoxigenic Escherichia coli secretes a highly conserved mucin-degrading metalloprotease to effectively engage intestinal epithelial cells. Infect Immun 2014;82:509-21.

Lu Y, Iyoda S, Satou $\mathrm{H}$ et al. A new immunoglobulin-binding protein, EibG, is responsible for the chain-like adhesion phenotype of locus of enterocyte effacement-negative, shigatoxin-producing Escherichia coli. Infect Immun 2006;74: 5747-55.

Macarisin D, Patel J, Bauchan G et al. Role of curli and cellulose expression in adherence of Escherichia coli 0157:H7 to spinach leaves. Foodborne Pathog Dis 2012;9:160-7.

Macnab RM. Flagella. In: Vol. I Neidhardt FC Ingraham JL Low $\mathrm{KB}$ et al. (eds). Escherichia coli and Salmonella typhimurium: Cellular and molecular biology. American society for microbiology press: Washington DC, 1987a, 70-83.

Macnab RM. Motility and chemotaxis. In: Vol. I Neidhardt FC Ingraham J L Low KB et al. (eds). Escherichia coli and Salmonella typhimurium: Cellular and molecular biology. American society for microbiology press: Washington DC, 1987b, 732-59.

Maeda S, Ito M, Ando T et al. Horizontal transfer of nonconjugative plasmids in a colony biofilm of Escherichia coli. FEMS Microbiol Lett 2006;255:115-20.
Mahajan A, Currie CG, Mackie S et al. An investigation of the expression and adhesin function of $\mathrm{H7}$ flagella in the interaction of Escherichia coli O157:H7 with bovine intestinal epithelium. Cell Microbiol 2009;11:121-37.

Mainil JG, Daube G, Jacquemin E et al. Virulence plasmids of enterotoxigenic Escherichia coli isolates from piglets. Vet Microbiol 1998;62:291-301.

Mallick EM, Brady MJ, Luperchio SA et al. Allele- and tirindependent functions of intimin in diverse animal infection models. Front Microbiol 2012;3:11.

Mancini J, Weckselblatt B, Chung YK et al. The heatresistant agglutinin family includes a novel adhesin from enteroaggregative Escherichia coli strain 60A. J Bacteriol 2011;193:4813-20.

Mann EA, Saeed SA. Gastrointestinal infection as a trigger for inflammatory bowel disease. Curr Opin Gastroenterol 2012;28:24-9.

Manwaring NP, Skurray RA, Firth N. Nucleotide sequence of the F plasmid leading region. Plasmid 1999;41:219-25.

Mao Y, Doyle MP, Chen J. Role of colanic acid exopolysaccharide in the survival of enterohaemorrhagic Escherichia coli 0157:H7 in simulated gastrointestinal fluids. Lett Appl Microbiol 2006;42:642-7.

Martin C, Boeuf C, Bousquet F. Escherichia coli CS31A fimbriae: molecular cloning, expression and homology with the K88 determinant. Microb Pathog 1991;10:429-42.

Martin C. The clp (CS31A) operon is negatively controlled by Lrp, $\mathrm{ClpB}$, and L-alanine at the transcriptional level. Mol Microbiol 1996;21:281-92.

Martinez-Gil M, Goh KGK, Rackaityte E et al. YeeJ is an inverse autotransporter from Escherichia coli that binds to peptidoglycan and promotes biofilm formation. Scientific Reports 2017;7:11326.

Martinez E, Garcia-Viejo MA, Blanco JL et al. Impact of switching from human immunodeficiency virus type 1 protease inhibitors to efavirenz in successfully treated adults with lipodystrophy. Clin Infect Dis 2000;31:1266-73.

Mason TG, Richardson G. Escherichia coli and the human gut: some ecological considerations. J Appl Bacteriol 1981;51:1-16.

Matthysse AG, Deora R, Mishra M et al. Polysaccharides cellulose, poly- $\beta$-1,6-n-acetyl-D-glucosamine, and colanic acid are required for optimal binding of Escherichia coli 0157:H7 strains to alfalfa sprouts and $\mathrm{K}-12$ strains to plastic but not for binding to epithelial cells. Appl Environ Microbiol 2008;74:2384-90.

Mattick JS. Type 4 pili and twitching motility. Ann Rev Microbiol 2002;56:289-314.

Maturin L, Curtiss R. Degradation of DNA by nucleases in intestinal tract of rats. Science 1977;196:216-8.

May T, Okabe S. Escherichia coli harboring a natural IncF conjugative $\mathrm{F}$ plasmid develops complex mature biofilms by stimulating synthesis of colanic acid and Curli. J Bacteriol 2008;190:7479-90.

May T, Tsuruta K, Okabe S. Exposure of conjugative plasmid carrying Escherichia coli biofilms to male-specific bacteriophages. ISME J 2011;5:771-5.

Mazariego-Espinosa K, Cruz A, Ledesma MA et al. Longus, a type 4 pilus of enterotoxigenic Escherichia coli, is involved in adherence to intestinal epithelial cells. J Bacteriol 2010;192:2791-2800.

Mazel D, Davies J. Antibiotic resistance in microbes. Cell Mol Life Sci 1999;56:742-54. 
McCrate OA, Zhou X, Reichhardt C et al. Sum of the parts: composition and architecture of the bacterial extracellular matrix. J Mol Biol 2013;425:4286-94.

McDaniel TK JK, Donnenberg MS, Kaper JB. A genetic locus of enterocyte effacement conserved among diverse enterobacterial pathogens. Proc Nat Acad Sci USA 1995;92:1664-8.

McNeilly TN, Naylor SW, Mahajan A et al. Escherichia coli 0157:H7 colonization in cattle following systemic and mucosal immunization with purified $\mathrm{H} 7$ flagellin. Infect Immun 2008;76:2594-602.

McWilliams BD, Torres AG. EHEC adhesins. Microbiol Spect 2014;2:EHEC00032013.

Mechin MC, Rousset E, Girardeau JP. Identification of surfaceexposed linear B-cell epitopes of the nonfimbrial adhesin CS31A of Escherichia coli by using overlapping peptides and antipeptide antibodies. Infect Immun 1996;64: 3555-64.

Melville S, Craig L. Type IV pili in Gram-positive bacteria. Microbiol Mol Biol Rev 2013;77:323-41.

Merino S, Shaw JG, Tomas JM. Bacterial lateral flagella: an inducible flagella system. FEMS Microbiol Lett 2006;263: 127-35.

Merkel V, Ohder B, Bielaszewska $\mathrm{M}$ et al. Distribution and phylogeny of immunoglobulin-binding protein $G$ in shigatoxinproducing Escherichia coli and its association with adherence phenotypes. Infect Immun 2010;78:3625-36.

Molin S, Tolker-Nielsen T. Gene transfer occurs with enhanced efficiency in biofilms and induces enhanced stabilisation of the biofilm structure. Curr Opin Biotechnol 2003;14:255-61.

Monaghan A, Byrne B, Fanning S et al. Serotypes and virulence profiles of non-0157 shigatoxin-producing Escherichia coli isolates from bovine farms. Appl Environ Microbiol 2011;77:8662-8.

Monteiro BT, Campos LC, Sircili MP et al. The dispersin-encoding gene (aap) is not restricted to enteroaggregative Escherichia coli. Diag Microbiol Infect Dis 2009;65:81-4.

Monteiro R, Ageorges V, Rojas-Lopez M et al. A secretome view of colonisation factors in shigatoxin-encoding Escherichia coli (STEC): from enterohaemorrhagic E. coli (EHEC) to related enteropathotypes. FEMS Microbiol Lett 2016;363:fnw179.

Montero DA, Velasco J, Del Canto F et al. Locus of adhesion and autoaggregation (LAA), a pathogenicity island present in emerging shigatoxin-producing Escherichia coli strains. Scientific Reports 2017;7:7011.

Moreira CG, Carneiro SM, Nataro JP et al. Role of type I fimbriae in the aggregative adhesion pattern of enteroaggregative Escherichia coli. FEMS Microbiol Lett 2003;226:79-85.

Moreira CG, Palmer K, Whiteley $\mathrm{M}$ et al. Bundle-forming pili and EspA are involved in biofilm formation by enteropathogenic Escherichia coli. J Bacteriol 2006;188:3952-61.

Moriel DG, Bertoldi I, Spagnuolo A et al. Identification of protective and broadly conserved vaccine antigens from the genome of extraintestinal pathogenic Escherichia coli. Proc Nat Acad Sci USA 2010;107:9072-7.

Mosquito S, Pons MJ, Riveros M et al. Diarrheagenic Escherichia coli phylogroups are associated with antibiotic resistance and duration of diarrheal episode. Scientific World $J$ 2015;2015:610403.

Muniesa M, Hammerl JA, Hertwig S et al. Shigatoxin-producing Escherichia coli O104:H4: a new challenge for microbiology. Appl Environ Microbiol 2012;78:4065-73.

Musken A, Bielaszewska M, Greune L et al. Anaerobic conditions promote expression of Sfp fimbriae and adherence of sorbitol-fermenting enterohemorrhagic
Escherichia coli 0157:NM to human intestinal epithelial cells. Applied and environmental microbiology 2008;74: 1087-93.

Muto Y, Goto S. Transformation by extracellular DNA produced by Pseudomonas aeruginosa. Microbiology and immunology 1986;30:621-28.

Nagy A, Mowery J, Bauchan GR et al. Role of extracellular structures of Escherichia coli 0157:H7 in initial attachment to biotic and abiotic surfaces. Applied and environmental microbiology 2015;81:4720-7.

Naili I, Baudner B, Bernalier-Donadille A et al. In vivo characterization of the immune response towards the pathogenic Escherichia coli antigen SslE and modulation of the intestinal microbiota. J Immunol 2017;198:147.123.

Naili I, Buonsanti C, Soriani M et al. In vivo characterization of the immune response towards the pathogenic Escherichia coli antigen SslE and modulation of the intestinal microbiota. Journal of immunology 2016;196:215.219.

Nakao R, Ramstedt M, Wai SN et al. Enhanced biofilm formation by Escherichia coli LPS mutants defective in Hep biosynthesis. PloS one 2012;7:e51241.

Nataro JP, Deng Y, Maneval DR et al. Aggregative adherence fimbriae I of enteroaggregative Escherichia coli mediate adherence to HEp-2 cells and hemagglutination of human erythrocytes. Infection and immunity 1992;60:2297-304.

Nataro JP, Kaper JB. Diarrheagenic Escherichia coli. Clin Microbiol Rev 1998;11:142-201.

Nataro JP, Yikang D, Yingkang D et al. AggR, a transcriptional activator of aggregative adherence fimbria I expression in enteroaggregative Escherichia coli. J Bacteriol 1994;176: 4691-9.

Navarro-Garcia F, Elias WP. Autotransporters and virulence of enteroaggregative Escherichia coli. Gut Microbes 2011;2:13-24.

Nesta B, Spraggon G, Alteri C et al. FdeC, a novel broadly conserved Escherichia coli adhesin eliciting protection against urinary tract infections. mBio 2012;3:e00010-2.

Nesta B, Valeri M, Spagnuolo A et al. SslE elicits functional antibodies that impair in vitro mucinase activity and in vivo colonization by both intestinal and extraintestinal Escherichia coli strains. PLoS Pathog 2014;10:e1004124.

Newton HJ, Sloan J, Bennett-Wood V et al. Contribution of long polar fimbriae to the virulence of rabbitspecific enteropathogenic Escherichia coli. Infect Immun 2004;72:1230-9.

Nicholls L, Grant T, Robins-Browne R. Identification of a novel genetic locus that is required for in vitro adhesion of a clinical isolate of enterohaemorrhagic Escherichia coli to epithelial cells. Mol Microbiol 2002;35:275-88.

Niewerth U, Frey A, Voss T et al. The AIDA autotransporter system is associated with F18 and Stx2e in Escherichia coli isolates from pigs diagnosed with edema disease and postweaning diarrhea. Clin Diagn Lab Immunol 2001;8:143-9.

Nilsson G, Belasco JG, Cohen SN et al. Growth-rate dependent regulation of mRNA stability in Escherichia coli. Nature 1984;312:75-7.

Nishi J, Sheikh J, Mizuguchi K et al. The export of coat protein from enteroaggregative Escherichia coli by a specific ATP-binding cassette transporter system. J Biolog Chem 2003;278:45680-9.

Nowicki B, Barrish JP, Korhonen T et al. Molecular cloning of the Escherichia coli O75X adhesin. Infect Immun 1987;55:3168-73.

Nowicki B, Labigne A, Moseley S et al. The Dr hemagglutinin, afimbrial adhesins AFA-I and AFA-III, and F1845 fimbriae of uropathogenic and diarrhea-associated Escherichia coli 
belong to a family of hemagglutinins with Dr receptor recognition. Infect Immun 1990;58:279-81.

Nowicki B, Moulds J, Hull $\mathrm{R}$ et al. A hemagglutinin of uropathogenic Escherichia coli recognizes the Dr blood group antigen. Infect Immun 1988;56:1057-60.

Nowrouzian F, Wold AE, Adlerberth I. P fimbriae and aerobactin as intestinal colonization factors for Escherichia coli in Pakistani infants. Epidemiol Infect 2001;126:19-23.

O'Toole G, Kaplan HB, Kolter R. Biofilm formation as microbial development. Ann Rev Microbiol 2000;54:49-79.

Obadia B, Lacour S, Doublet P et al. Influence of tyrosine-kinase Wzc activity on colanic acid production in Escherichia coli K12 cells. J Mol Biol 2007;367:42-53.

Oberhettinger P, Schutz M, Leo JC et al. Intimin and invasin export their C-terminus to the bacterial cell surface using an inverse mechanism compared to classical autotransport. PloS one 2012;7:e47069.

Ogasawara H, Yamada K, Kori A et al. Regulation of the Escherichia coli csgD promoter: interplay between five transcription factors. Microbiology 2010;156:2470-83.

Ogunleye A, Bhat A, Irorere VU et al. Poly-gamma-glutamic acid: production, properties and applications. Microbiology 2015;161:1-17.

Okeke IN, Wallace-Gadsden F, Simons HR et al. Multi-locus sequence typing of enteroaggregative Escherichia coli isolates from Nigerian children uncovers multiple lineages. PloS one 2010;5:e14093.

Olsen A, Arnqvist A, Hammar M et al. Environmental regulation of curli production in Escherichia coli. Infect Agents Dis 1993;2:272-4.

Omadjela O, Narahari A, Strumillo J et al. BcsA and BcsB form the catalytically active core of bacterial cellulose synthase sufficient for in vitro cellulose synthesis. Proc Nat Acad Sci USA 2013;110:17856-61.

Ong CL, Beatson SA, McEwan AG et al. Conjugative plasmid transfer and adhesion dynamics in an Escherichia coli biofilm. Appl Environ Microbiol 2009;75:6783-91.

Orndorff PE, Devapali A, Palestrant S et al. Immunoglobulinmediated agglutination of and biofilm formation by Escherichia coli $\mathrm{K}-12$ require the type 1 pilus fiber. Infect Immun 2004;72:1929-38.

Oropeza R, Salgado-Bravo R, Calva E. Deletion analysis of RcsC reveals a novel signalling pathway controlling poly$\mathrm{N}$-acetylglucosamine synthesis and biofilm formation in Escherichia coli. Microbiology 2015;161:903-13.

Otto K, Hermansson M. Inactivation of OmpX causes increased interactions of type 1 fimbriated Escherichia coli with abiotic surfaces. J Bacteriol 2004;186:226-34.

Otto K, Norbeck J, Larsson T et al. Adhesion of type 1-fimbriated Escherichia coli to abiotic surfaces leads to altered composition of outer membrane proteins. J Bacteriol 2001;183: 2445-53.

Owen P, Meehan M, de Loughry-Doherty $\mathrm{H}$ et al. Phase-variable outer membrane proteins in Escherichia coli. FEMS Immun Med Microbiol 1996;16:63-76.

Palchevskiy V, Finkel SE. Escherichia coli competence gene homologs are essential for competitive fitness and the use of DNA as a nutrient. J Bacteriol 2006;188:3902-10.

Palmen R, Hellingwerf KJ. Acinetobacter calcoaceticus liberates chromosomal DNA during induction of competence by cell lysis. Curr Microbiol 1995;30:7-10.

Partridge JD, Harshey RM. Swarming: flexible roaming plans. J Bacteriol 2013;195:909-18.
Paton AW, Paton JC. Direct detection and characterization of shigatoxigenic Escherichia coli by multiplex PCR for stx1, stx2, eae, ehxA, and saa. J Clin Microbiol 2002;40:271-4.

Paton AW, Srimanote P, Woodrow MC et al. Characterization of Saa, a novel autoagglutinating adhesin produced by locus of enterocyte effacement-negative shigatoxigenic Escherichia coli strains that are virulent for humans. Infect Immun 2001;69:6999-7009.

Pawar DM, Rossman ML, Chen J. Role of curli fimbriae in mediating the cells of enterohaemorrhagic Escherichia coli to attach to abiotic surfaces. J Appl Microbiol 2005;99:418-25.

Pereira AL, Silva TN, Gomes AC et al. Diarrhea-associated biofilm formed by enteroaggregative Escherichia coli and aggregative Citrobacter freundii: a consortium mediated by putative F pili. BMC microbiology 2010;10:57.

Perna NT, Plunkett G, 3rd, Burland V et al. Genome sequence of enterohaemorrhagic Escherichia coli 0157:H7. Nature 2001;409:529-33.

Pettengill EA, Pettengill JB, Binet R. Phylogenetic analyses of Shigella and enteroinvasive Escherichia coli for the identification of molecular epidemiological markers: Wholegenome comparative analysis does not support distinct genera designation. Front Microbiol 2015;6:1573.

Pettigrew D, Anderson KL, Billington J et al. High resolution studies of the Afa/Dr adhesin DraE and its interaction with chloramphenicol. J Biol Chemis 2004;279:46851-7.

Platenkamp A, Mellies JL. Environment controls LEE regulation in enteropathogenic Escherichia coli. Front Microbiol 2018;9:1694.

Platt TG, Fuqua C. What's in a name? The semantics of quorum sensing. Trends Microbiol 2010;18:383-7.

Power ML, Ferrari BC, Littlefield-Wyer J et al. A naturally occurring novel allele of Escherichia coli outer membrane protein A reduces sensitivity to bacteriophage. Appl Environ Microbiol 2006;72:7930-2.

Prasadarao NV, Wass CA, Weiser JN et al. Outer membrane protein A of Escherichia coli contributes to invasion of brain microvascular endothelial cells. Infect Immun 1996;64: 146-53.

Pratt LA, Kolter R. Genetic analysis of Escherichia coli biofilm formation: roles of flagella, motility, chemotaxis and type I pili. Mol Microbiol 1998;30:285-93.

Prigent-Combaret C, Brombacher E, Vidal O et al. Complex regulatory network controls initial adhesion and biofilm formation in Escherichia coli via regulation of the csgD gene. Journal of bacteriology 2001;183:7213-23.

Prigent-Combaret C, Prensier G, Le Thi TT et al. Developmental pathway for biofilm formation in curli-producing Escherichia coli strains: role of flagella, curli and colanic acid. Environmental microbiology 2000;2:450-64.

Prigent-Combaret C, Vidal O, Dorel C et al. Abiotic surface sensing and biofilm-dependent regulation of gene expression in Escherichia coli. J Bacteriol 1999;181:5993-6002.

Pruss BM, Besemann C, Denton A et al. A complex transcription network controls the early stages of biofilm development by Escherichia coli. Journal of bacteriology 2006;188:3731-9.

Pruss BM. Involvement of two-component signaling on bacterial motility and biofilm development. Journal of bacteriology 2017;199:e00259-17.

Puttamreddy S, Cornick NA, Minion FC. Genome-wide transposon mutagenesis reveals a role for p0157 genes in biofilm development in Escherichia coli O157:H7 EDL933. Infection and immunity 2010;78:2377-84. 
Qin Z, Ou Y, Yang L et al. Role of autolysin-mediated DNA release in biofilm formation of Staphylococcus epidermidis. Microbiology 2007;153:2083-92.

$\mathrm{Qu} \mathrm{Z}$, Temel FZ, Henderikx $\mathrm{R}$ et al. Changes in the flagellar bundling time account for variations in swimming behavior of flagellated bacteria in viscous media. Proceedings of the national academy of sciences of the united states of america 2018;115:1707-12.

Radchenkova N, Boyadzhieva I, Atanasova N et al. Extracellular polymer substance synthesized by a halophilic bacterium Chromohalobacter canadensis 28. Applied microbiology and biotechnology 2018;102:4937-49.

Raetz CR, Whitfield C. Lipopolysaccharide endotoxins. Annual review of biochemistry 2002;71:635-700.

Rajakumar K, Sasakawa C, Adler B. Use of a novel approach, termed island probing, identifies the Shigella flexneri she pathogenicity island which encodes a homolog of the immunoglobulin A protease-like family of proteins. Infection and immunity 1997;65:4606-14.

Ramer SW, Bieber D, Schoolnik GK. BfpB, an outer membrane lipoprotein required for the biogenesis of bundle-forming pili in enteropathogenic Escherichia coli. Journal of bacteriology 1996;178:6555-63.

Ramer SW, Schoolnik GK, Wu CY et al. The type 4 pilus assembly complex: biogenic interactions among the bundle-forming pilus proteins of enteropathogenic Escherichia coli. Journal of bacteriology 2002;184:3457-65.

Ratiner IA. Мутация кишечной палочки относительно Н-антигена. I. Выделение мутантов Н-антигена из тестируемых Н-штаммов культур Escherichia. [Mutation of E. coli with regard to the $\mathrm{H}$-antigen. I. Isolation of $\mathrm{H}$-antigen mutants from test $\mathrm{H}$ strains of Escherichia cultures]. Zhurnal mikrobiologii, epidemiologii, i immunobiologii 1967;44:23-29.

Redfield RJ. Is quorum sensing a side effect of diffusion sensing? Trends in microbiology 2002;10:365-70.

Reidl S, Lehmann A, Schiller R et al. Impact of O-glycosylation on the molecular and cellular adhesion properties of the Escherichia coli autotransporter protein Ag43. International journal of medical microbiology 2009;299:389-401.

Reisner A, Haagensen JA, Schembri MA et al. Development and maturation of Escherichia coli K-12 biofilms. Molecular microbiology 2003;48:933-46.

Reisner A, Maierl M, Jorger M et al. Type 1 fimbriae contribute to catheter-associated urinary tract infections caused by Escherichia coli. Journal of bacteriology 2014;196:931-9.

Ren CP, Beatson SA, Parkhill J et al. The flag-2 locus, an ancestral gene cluster, is potentially associated with a novel flagellar system from Escherichia coli. Journal of bacteriology 2005;187:1430-40.

Rendon MA, Saldana Z, Erdem AL et al. Commensal and pathogenic Escherichia coli use a common pilus adherence factor for epithelial cell colonization. Proceedings of the national academy of sciences of the united states of america 2007;104:10637-42.

Roe AJ, Currie C, Smith DG et al. Analysis of type 1 fimbriae expression in verotoxigenic Escherichia coli: a comparison between serotypes 0157 and O26. Microbiology 2001;147: 145-52.

Rogers TJ, Thorpe CM, Paton AW et al. Role of lipid rafts and flagellin in invasion of colonic epithelial cells by shigatoxigenic Escherichia coli O113:H21. Infection and immunity 2012;80:2858-67.

Rojas-Lopez M, Arenas-Hernandez MM, Medrano-Lopez A et al. Regulatory control of the Escherichia coli 0157:H7 lpf1 operon by H-NS and Ler. Journal of bacteriology 2011;193: 1622-32.

Rojas-Lopez M, Martinelli M, Brandi V et al. Identification of lipid A deacylase as a novel, highly conserved and protective antigen against enterohemorrhagic Escherichia coli. Scientific reports 2019;9:17014.

Rojas-Lopez M, Monterio R, Pizza M et al. Intestinal pathogenic Escherichia coli: Insights for vaccine development. Frontiers in microbiology 2018;9:440.

Rojas-Lopez M, Zorgani MA, Kelley LA et al. Identification of the autochaperone domain in the Type Va secretion system (T5aSS): prevalent feature of autotransporters with a $\beta$ helical passenger. Frontiers in microbiology 2017;8:2607.

Romling U, Amikam D. Cyclic di-GMP as a second messenger. Current opinion in microbiology 2006;9:218-28.

Romling U, Rohde M, Olsen A et al. AgfD, the checkpoint of multicellular and aggregative behaviour in Salmonella typhimurium regulates at least two independent pathways. Molecular microbiology 2000;36:10-23.

Rose PW, Prlic A, Altunkaya A et al. The RCSB protein data bank: integrative view of protein, gene and 3D structural information. Nucleic Acids Res 2017;45:D271-81.

Rossi E, Cimdins A, Luthje P et al. "It's a gut feeling" - Escherichia coli biofilm formation in the gastrointestinal tract environment. Critical reviews in microbiology 2018;44:1-30.

Roux A, Beloin C, Ghigo JM. Combined inactivation and expression strategy to study gene function under physiological conditions: application to identification of new Escherichia coli adhesins. Journal of bacteriology 2005;187:1001-13.

Roy K, Hilliard GM, Hamilton DJ et al. Enterotoxigenic Escherichia coli EtpA mediates adhesion between flagella and host cells. Nature 2009;457:594-8.

Ruiz-Perez F, Nataro JP. Bacterial serine proteases secreted by the autotransporter pathway: classification, specificity, and role in virulence. Cellular and molecular life sciences 2014;71: 745-70.

Ryan RP, Tolker-Nielsen T, Dow JM. When the PilZ don't work: effectors for cyclic di-GMP action in bacteria. Trends in microbiology 2012;20:235-42.

Sailer FC, Meberg BM, Young KD. $\beta$-lactam induction of colanic acid gene expression in Escherichia coli. FEMS microbiology letters 2003;226:245-9.

Sakellaris H, Hannink NK, Rajakumar K et al. Curli loci of Shigella spp. Infection and immunity 2000;68:3780-3.

Saldana Z, Xicohtencatl-Cortes J, Avelino F et al. Synergistic role of curli and cellulose in cell adherence and biofilm formation of attaching and effacing Escherichia coli and identification of Fis as a negative regulator of curli. Environmental microbiology 2009;11:992-1006.

Samadder P, Xicohtencatl-Cortes J, Saldana Z et al. The Escherichia coli ycbQRST operon encodes fimbriae with laminin-binding and epithelial cell adherence properties in shigatoxigenic E. coli O157:H7. Environmental microbiology 2009;11:1815-26.

Sanchez-Torres V, Hu H, Wood TK. GGDEF proteins YeaI, YedQ and YfiN reduce early biofilm formation and swimming motility in Escherichia coli. Applied microbiology and biotechnology 2011;90:651-8.

Sandkvist M. Biology of Type II secretion. Molecular microbiology 2001;40:271-83.

Sandt $\mathrm{CH}$, Hill CW. Four different genes responsible for nonimmune immunoglobulin-binding activities within a single strain of Escherichia coli. Infection and immunity 2000;68: 2205-14. 
Sandt CH, Hill CW. Nonimmune binding of human immunoglobulin A (IgA) and IgG Fc by distinct sequence segments of the EibF cell surface protein of Escherichia coli. Infection and immunity 2001;69:7293-303.

Sauer FG, Mulvey MA, Schilling JD et al. Bacterial pili: molecular mechanisms of pathogenesis. Current opinion in microbiology 2000;3:65-72.

Savelkoul PH, Willshaw GA, McConnell MM et al. Expression of CFA/I fimbriae is positively regulated. Microbial pathogenesis 1990;8:91-9.

Scaletsky IC, Michalski J, Torres AG et al. Identification and characterization of the locus for diffuse adherence, which encodes a novel afimbrial adhesin found in atypical enteropathogenic Escherichia coli. Infection and immunity 2005;73:4753-65.

Schembri MA, Dalsgaard D, Klemm P. Capsule shields the function of short bacterial adhesins. Journal of bacteriology 2004;186:1249-57.

Schembri MA, Kjaergaard K, Klemm P. Global gene expression in Escherichia coli biofilms. Molecular microbiology 2003;48: 253-67.

Schiffrin B, Brockwell DJ, Radford SE. Outer membrane protein folding from an energy landscape perspective. BMC Biology 2017;15:123.

Schmidt MA. LEEways: tales of EPEC, ATEC and EHEC. Cellular microbiology 2010;12:1544-52.

Schooling SR, Beveridge TJ. Membrane vesicles: an overlooked component of the matrices of biofilms. Journal of bacteriology 2006;188:5945-57.

Schroeder GN, Hilbi H. Molecular pathogenesis of Shigella spp.: controlling host cell signaling, invasion, and death by Type III secretion. Clinical microbiology reviews 2008;21:134-56.

Seidler NW. GAPDH, as a virulence factor. Advances in experimental medecine and biology 2013;985:149-78.

Selkrig J, Leyton DL, Webb CT et al. Assembly of $\beta$-barrel proteins into bacterial outer membranes. Biochimica et biophysica acta: Molecular cell research 2014;1843:1542-50.

Serra DO, Richter AM, Hengge R. Cellulose as an architectural element in spatially structured Escherichia coli biofilms. Journal of bacteriology 2013;195:5540-54.

Servin AL. Pathogenesis of Afa/Dr diffusely adhering Escherichia coli. Clinical microbiology reviews 2005;18:264-92.

Servin AL. Pathogenesis of human diffusely adhering Escherichia coli expressing Afa/Dr adhesins (Afa/Dr DAEC): current insights and future challenges. Clinical microbiology reviews 2014;27:823-69.

Shaw RK, Berger CN, Feys B et al. Enterohemorrhagic Escherichia coli exploits EspA filaments for attachment to salad leaves. Applied and environmental microbiology 2008;74: 2908-14.

Shaw RK, Berger CN, Pallen MJ et al. Flagella mediate attachment of enterotoxigenic Escherichia coli to fresh salad leaves. Environmental microbiology reports 2011;3:112-7.

Sheikh A, Rashu R, Begum YA et al. Highly conserved type 1 pili promote enterotoxigenic Escherichia coli pathogen-host interactions. PLoS neglected tropical diseases 2017;11:e0005586.

Sheikh J, Czeczulin JR, Harrington S et al. A novel dispersin protein in enteroaggregative Escherichia coli. The journal of clinical investigation 2002;110:1329-37.

Sheikh J, Hicks S, Dall'Agnol $M$ et al. Roles for Fis and YafK in biofilm formation by enteroaggregative Escherichia coli. Molecular microbiology 2001;41:983-97.

Sheng H, Lim JY, Watkins MK et al. Characterization of an Escherichia coli 0157:H7 O-antigen deletion mutant and effect of the deletion on bacterial persistence in the mouse intestine and colonization at the bovine terminal rectal mucosa. Applied and environmental microbiology 2008;74: 5015-22.

Sherlock O, Dobrindt U, Jensen JB et al. Glycosylation of the selfrecognizing Escherichia coli Ag43 autotransporter protein. Journal of bacteriology 2006;188:1798-807.

Sherlock O, Schembri MA, Reisner A et al. Novel roles for the AIDA adhesin from diarrheagenic Escherichia coli: cell aggregation and biofilm formation. Journal of bacteriology 2004;186:8058-65.

Sherlock O, Vejborg RM, Klemm P. The TibA adhesin/invasin from enterotoxigenic Escherichia coli is self recognizing and induces bacterial aggregation and biofilm formation. Infection and immunity 2005;73:1954-63.

Shimoji Y, Ogawa Y, Osaki M et al. Adhesive surface proteins of Erysipelothrix rhusiopathiae bind to polystyrene, fibronectin, and type I and IV collagens. Journal of bacteriology 2003;185:2739-48.

Shrivastava S, Mande SS. Identification and functional characterization of gene components of Type VI secretion system in bacterial genomes. PloS one 2008;3:e2955.

Shu Q, Crick SL, Pinkner JS et al. The Escherichia coli CsgB nucleator of curli assembles to $\beta$-sheet oligomers that alter the CsgA fibrillization mechanism. Proceedings of the national academy of sciences of the united states of america 2012;109:6502-07.

Sjoberg PO, Lindahl M, Porath J et al. Purification and characterization of CS2, a sialic acid-specific haemagglutinin of enterotoxigenic Escherichia coli. The biochemical journal 1988;255:105-11.

Sjoling A, von Mentzer A, Svennerholm AM. Implications of enterotoxigenic Escherichia coli genomics for vaccine development. Expert review of vaccines 2015;14:551-60.

Sledjeski D, Gottesman S. A small RNA acts as an antisilencer of the H-NS-silenced rcsA gene of Escherichia coli. Proceedings of the national academy of sciences of the united states of america 1995;92:2003-07.

Smajs D, Pilsl H, Braun V. Colicin U, a novel colicin produced by Shigella boydii. Journal of bacteriology 1997;179:4919-28.

Smati M, Clermont O, Bleibtreu A et al. Quantitative analysis of commensal Escherichia coli populations reveals hostspecific enterotypes at the intra-species level. Microbiologyopen 2015;4:604-15.

Smith SG, Mahon V, Lambert MA et al. A molecular Swiss army knife: OmpA structure, function and expression. FEMS microbiology letters 2007;273:1-11.

Smyth CJ, Marron MB, Twohig JM et al. Fimbrial adhesins: similarities and variations in structure and biogenesis. FEMS immunology and medical microbiology 1996;16: 127-39.

Snoeck V, Van den Broeck W, De Colvenaer V et al. Transcytosis of F4 fimbriae by villous and dome epithelia in F4-receptor positive pigs supports importance of receptordependent endocytosis in oral immunization strategies. Veterinary immunology and immunopathology 2008;124: 29-40.

Sohel I, Puente JL, Ramer SW et al. Enteropathogenic Escherichia coli: identification of a gene cluster coding for bundleforming pilus morphogenesis. Journal of bacteriology 1996;178:2613-28.

Solano C, Garcia B, Valle J et al. Genetic analysis of Salmonella enteritidis biofilm formation: critical role of cellulose. Molecular microbiology 2002;43:793-808. 
Sorensen HP, Mortensen KK. Advanced genetic strategies for recombinant protein expression in Escherichia coli. Journal of biotechnology 2005;115:113-28.

Soto GE, Hultgren SJ. Bacterial adhesins: common themes and variations in architecture and assembly. Journal of bacteriology 1999;181:1059-71.

Souza V, Rocha M, Valera A et al. Genetic structure of natural populations of Escherichia coli in wild hosts on different continents. Applied and environmental microbiology 1999;65: 3373-85.

Spurbeck RR, Stapleton AE, Johnson JR et al. Fimbrial profiles predict virulence of uropathogenic Escherichia coli strains: contribution of Ygi and Yad fimbriae. Infection and immunity 2011;79:4753-63.

Starkey M, Parsek MR, Gray KA et al. A sticky business: the extracellular polymeric substance matrix of bacterial biofilms. In: Microbial Biofilms(Ghannoum M O'Toole G . (eds). 74-191 American society for microbiology press, Washington DC. 2004.

Stathopoulos C, Hendrixson DR, Thanassi DG et al. Secretion of virulence determinants by the general secretory pathway in Gram-negative pathogens: an evolving story. Microbes and infection 2000;2:1061-72.

Steinberger RE, Allen AR, Hansa HG et al. Elongation correlates with nutrient deprivation in Pseudomonas aeruginosa-unsaturates biofilms. Microbial ecology 2002;43: 416-23.

Steinmoen H, Knutsen E, Havarstein LS. Induction of natural competence in Streptococcus pneumoniae triggers lysis and DNA release from a subfraction of the cell population. Proceedings of the national academy of sciences of the united states of america 2002;99:7681-86.

Stenutz R, Weintraub A, Widmalm G. The structures of Escherichia coli O-polysaccharide antigens. FEMS microbiology reviews 2006;30:382-403.

Stevens MP, Frankel GM. The locus of enterocyte effacement and associated virulence factors of enterohemorrhagic Escherichia coli. Microbiology spectrum 2014;2:EHEC0007-2013.

Stevens MP, Roe AJ, Vlisidou I et al. Mutation of toxB and a truncated version of the efa-1 gene in Escherichia coli 0157:H7 influences the expression and secretion of locus of enterocyte effacement-encoded proteins but not intestinal colonization in calves or sheep. Infection and immunity 2004;72:5402-11.

Stevenson G, Andrianopoulos K, Hobbs M et al. Organization of the Escherichia coli $\mathrm{K}-12$ gene cluster responsible for production of the extracellular polysaccharide colanic acid. Journal of bacteriology 1996;178:4885-93.

Strauss J, Burnham NA, Camesano TA. Atomic force microscopy study of the role of LPS O-antigen on adhesion of Escherichia coli. Journal of molecular recognition 2009;22:347-55.

Sugawara E, Nikaido H. Pore-forming activity of OmpA protein of Escherichia coli. The journal of biological chemistry 1992;267:2507-11.

Sutcliffe IC. New insights into the distribution of WXG100 protein secretion systems. Antonie van leeuwenhoek 2011;99: 127-31.

Sutherland IW. The biofilm matrix-an immobilized but dynamic microbial environment. Trends in microbiology 2001;9:222-7.

Svennerholm AM, Lundgren A. Recent progress toward an enterotoxigenic Escherichia coli vaccine. Expert review of vaccines 2012;11:495-507.
Szabo E, Skedsmo A, Sonnevend A et al. Curli expression of enterotoxigenic Escherichia coli. Folia microbiologica 2005;50:40-6.

Szalo IM, Goffaux F, Pirson V et al. Presence in bovine enteropathogenic (EPEC) and enterohaemorrhagic (EHEC) Escherichia coli of genes encoding for putative adhesins of human EHEC strains. Research in microbiology 2002;153:653-8.

Szalo IM, Taminiau B, Mainil J. Le lipopolysaccharide d'Escherichia coli: structure, biosynthèse et rôles [Lipopolysaccharide in Escherichia coli: structure, biosynthesis and role]. Annales de médecine vétérinaire 2006;150:108-24.

Tacket CO, Taylor RK, Losonsky G et al. Investigation of the roles of toxin-coregulated pili and mannose-sensitive hemagglutinin pili in the pathogenesis of Vibrio cholerae O139 infection. Infection and immunity 1998;66:692-5.

Tampakaki AP, Fadouloglou VE, Gazi AD et al. Conserved features of Type III secretion. Cellular microbiology 2004;6:805-16.

Taniguchi T, Fujino Y, Yamamoto K et al. Sequencing of the gene encoding the major pilin of pilus colonization factor antigen III (CFA/III) of human enterotoxigenic Escherichia coli and evidence that CFA/III is related to type 4 pili. Infection and immunity 1995;63:724-8.

Tarr PI, Bilge SS, Vary JC, Jr. et al. Iha: a novel Escherichia coli 0157:H7 adherence-conferring molecule encoded on a recently acquired chromosomal island of conserved structure. Infection and immunity 2000;68:1400-7.

Tatsuno I, Horie M, Abe $\mathrm{H}$ et al. toxB gene on p0157 of enterohemorrhagic Escherichia coli $0157: \mathrm{H7}$ is required for full epithelial cell adherence phenotype. Infection and immunity 2001;69:6660-9.

Tatsuno I, Kimura $\mathrm{H}$, Okutani $\mathrm{A}$ et al. Isolation and characterization of mini-Tn5Km2 insertion mutants of enterohemorrhagic Escherichia coli 0157:H7 deficient in adherence to Caco-2 cells. Infection and immunity 2000;68:5943-52.

Tenaillon O, Skurnik D, Picard B et al. The population genetics of commensal Escherichia coli. Nature reviews microbiology 2010;8:207-17.

Teng CH, Xie Y, Shin S et al. Effects of ompA deletion on expression of type 1 fimbriae in Escherichia coli K1 strain RS218 and on the association of $\mathrm{E}$. coli with human brain microvascular endothelial cells. Infection and immunity 2006;74:5609-16.

Thanassi DG, Saulino ET, Hultgren SJ. The chaperone/usher pathway: a major terminal branch of the general secretory pathway. Current opinion in microbiology 1998;1:223-31.

Tobe T, Sasakawa C, Okada N et al. vacB, a novel chromosomal gene required for expression of virulence genes on the large plasmid of Shigella flexneri. Journal of bacteriology 1992;174:6359-67.

Tobe $\mathrm{T}$. The roles of two-component systems in virulence of pathogenic Escherichia coli and Shigella spp. Advances in experimental medicine and biology 2008;631:189-99.

Toma C, Martinez Espinosa E, Song $\mathrm{T}$ et al. Distribution of putative adhesins in different seropathotypes of shigatoxinproducing Escherichia coli. J Clin Microbiol 2004;42:4937-46.

Tomme P, Creagh AL, Kilburn DG et al. Interaction of polysaccharides with the $\mathrm{N}$-terminal cellulose-binding domain of Cellulomonas fimi CenC. 1. Binding specificity and calorimetric analysis. Biochemistry 1996;35:13885-94.

Torres-Cruz J, van der Woude MW. Slipped-strand mispairing can function as a phase variation mechanism in Escherichia coli. J Bacteriol 2003;185:6990-4.

Torres AG, Jeter C, Langley W et al. Differential binding of Escherichia coli O157:H7 to alfalfa, human epithelial cells, 
and plastic is mediated by a variety of surface structures. Appl Environ Microbiol 2005;71:8008-15.

Torres AG, Kanack KJ, Tutt CB et al. Characterization of the second long polar (LP) fimbriae of Escherichia coli O157:H7 and distribution of LP fimbriae in other pathogenic E. coli strains. FEMS Microbiol Lett 2004;238:333-44.

Torres AG, Kaper JB. Multiple elements controlling adherence of enterohemorrhagic Escherichia coli O157:H7 to HeLa cells. Infect Immun 2003;71:4985-95.

Torres AG, Milflores-Flores L, Garcia-Gallegos JG et al. Environmental regulation and colonization attributes of the long polar fimbriae (LPF) of Escherichia coli O157:H7. Int J Med Microbiol 2007;297:177-85.

Torres AG, Perna NT, Burland V et al. Characterization of Cah, a calcium-binding and heat-extractable autotransporter protein of enterohaemorrhagic Escherichia coli. Mol Microbiol 2002;45:951-66.

Torres AG. Escherichia coli diseases in Latin America a 'One Health' multidisciplinary approach. Pathog Dis 2017;75:ftx012.

Totsika M, Wells TJ, Beloin C et al. Molecular characterization of the EhaG and UpaG trimeric autotransporter proteins from pathogenic Escherichia coli. Appl Environ Microbiol 2012;78:2179-89.

Touchon M, Hoede C, Tenaillon O et al. Organised genome dynamics in the Escherichia coli species results in highly diverse adaptive paths. PLoS Gene 2009;5:e1000344.

Troge A, Scheppach W, Schroeder BO et al. More than a marine propeller-the flagellum of the probiotic Escherichia coli strain Nissle 1917 is the major adhesin mediating binding to human mucus. Inter J Med Microbiol 2012;302:304-14.

Trunk T, Khalil HS, Leo JC. Bacterial autoaggregation. AIMS Microbiol 2018;4:140-64.

Tsai JC, Yen MR, Castillo $\mathrm{R}$ et al. The bacterial intimins and invasins: a large and novel family of secreted proteins. PloS one 2010;5:e14403.

Turner NCA, Connolly JPR, Roe AJ. Control freaks-signals and cues governing the regulation of virulence in attaching and effacing pathogens. Biochem Soc Transac 2018;47:229-38.

Udekwu KI, Darfeuille F, Vogel J et al. Hfq-dependent regulation of OmpA synthesis is mediated by an antisense RNA. Genes Develop 2005;19:2355-66.

Ude S, Arnold DL, Moon CD et al. Biofilm formation and cellulose expression among diverse environmental Pseudomonas isolates. Environ Microbiol 2006;8:1997-2011.

Ulett GC, Mabbett AN, Fung KC et al. The role of F9 fimbriae of uropathogenic Escherichia coli in biofilm formation. Microbiology 2007a;153:2321-31.

Ulett GC, Valle J, Beloin C et al. Functional analysis of antigen 43 in uropathogenic Escherichia coli reveals a role in longterm persistence in the urinary tract. Infect Immun 2007b;75: 3233-44.

Ulett GC, Webb RI, Schembri MA. Antigen-43-mediated autoaggregation impairs motility in Escherichia coli. Microbiology 2006;152:2101-10.

Unnikrishnan M, Constantinidou C, Palmer T et al. The enigmatic Esx proteins: Looking beyond Mycobacteria. Trends Microbiol 2017;25:192-204.

Valle J, Mabbett AN, Ulett GC et al. UpaG, a new member of the trimeric autotransporter family of adhesins in uropathogenic Escherichia coli. J Bacteriol 2008;190:4147-61.

van der Woude AD, Luirink J, Bitter W. Getting across the cell envelope: mycobacterial protein secretion. Current topics in microbiology and immunology 2013;374:109-34. van der Woude MW, Henderson IR. Regulation and function of Ag43 (flu). Annual review of microbiology 2008;62:153-69.

van Diemen PM, Dziva F, Stevens MP et al. Identification of enterohemorrhagic Escherichia coli O26:H- genes required for intestinal colonization in calves. Infection and immunity 2005;73:1735-43.

van Elsas JD, Semenov AV, Costa $R$ et al. Survival of Escherichia coli in the environment: fundamental and public health aspects. ISME J 2011;5:173-83.

Van Gerven N, Klein RD, Hultgren SJ et al. Bacterial amyloid formation: structural insights into curli biogenesis. Trends Microbiol 2015;23:693-706.

van Houdt R, Michiels CW. Role of bacterial cell surface structures in Escherichia coli biofilm formation. Res Microbiol 2005;156:626-33.

Vaziri F, Brosch R. ESX/type VII secretion systems-an important way out for mycobacterial proteins. Microbiol Spect 2019;7:PSIB-0029-2019.

Velarde JJ, Varney KM, Inman KG et al. Solution structure of the novel dispersin protein of enteroaggregative Escherichia coli. Mol Microbiol 2007;66:1123-35.

Vermassen A, Talon R, Andant C et al. Cell-wall hydrolases as antimicrobials against Staphylococcus species: Focus on Sle1. Microorganisms 2019;7:E559.

Vidal O, Longin R, Prigent-Combaret C et al. Isolation of an Escherichia coli K-12 mutant strain able to form biofilms on inert surfaces: involvement of a new ompR allele that increases curli expression. J Bacteriol 1998;180:2442-9.

Vikram A, Jayaprakasha GK, Uckoo RM et al. Inhibition of Escherichia coli 0157:H7 motility and biofilm by $\beta$-sitosterol glucoside. Biochimica et biophysica acta: General Subjects 2013;1830:5219-28.

Vogel C, Marcotte EM. Insights into the regulation of protein abundance from proteomic and transcriptomic analyses. Nat Rev Gene 2012;13:227-32.

Vogeleer P, Tremblay YD, Jubelin G et al. Biofilm-forming abilities of shigatoxin-producing Escherichia coli isolates associated with human infections. Appl Environ Microbiol 2015;82: 1448-58.

Vo JL, Martinez Ortiz GC, Subedi P et al. Autotransporter adhesins in Escherichia coli pathogenesis. Proteomics 2017;17:1600431.

Vytvytska O, Moll I, Kaberdin VR et al. Hfq (HF1) stimulates ompA mRNA decay by interfering with ribosome binding. Genes Develop 2000;14:1109-18.

Wakimoto N, Nishi J, Sheikh J et al. Quantitative biofilm assay using a microtiter plate to screen for enteroaggregative Escherichia coli. Am J Tropic Med Hyg 2004;71:687-90.

Walczuk U, Sobieszczanska B, Turniak M et al. The prevalence of mucosa-associated diffusely adherent Escherichia coli in children with inflammatory bowel disease. Adv Clin Exper Med 2019;28:899-905.

Walk ST, Alm EW, Gordon DM et al. Cryptic lineages of the genus Escherichia. Appl Environ Microbiol 2009;75:6534-44.

Wall D. Kin recognition in bacteria. Ann Reu Microbiol 2016;70:143-60.

Wallecha A, Oreh H, van der Woude MW et al. Control of gene expression at a bacterial leader RNA, the agn43 gene encoding outer membrane protein Ag43 of Escherichia coli. J Bacteriol 2014;196:2728-35.

Wang P, Xiong Y, Lan R et al. p0157-Sal, a novel conjugative plasmid detected in outbreak isolates of Escherichia coli O157:H7. J Clin Microbiol 2011;49:1594-7.

Wang S, Xia Y, Dai J et al. Novel roles for autotransporter adhesin AatA of avian pathogenic Escherichia coli: colonization 
during infection and cell aggregation. FEMS Immunol Med Microbiol 2011;63:328-38.

Wang S, Yang F, Yang B. Global effect of CsrA on gene expression in enterohemorrhagic Escherichia coli O157:H7. Res Microbiol 2017;168:700-9.

Wang W, Chanda W, Zhong M. The relationship between biofilm and outer membrane vesicles:a novel therapy overview. FEMS Microbiol lett 2015;362:fnv117.

Wang X, Preston JF, 3rd, Romeo T. The pgaABCD locus of Escherichia coli promotes the synthesis of a polysaccharide adhesin required for biofilm formation. J Bacteriol 2004;186:2724-34.

Wang Y. The function of OmpA in Escherichia coli. Biochem Biophysical Res Commun 2002;292:396-401.

Weilbacher T, Suzuki K, Dubey AK et al. A novel sRNA component of the carbon storage regulatory system of Escherichia coli. Mol Microbiol 2003;48:6157-70.

Weissman SJ, Chattopadhyay S, Aprikian P et al. Clonal analysis reveals high rate of structural mutations in fimbrial adhesins of extraintestinal pathogenic Escherichia coli. Mol Microbiol 2006;59:975-88.

Wells TJ, McNeilly TN, Totsika $\mathrm{M}$ et al. The Escherichia coli O157:H7 EhaB autotransporter protein binds to laminin and collagen I and induces a serum IgA response in 0157:H7 challenged cattle. Environ Microbiol 2009;11:1803-14.

Wells TJ, Sherlock O, Rivas L et al. EhaA is a novel autotransporter protein of enterohemorrhagic Escherichia coli 0157:H7 that contributes to adhesion and biofilm formation. Environ Microbiol 2008;10:589-604.

Wells TJ, Totsika M, Schembri MA. Autotransporters of Escherichia coli: a sequence-based characterization. Microbiology 2010;156:2459-69.

Werneburg GT, Thanassi DG. Pili assembled by the chaperone/usher pathway in Escherichia coli and Salmonella. EcoSal Plus 2018;8:ESP-0007-2017.

Westerlund B, Kuusela P, Risteli J et al. The O75X adhesin of uropathogenic Escherichia coli is a type IV collagen-binding protein. Mol Microbiol 1989;3:329-37.

West SA, Winzer K, Gardner A et al. Quorum sensing and the confusion about diffusion. Trends Microbiol 2012;20:586-94.

Whitchurch CB, Tolker-Nielsen T, Ragas PC et al. Extracellular DNA required for bacterial biofilm formation. Science 2002;295:1487.

Whitfield C, Keenleyside WJ. Regulation of expression of group IA capsular polysaccharides in Escherichia coli and related extracellular polysaccharides in other bacteria. J Ind Microbiol 1995;15:361-71.

Whitfield C, Roberts IS. Structure, assembly and regulation of expression of capsules in Escherichia coli. Mol Microbiol 1999;31:1307-19.

Whitfield C. Biosynthesis and assembly of capsular polysaccharides in Escherichia coli. Ann Rev Biochem 2006;75:39-68.

Wong AR, Pearson JS, Bright MD et al. Enteropathogenic and enterohaemorrhagic Escherichia coli: even more subversive elements. Mol Microbiol 2011;80:1420-38.

Wood TK, Gonzalez Barrios AF, Herzberg M et al. Motility influences biofilm architecture in Escherichia coli. Appl Microbiol Biotechnol 2006;72:361-7.

Wright KJ, Seed PC, Hultgren SJ. Development of intracellular bacterial communities of uropathogenic Escherichia coli depends on type 1 pili. Cell Microbiol 2007;9:2230-41.

Wuertz S, Okabe S, Hausner M. Microbial communities and their interactions in biofilm systems: an overview. Water Sci Technol 2004;49:327-36.
Wurpel DJ, Beatson SA, Totsika M et al. Chaperone-usher fimbriae of Escherichia coli. PloS one 2013;8:e52835.

Xi C, Wu J. dATP/ATP, a multifunctional nucleotide, stimulates bacterial cell lysis, extracellular DNA release and biofilm development. PloS one 2010;5:e13355.

Xicohtencatl-Cortes J, Monteiro-Neto V, Saldana Z et al. The type 4 pili of enterohemorrhagic Escherichia coli 0157:H7 are multipurpose structures with pathogenic attributes. J Bacteriol 2009;191:411-21.

Xicohtencatl-Cortes J, Saldana Z, Deng W et al. Bacterial macroscopic rope-like fibers with cytopathic and adhesive properties. J Biol Chem 2010;285:32336-42.

Xicohtencatl-Cortes J, Sanchez Chacon E, Saldana Z et al. Interaction of Escherichia coli 0157:H7 with leafy green produce. J Food Protect 2009;72:1531-37.

Yang J, Baldi DL, Tauschek $\mathrm{M}$ et al. Transcriptional regulation of the yghJ-pppA-yghG-gspCDEFGHIJKLM cluster, encoding the Type II secretion pathway in enterotoxigenic Escherichia coli. J Bacteriol 2007;189:142-50.

Yaron S, Romling U. Biofilm formation by enteric pathogens and its role in plant colonization and persistence. Microb Biotechnol 2014;7:496-516.

Yin X, Wheatcroft R, Chambers JR et al. Contributions of $\mathrm{O}$ island 48 to adherence of enterohemorrhagic Escherichia coli 0157:H7 to epithelial cells in vitro and in ligated pig ileal loops. Appl Environ Microbiol 2009;75:5779-86.

Yonezawa H, Osaki T, Kurata S et al. Outer membrane vesicles of Helicobacter pylori TK1402 are involved in biofilm formation. BMC Microbiol 2009;9:197.

Young GM, Schmiel DH, Miller VL. A new pathway for the secretion of virulence factors by bacteria the flagellar export apparatus functions as a protein-secretion system. Proc Nat Acad Sci USA 1999;96:6456-61.

Yu B, Giltner CL, van Schaik EJ et al. A novel biometallic interface: high affinity tip-associated binding by pilin-derived protein nanotubes. J Bionanosci 2007;1:73-83.

Zhao $\mathrm{H}$, Chen $\mathrm{C}$, Xiong $\mathrm{Y}$ et al. Global transcriptional and phenotypic analyses of Escherichia coli 0157:H7 strain Xuzhou21 and its p0157-Sal cured mutant. PloS one 2013; 8:e65466.

Zhou M, Duan Q, Zhu X et al. Both flagella and F4 fimbriae from $\mathrm{F} 4 \mathrm{ac}+$ enterotoxigenic Escherichia coli contribute to attachment to IPEC-J2 cells in vitro. Vet Res 2013;44:30.

Zhou M, Guo Z, Yang Y et al. Flagellin and F4 fimbriae have opposite effects on biofilm formation and quorum sensing in F4ac+ enterotoxigenic Escherichia coli. Vet Microbiol 2014;168:148-53.

Zhou M, Yang Y, Chen $\mathrm{P}$ et al. More than a locomotive organelle: flagella in Escherichia coli. Appl Microbiol Biotechnol 2015;99:8883-90.

Zogaj X, Nimtz M, Rohde M et al. The multicellular morphotypes of Salmonella typhimurium and Escherichia coli produce cellulose as the second component of the extracellular matrix. Mol Microbiol 2001;39:1452-63.

Zorraquino V, Garcia B, Latasa C et al. Coordinated cyclic-di-GMP repression of Salmonella motility through YcgR and cellulose. J Bacteriol 2013;195:417-28.

Zschiedrich CP, Keidel V, Szurmant H. Molecular mechanisms of two-component signal transduction. J Mol Biol 2016;428:3752-75.

Zude I, Leimbach A, Dobrindt U. Prevalence of autotransporters in Escherichia coli: what is the impact of phylogeny and pathotype? Intern J Med Microbiol 2014;304: 243-56. 